\title{
Die Gefahren der Ligatur der grossen Halsschlagadern für das Auge und das Leben des Menschen.
}

\author{
Von
}

\author{
Dr. med. August Siegrist, \\ Augenarzt in Basel.
}

Hierzu Taf. XVII-XXIII, Fig. 1-21 und 1 Figur im Text.

\section{Theil.}

\section{Physiologisch wie Klinisch Bekanntes.}

Der Einfluss der Ligatur der grossen Halsschlagadern auf das Auge war schon zu wiederholten Malen Gegenstand eingehender, theils klinischer, theils experimenteller Studien.

In den zahlreichen Statistiken über die aus allen möglichen Indicationen beim Menschen einseitig, wie doppelseitig ausgeführten Carotisligaturen finden wir eine gewisse Anzahl von Fällen, bei welchen der Ligatur der Carotis Störungen des gleichseitigen Sehorganes folgten.

Dieser schädigende Einfluss der Carotisligatur auf das Auge wurde bereits von autoritativer Seite(1) dazu benützt, um den angeblich grossen, keineswegs aber bewiesenen Einfluss ron Circulationsstörungen im Gebiete einer Carotis communis auf das gleichseitige Auge sicher zu stellen.

Wollen wir uns selbst eine deutliche Vorstellung von der Wirkung der Carotisligatur auf das Auge verschaffen, so müssen wir entschieden zwei Fragen auseinander halten.

จ. Graefe's Archiv für Ophthalmologie. L. 3. 
1. Ist die Ligatur der Carotis communis oder interna beim gesunden Menschen physiologischer Weise mit Gefahren für das entsprechende, gleichseitige Auge verbunden?

2. Wie verhält es sich mit diesen Gefahren unter pathologischen Verhältnissen, unter denen doch eigentlich in praxi die Ligatur zur Anwendung gelangt?

Da bei völlig gesunden Menschen eine Carotisligatur nicht ausgeführt wird, müssen wir zur Beantwortung der ersten Frage das Thierexperiment, wie Compressionsversuche beim Menschen zu Hilfe nehmen. Beiden Verfahren haften aber gewisse, nicht' zu vermeidende Mängel an.

Vom Thierexperiment kann nicht immer mit Sicherheit auf den Menschen geschlossen werden, und bei einer Compression der grossen Halsschlagadern ist nicht mit Sicherheit eine Compression der grossen Venen und Nerven des Halses auszuschliessen. Ausserdem ist man bei einer Compression der Carotis nicht immer sicher, ob auch ihr Zweck, die völlige Verlegung der Arterie für den Blutstrom, erreicht ist. Auch kann es vorkommen, wie Ehrmann betont, dass man zugleich mit der Carotis eine Vertebralarterie comprimirt.

Die experimentellen Unterbindungen der Carotiden beim Kaninchen sind immerbin für den Menschen von nicht zu unterschätzender Beweiskraft, da, wie v. Schultén (2) in seiner Arbeit anführt, die anatomischen Verhältnisse des Kaninchenauges nicht wesentlich von denen des menschlichen Auges verschieden sind und da sich - nach einer Specialarbeit ron Hans Virchow (3) - mit Hinsicht auf die Gefässvertheilung kaum wesentliche Verschiedenheiten finden.

Die zahlreichen Versuche der Compression der Carotiden beim Menschen ergaben nun als häufige Folge für das Schorgan:

I. Bei doppelseitiger Compression: 
Die Gefahren der Ligatur der grossen Halsschlagadern etc. 513

1. Verdunklung des Gesichtes, (Jacobi (4), Ehrmann (5)).

2. Verengerung der Pupille, - nicht bei allen -, auf welche bedentende Erweiterung - bei allen - folgte. (Kussmanl und Tenner (6), Ehrmann (5)).

II. Bei einseitiger Compression zeigte sich ophthalmoskopiseh:

1. Ein Verschwinden des etwa zuvor vorhandenen Venenpulses. (Wadsworth und Putram (7)).

2. Ein nur kurze Zeit dauerndes Erblassen der Papille sofort nach der Compression, eine schwächere Blutsäule in den arteriellen Verzweigungen und eine Abnahme der Breite derselben in den venösen. Sehr rasch verschwinden diese Erscheinungen; an Stelle der Blässe der Papille tritt eine etwas stärkere Röthe, als sie zuvor vorhanden war, und in sehr auffallender Weise macht sich eine starke venöse Stauung mit Feblen des Venenpulses geltead. Lässt man rasch die Compression los, so verschwindet die venöse Blutsäule zuerst vollständig oder fast vollständig, um sofort wieder zu erscheinen und schnell von Neuem zu verschwinden. Für kurze Zeit siud daher gleichsam wogende Bewegungen vorhanden; vollkommene oder fast vollkommene Leerheit, rasch abwechselnd mit starker Füllung ist das Charakteristische dieses Stadiums. Kurze Zeit darauf bat die Circulation wieder ihren früheren regelmässigen Gang aufzuweisen. (v. Michel(1)).

Leber(8) fand im Gegensatz zum Obigen bei der Compression beider Carotiden am Menschen keine merklichen Veräuderungen.

Die experimentelle Ligatur beim Thier — speciell beim Kaninchen and Hund - warde schon von zahlreichen älteren Forschern ausgeführt Wir werden uns im Nacbfolgenden wie bereits im Vorausgegangenen geschehen - nur an die neueren Arbeiten von v. Michel(1) und v. Schultén (2), welehe bereits die Resultate der früheren experimentellen Carotisligaturen beim Thier mit berücksichtigt haben, halten und messen ganz specielle Wichtigkeit den Untersuchungen v. Schultén's bei, da sich derselbe bei seinen ungemein sorgfältigen and eingehenden Untersuchungen zweier bemerkenswerthen, eigens zu diesem Zwecke construirten, Instrumente bediente: eines Ophthalmoskopes, das wesentlich stärker als die ublichen Angenspiegel vergrössert, und eines äusserst empfindlichen Manometers zur Messung des intraocularen Druckes. 
I. Bei einseitiger Ligatur der Carotis des Kaninchens beobachtete v. Schultén:

1. Leichte, aber bei genauer Beobachtung doch deutlich verminderte Blutfüllung der Retinalarterien, deren Caliber sich gleichwohl nicht merkbar verändert.

Die Ligatur beider Carotiden rerändert dieses Bild nur wenig.

2. Eine höchst bedentende, mehrere Tage andauernde, Verminderung des intraocularen Druckes auf derselben Seite - von $22 \mathrm{~mm} \mathrm{Hg}$ auf $12 \mathrm{~mm}$. -

Ligatur der Carotis auch auf der anderen Seite setzt den Druck nur ein paar Millimeter weiter herab.

Bedeutende Druckrerminderung fanden auch Adamük, v. Hippel und Grünhagen(2) bei Katzen und Hunden.

Es beeinflusst also die Carotisligatur ganz wesentlich die Blutfüllung des Anges, da bei völlig aufgehobenem Blutzuflusse die Spannung des Bulbus bioss noch etwa $10-9 \mathrm{~mm} \mathrm{Hg}$ ausmacht.

3. Eine bedentende Verminderung des Blutdruckes in der gleichseitigen Arteria ophthalmica, während in der entgegengesetzten Ophthalmica der Blutdruck gar nicht oder nur in geringem Grade vermindert ist.

II. Bei einseitiger Ligatur der Carotis des Hundes beobachtete v. Michel:

1. Es vergeht nach der Ligatur ein ganz kurzer Zeitraum bis, der Seite entsprechend, die Papille blass weiss erscheint, und die Blutsäule in allen Gefässen, sowohl venösen wie arteriellen, verschwunden ist; nach einem gleich kurzen Zeitraum tritt aber wieder eine Füllung wie mit einem Schlage ein. In den folgenden Tagen, ja Wochen zejgt sich die Papille der entsprechenden Seite etwas blasser, die arteriellen Verzweigungen etwas schwächer gefüllt. Relativ zor schwachen Füllung der arteriellen Verzweigungen erscheint die Bhutsänle in den venösen Aesten breit; auch die Retina erscheint in der Umgebung der Papille etwas stärker reflectirend. Ferner fehlt der rhythmische, d. h. der von der Herzaction abhängige Venenpuls auf der entsprechenden Seite, während er auf der entgegengesetzten Seite viel stärker als unter normalen Verhältuissen anftritt.

2. Herabsetzung des intraocularen Drucles, im gleichseitigen Auge. Hierfür sprechen r. Michel's manometrische 
Die Gefahren der Ligatur der grossen Halsschlagadern etc. 515

Messungen beim Kaninchen und die Palpationsresultate beim Hund, ferner das Verhalten des Venempulses.

3. Steigerung des intraocularen Druckes, im entgegengesetzten Auge. Hierfür spricht das Verhalten des Venenpulses an diesem Auge.

Bei allen diesen, selbst bei den simultan doppelseitigen Ligaturen bleibt, wie ich mich selbst bei 45 von mir zu den verschiedensten $Z$ wecken beim Kaninchen ausgeführten doppelseitigen Ligaturen überzeugte, die Sehkraft beider Augen regelmässig; so weit ersichtlich, völlig unverändert.

Nach den Folgen zu schliessen, welche die Compression der Carotiden beim Menschen, wie die experimentelle Ligatur der Carotiden beim Kaninchen aufweist, scheint die Ligatur einer Carotis communis keine Gefahren für das Sehorgan des gesunden Menschen physiologischer Weise mit sich zu bringen, da die leichte Anaemie der Netzhaut und die intraoculare Druckverminderung, wie die Veränderungen in der Pupillenweite, in kurzer Zeit sich wieder ausgleichen.

Diese Ansicht wird bestärkt, wenn nicht bewiesen, durch eine grössere Zahl von Carotisligaturen bei relativ gesunden Individuen, welche alle ohne die geringsten Störungen von Seiten des gleichseitigen Auges verliefen. Fs handelt sich dabei um Fälle von Epilepsie, Neuralgie oder Elephantiasis faciei, zu deren Heilung früher gleichfalls die Carotisligatur herangezogen wurde - siehe die statistischen Arbeiten von Pilz (9), Friedländer (10) etc. -

Wie verhält es sich nun mit den Gefahren der Carotisligatur unter pathologischen Verhältnissen?

Zur Beantwortung dieser Frage gehört eine genauere Kenntniss der umfangreichen chirurgischen, medicinischen, sowie ophthalmologischen Literatur, denn hier entscheidet nicht das Thierexperiment oder der Compressionsversuch, sondern die Erfahrung im Operationssaale, am Krankenbette und am Sectionstische. 
Die bisher publicirten brauchbaren Fälle von Carotisligatur, so weit sie mir aus den grösseren statistischen Arbeiten von Ehrmann(5), Günther (11), Pilz (9), Friedländer (10), Reis (29), Zimmermann (44), dann Sattler (12), Müller(13) und Kellèr (14) bekannt geworden, übersteigen die Zabl 800 .

Dazu kommen noch über 172 Fälle von Carotisligatur, welche ich selbst seit dem Jahre 1880 bis 1897 gesammelt babe aus den Jahrbüchern yon Schmidt (15) sowie von Virchow-Hirsch (16) und von denen ich einen grossen Theil auch im Originale einsah, - die im Orignal eingesehenen Arbeiten finden sich im Literaturverzeichnisse des ersten Theiles-, so dass ich nun über ein Material yon 997 Carotisligaturen unter den verschiedensten pathologischen Verhältnissen verfüge ${ }^{1}$ ).

Unter diesen 997 Fällen von Carotisligatur wurden 42 Mal Störungen des gleichseitigen Auges beobachtet, die meist rasch vorübergehenden Veränderungen in der Weite der Pupille nicht mitgerechnet, also in etwa $4,2 \%$ der Fälle.

Diese Störungen vertheilen sich wie folgt:

1. Bleibende, oder doch äusserst lange dauernde schwere Selistörungen, selbst yöllige Erblindungen: 8 Mal.

2. Vorübergehende, mehr oder weniger lange dauernde Sehstörungen:

14 Mal.

3. Entzündliche Erkrankungen und Zerstörungen des Bulbus, meist Panophthalmieen:

9 Mal.

4. Strabismus:

5 Mal.

5. Affectionen verschiedenster Art:

$8 \mathrm{Mal}$

Einen Auszug aus den betreffenden krankengeschichten sammt dem zugehörenden Literaturverzeichnisse lasse ich folgen.

Die Arbeiten der gesperrt gedruckten Autoren wurden im Original eingesehen.

I) Die Zusammenstellung macht keineswegs auf Vollständigkeit Anspruch. Denn bei der ungeheueren Schwierigkeit der ausnahmslosen Auffindung der in den zahlreichen Zeitschriften der verschiedenen Ländern, theils ophthalmologischen, theils medicinischen oder chirurgischen Inhaltes niedergelegten Krankengeschichten und der Beschaffung der Originalarbeiten selbst, ist eine volikommene Literaturkenntniss nicht jedem möglich. Ich boffe daher, dass die zweifellos existirende Unvollkommenheit eine gewisse Entschuldigung finden werde. - 
Die Gefahren der Ligatur der grossen Halsschlagadern etc. 517

Die oft äusserst kurzen und unbefriedigenden Angaben, speciell über die an dem Auge beobachteten Störungen, finden ihre Erklärung lediglich in den mangelhaften Originalberichten und dürfen nicht dem Auszuge als solchem zur Last gelegt werden.

\section{Affectionon des Sehorganes nach Ligatur der Carotis communis oder interna beobachtet von $1800-1897$.}

I. Dauernde schwere Störungen der Sehkraft oder völlige Erblindung.

1. 1830. Neumeister-Wyeth-Friedländer. Mann von 51 Jahren mit Aneurysma-anonymae, stark pulsirend.

13. VI. 1829 oder 1830 Ligatur der Carotis communis dext. Geringer Schmerz in Arm und Schulter. Pulsation nicht mehr so heftig.

16. VI. Sehvermögen im rechton Auge theilweise verloren. Schmerzen im rechten Ohr, Lähmung der linken Seite, welche sich vergrössert.

18. VI. Deliriren, Exitus.

2. 1838. Thomas J. Lauda-Giun ther. Manr von 22 Jahren. Messerstich in den oberen Theil des linken Halses. Aneurysma der Carotis.

1838. Ligatur der Carotis communis sin. doppelt. Nach der Operation: das linke obere Augenlid hängt gelähmt herab. Patient sieht nichts mit dem linken Auge und hört nichts mit dem linken Ohr. Kopfschmerz links, Schlafsucht ohne Schlaf. Das linke Gesicht kälter, das rechte wärmer. Heilung.

3. 1842. Sédillot-Günth er-Ehrmaun. Kräftiger Mann von 19 Jahren. Stich hinter dem rechten Unterkiefer, starke Blutungen, vergebliche Compression. April 1842: Ligatur der Carotis communis dext. versucht, aber missglückt. Blutung davert fort. Turniquet in der Gegend der Parotis. Nach drei Tagen neue Blutungell. Wunde wurde brandig Aneurysmatische Geschwulst in der Tiefe, die auf Druck auf die Carotis sehwand. Einschnitt am inneren Rand des Sternocleido mast.; die von Eiter infiltrirten Theile waren kaum zu unterscheiden. Gefäss- und Muskelscheiden waren fibrös verhärtet. Nach Anlegung der Ligatur der Carotis schwand der Puls im Aneurysma. 
Patient betäubt. Gehör rechts stumpf, Auge rechts nach innen schielend, blind; oberes Lid hängend. Muskeln der Nase und des Mundes lahm.

Am 28. April Fröste, Pyaemie. 2. Mai Exitus.

Section: Gelbe Erweichung des vorderen Hirnlappens rechts, zahlreiche kleine Abscesse in der Lunge.

4. 1842. Kuhl-Pilz. Mann von 53 Jahren, mit Aneurysma anastom. in regione occipitale seit bereits 24 Jahren. 24. V. 1834, Ligatur der Carotis communis sin. Sogleich nach der Operation Convulsionen, dann Obnmacht. Venaesectionen helfen. Am 3. August Blutung.

4. VIII. 1834. Ligatur der Carotis communis dest. Sofort leise Convulsionen. Gesicht ist blass und kalt.

7. VIII. Parese des rechten Armes, Kopfschmerzen. Verminderung des Sehvermögens. Schlingen erschwert, Blutungen, Fröste, - Besserung. Abnahme der Tumoren. - Heilung.

5. 1857. Bertherand-Pilz. 30jähriger Mann. 25. VI. 1854. Ligatur der Carotis communis sin., in Folge einer Blutung ans einer Schusswunde in den linken Oberkieter. Es folgten keine eigentlichen Hirnsymptome. Beträchtliche Abschwächang der Sehkraft des linken Auges. Taubheit auf derselben Seite und unvollständige Dysphagie und Aphonie.

Sechs oder acht Wochen naci der Operation complicirten zwei Anfälle von Cholera dio Reconvalescenz, hierdurch schien die Aphonie verstärkt, welche mehr als zwei Jahre bestehen blieb.

Auf die Dysphagie folgte eine Art Anaesthesie der entsprechenden Seite des Pharynx. In der ganzen linken Seite hat das Individum eine nur unvollkommene Perception der passirenden Speisen.

Die Sehraft blieb links gotrübt etwa während drei Jahren. Ein dichter Nebel schien das Gesichtsfeld za verdunkeln. Nicbts konnte aber jemals bei der äusseren Examination gefunden werden. Nachdem die Sehkraft wieder seit 18 Monaten normal war, wurde der Fundus mit dem Augenspiegel von Ehrmann untersucht, aber nichts Aufälliges oder von der anderen Seite Differentes gefunden.

Die Taubbeit ist eine Folge der Schussverletzung.

Interessant ist der Ausfall der Haare des Patienten. Derselbe begann auf der Seite der Ligatur. Die Bart- und Kopfhaare fielen streckenweise ans. Die Brauen und Cilienhaare 
Die Gefahren der Ligatur der grossen Halsschlagadern. etc. 519

schwanden in den ersten Monaten nach der Operation fast ausschliesslich anf der linken Seite. Später wurde die Alopecia allgemein.

6. 1866. J.Jolly-Broca. 47 Jahre alter Mann. Wiederholte Blutungen aus dem rechten Ohr, das schon zwei Monate taub war und von Zeit zu Zeit Eiterfluss aufwies. Tiefe Anaemie in Folge dessen. Beiderseitige Lungenphthise. Nach einer Unzahl von erneuten Blutungen, und nachdem Patient in Folge der Anaemie und einem scorbutartigen Leiden fast todt war, entschloss sich Broca am 26. III. 1866 zur Ligatur der Carotis communis dext.

Am 27. III. ist die Sehkraft des rechten Auges etwas geschwächt. Da der Patient sich in den folgenden Tagen über die Sebschwächo des rechten Auges beklagt, so constatirt eine genauere Untersuchung, dass er nur ganz grosse Lettern mit diesem Auge lesen kann. Der Augenspiegel zeigt keine wichtige Veränderung, die Retinalgefässe sind vielleicht etwas verengt.

22. IV. Exitus durch Lungenphthise.

7. 1869. Jüngken. Junger Mann mit bedeutend grosser telangiektatischer Geschwulst auf der rechten Seite des Kopfes.

Eines Nachts platzte die Geschwalst; gewaltiger Blutverlust: Durch Anlegung von Suturae circumvolutae konnte die Blutung zum Stehen gebracht werden.

$\mathrm{D}_{\mathrm{w}}$ wieder Blutungen folgen, am 17. I. 1843 Ligatur der Carotis communis dext.

Im Augenblick, als die Ligatur geschlossen ward, klagte Patient, dass er auf dem Auge der leidenden Seite total erblindet und auf dem Ohre vollständig taub sei, während er ganz kurz vor der operation noch gesehen und gehört habe.

Am dritten Tage stellte sich auf dem erblindeten Auge wieder etwas Lichtschimmer und auf dem tauben Ohr wieder eine ganz leichte Spur ron Gehör ein, begleitet von einem Geräusche und Sausen.

Das rechte Auge sah wie durch einen dichten Nebel oder durch einen dicken Flor. Die Geschwulst fiel allmählich zusammen und Patient crholte sich langsam. Der Patient wurde später Landwirth und starb 1850 in Folgo schwerer Blutung aus der neu entstandenen Geschwulst. 
8. 1898. Axenfeld. Axenfeld hat in der chirurgischen Klinik in Marburg eimen arteriosklerotischen etwa $60 j a ̈ b$. rigen Patienten beobachtet, bei dem kurze Zeit nach der rechtsseitigen Unterbindung der Carotis communis, die wegen Carcinom ausgeführt, wurde, bei negatirem ophthalmoskopischen Befunde und normalem Verhalten der Pupille eine linksseitige homonyme Hemianopsie hervortrat mit linksseitiger Hemiplegie. Fxitus letalis nach circa acht Tagen.

Die Section zeigte eine aufsteigende Thrombose der Carotis, doch uicht bis in den Circulus arteriosus hinein. Arteria ophthaimica frei.

II. Vorübergehende mehr oder weniger langedauernde Verminderung der Sehkraft.

9. 1828. Majo-Pilz. 23jähriger Mann: Blutung aus syphilitischer Ulceration im Schlundkopfe.

19. X. 1828. Ligatur der Carotis communis dext.

Nach der Ligatur einige Ohnmachten. Sehvermögen auf dem rechten Auge wird geschwächt, bessert sich aber schnell. Heftiges Klopfen in der linken Kopfseite. Heilung.

10. 1828. Molina. 29jährige Frau mit Lues. Kurz nachdem dieselbe eine $\mathrm{Hg}$-Cur im Spital durchgemacht, schwollen und vereiterten die Halsdrüsen der rechten Seite. Allgemeine Besserung, nur eine Drüse blieb geschwollen. Dieselbe entpuppte sich bald als ein Aneurysma der Carotis communis dext. unter dem Kinubackenwinkel.

23. V. 1828. Ligatur der Carotis communis dext. Ton Scarpa. Die Pulsation hörte auf und der Tumor verkleinerte sich. Gesicht rochts kalt und bleieh.

Unmittolbar nach der Ligatur tribte sich die Sehkraft für einige Augenbliclie, (Lieve offuscamento di vista) zugleich Herzklopfen.

Am vierten Tage war alles in gutem Gang, nur dic Wunde eiterte. Vom 21. Tage an offene Wundbehandiung. Erst auf nochmalige antiluetische Cur heilte die Wande völlig am Ende des zweiten Monats.

11. 1829. Sisco. 17jäbriger Mann. Stich in die vordere Halsgegend links. Starke Blutung, die fast zum Exitus führte. Nacl 3 Stunden nene enorme Blutung. Durch wiederholte Venaesectionen, Compressionen und Eisumschläge gelang es, die Blutung zu bannew. Wunde heilte. Patient nach zehn Tagen entlassen. 
Die Gefahren der Ligatur der grossen Halsschlagadern etc. 521

Nach kurzer Zeit bildete sich in der Narbengegend ein Tumor, der enorm rasch wuchs und Erstickungsgefahr mit sich brachte. Daher am 11. IX. 1829 Ligatur der Carotis communis sin.

Während der Operation eine fast tödtliche Blutung. Durch Digitalis, Diät, Venaesectionen gelang nach 30 Tagen die völlige Heilung der Wunde.

Sis co bemerkt: Im ganzen Heilungsprocesse wurde nichts Besonderes beobachtet, nur dass das Auge auf der verletzten Seite das Gesicht verlor und das Gehör auf der entsprechenden Seite vermindert wurde. Beide Functionen haben sich später wieder hergestellt.

12. 1848. Blackmann. Jüngling von 15 Jahren. Vor z.wei Jahren wollte ein Wundarzt eine polypartige Wucherung im rechten Nasenloch entfernen. Der Versuch gelang nicht völlig. Tumor, der wohl aus dem Sinus maxillaris stammte, wuchs weiter und dehnte sich auch über das linke Nasenloch aus. Oeftere Blutungen aus dem Tumor und Schwinden der Gesundheit des Knaben.

Ein ernenter Versuch, den Tumor zu excidiren, misslang wegen der heftigen Blutung. Der Tumor wuchs, die Wange schwoll an und unter dem äusseren Lidwinkel des rechten Auges zeigte sich eine neue kleinere Geschwulst. Da die Blutungen sich mehrten:

am 24. VII. 1849 Ligatur der Carotis communis dext. Keine unangenchmen Symptome irgend welcher Art. Die Wunde heilte rasch. Nach drei Wochen war ein Recidiv an der Oberlippe so mächtig geschwollen, dass die Ligatur der Carotis communis sin. nöthig wurde. Einige Secunden nach der Ligatur erblindete das linke Auge, doch schon eine halbe Stunde später kehrte die Sehkraft zum Theil wieder zurück. Sonst keine weiteren beunruhigenden Symptome. Nur Gedächtniss und Sehkraft des linken Auges für einige Wochen geschwächt. Nach sechs Monaten alles wieder normal und die Wunde geheilt.

Der Tumor fiel wenige Tage nach der zweiten Operation von Mund und Nase ab. Der Appetit kam von Neuem, and nach wenigen Wochen fühlte sich der Patient so gut, dass er wieder ausreiten konnte. Endresultat unbekannt.

13, 1851. A. Robert. 19jähriges Mädchen. Mächtiges Aneurysma cirsoides der Stirne, das laäufig zu Blutungen Anlass gab. 
15. VI. 1846. Ligatur der Carotis communis sin. Stimme rauh, sonst keine weiteren Symptome. Nach anderthalb Monaten erneute Blutungen.

22. II. 1847. Ligatur der Carotis communis dext.

Im Momente der Ligatur wurde Patientin sehr blass, klagte über heftigen Kopfschmerz und etwas Selschwäche, Schmerz im rechten A uge, Brechneigung und etwas Ameisenkriechen in den unteren Extremitäten. Diese Symptome blieben den ganzen Tag. Auch am folgenden Tag dauerte die Sehschwäche fort. (Rechts oder links?)

Am vierten Tage war die Sehkraft kaum mehr alterirt.

1. V. 1847. Tumor verkleinert, ohne Pulsation und Geräusch.

14. 1853. Mussey-Pilz-Ehrmann. 19jähriger Jüngling mit Naevus vasculosus in regione auris. Seit acht Jahren stärkeres Wachsthum und heftige Blutungen; imnerhalb eines Monates wurden beide Carotides communes ligirt, $\mathrm{n} u r$ von vorübergehender Schwächung des gleichseitigen Auges gefolgt. (Dieses Symptom wurde aber erst bemerkt, als Patient einige Tage nach der Operation aufzustehen begann.) (Ehrmann: VI. Fall.)

15. 1853. Jüngken-Pilz. Mann. Blutung aus Aneurysma anast. traumaticum. Ligatur der Carotis communis dext.

Mit der Ligatur sank die Geschwulst zusammen, das Sehvermögen des rechten Auges wurde auf kurze Zeit herabgesetzt; später wieder Pulsation im Tumor. Nene Blutung durch Umstechung und Glöheisen gestillt.

16. 1856. Dropsy-Burnotte. 25jährige Frau. In Folge eines heftigen Brechactes bildete sich an der linken Halsseite ein hühnereigrosses A neurysma der Carotis commuuis sin.

Juni 1852: Ligatur der Carotis communis sin.

UnmitteIbar nach der Operation verdusterte sich das Gesicht. (La vue se troubla.) Die Patientin wurde bleich, und es drohte Syncope. Ein Glas Wein zerstreute alle diese Erscheinungen.

18 Tage nach der Operation: Heilung der Wunde.

1855: Heilung vollkommen.

17. 1864. Hueter-Pilz. Mann, 58jäbrig. Nach Exstirpation eines Tumors über dem linken Kieferwinkel trat am zweiten Tage eine heftige Nachblutung auf, welche am 23. XII. 1864 die Ligatur der Carotis communis sin. nöthig machte. Am 25.XII. Sehvermögen links schwächer und ebenso die rechte Seite des Körpers geschwächt. 
Die Gefahren der Ligatur der grossen Halsschlagadern etc. 523

8. I. 1865. Sehkraft besser, aber die rechte Seite noch geschwächt. Heilung.

18. 1864. Partridge. 21jähriger Mann. Tiefe Stichwunde hinter dem rechten Kinnbacken. Wiederholte Blutungen und Abscessbildungen.

8. IV. 1864. Ligatur der Carotis communis dext.

Mit der Ligatur stand die Blutung. Fünf Tage lang war die Sehkraft im rechten Auge geschwächt.

18. IV. Blutung beim Husten aus der früheren Stelle.

25. IV. Schwellung des Gesichts rechts, dann Fröste und Dyspnoe. Tod plötzlich durch Glottisoedem, 29 Tage nach der Ligatur.

19. 1898. Jüngken-Pilz. Mann in mittleren Jahren. Stichwunde links. Kurze Zeit darauf Ligatur der Carotis communis sin.

Nur das Sehvermögen des linken Auges wurde mit der Ligatur auf einige Zeit geschwächt. Heilung.

20. 1880. King. Arbeiter von 40 Jahren. Seit acht Monaten entwickelte sich an der Basis des Halses ein Aneurysma.

28. VII. 1880. Ligatur der Carotis communis und Subclavia dext. Pulsation über dem Sternum abgeschwächt. Schmerzen im rechten Arm verschwunden.

31. VII. Verband entfernt. Wunde per primam geheilt.

King bemerkt unter diesem Datum: Das Augenlicht hatte sich gebessert, und die linke Pupille blieb grösser als die rechte, wie sie vor der Operation war.

23. 1X. geheilt und frei von Beschwerden entlassen.

21. 1891. Zimmermann. Mann von 69 Jahren mit mächtig ulcerirtem Carcinom im oberen Halsdreieck.

12. VI, 1888. Exstirpation des Tumors versucht. Radicale Exstirpation unmöglich. Wunde eiterte in den folgenden Tagen.

20. VI. Enorme Nachblutung Nachts. Sofort Ligatur der Carotis communis sin.

21. VI. Allgemeines Wohlbefinden. Keine Hirnsymptome, nur Flimmern und Schwarzsehen vor den A ugeu. Pupillen reagiren prompt, beide gleich weit.

4. VII. Patient darf aufstehen.

10. VII. Anfälle von Schwäche in den Streckmuskeln.

11. VII. Schüttelfrost, Aphasie, Hemiplegie und Facialisparalyse rechts. Fieber. Linke Pupille weiter als rechte, beide aber eng. 
12. VH. Sensorium benommen, hohes Fieber. Puls 140 klein.

14. VII. Collaps. Puils 166. Exitus.

III. Zerstörung des Auges, durcle entzündliche Affectionen, meist Panophthalmie.

22. 182\%. Wardrop. Mann von 22 Jahren. Eine mächtige, pulsirende Gefässgeschwuist, das linke Stirn-Parietal- und Schläfenbein bedeckend, vor zwölf Jahren in Folge von Trauma entstanden und nur allmählich entwickelt.

October 1827. Ligatur der Carotis communis sin. Die Pulsation hörte auf. Die Anschwellung blieb.

Wundveriauf gut bis zum fünften Tage, an dem Patient einen starken Frostanfall hatte, daraufhin heftigen Kopfschmerz, Durst und allgemein febrile Symptome. Aderlass, Calomel.

$A m$ siebenten Tage bei einer Kraftanstrengung heftige Blutung, Fieber erhöht, Puls 120, Aderlass.

Am zehnten Tage Exophthalmus und Chemosis links, aber nur geringe Entzundung der Augenhäute. Wunde schien zu heilen, Tumor verkleinert. Pulsation schwach. Zwei kleinere Abscesse in der Hals- und Schulterblattgegend wurden geöffnet.

Am 18. Tage wurde das Auge gewaltig nach vorne gedrückt. Es bildete sich an dem oberen Theile der Sklera Eiter, der sich rasch durch die Augenhäute ausbreitete und zur Entleerung des Augeninhaltes führte.

Weiterer Verlauf der Wundheilung ginnstig.

23. 1831. Delpech-Günther. Ein 21 jähriger Soldat erhielt am 3. VI. 1831 einen Bajonnettstich, der durch die Haut unmittelbar vor dem Musculus masseter sin. eindrang, dann unter das Ohr und dem Processus mast. führte und unter dem linken Hinterbaupthöcker wieder herauskam.

b. VII. Eine Geschwulst hatte sich gebildet, welche für einen Abscess gehalten wurde. Bei einem Einstich erschien Blut.

16. VII. Spontane Oeffnung der Austrittsstelle am Hinterhaupt und bedeutende arterielle Blatung aus derselben.

17. VII. Pulsirende Geschwulst bildete sich taselbst.

Nachts auf 22. VII. starke Blutung aus der vorderen Wunde. Compression, Eis.

27. VII. 1831. Blutung aus dem Gehörgang. Ligatur der Carotis communis sil. Uumittelbar darnach Aufhören 
der Pulsation im Tumor und des Blutflusses aus dem Ohre. Mehrere Aderlasse, Eis, Fieber, Frostschauer. Strang im Verlauf der Vena jugul. int. bemerkbar.

Oedem in der Orbita dext. Beinahe vollständige Blindheit auf dieser Seite. Zunahme der Symptome. Tod am 6. VIII. 1831.

Section: Art. transversa faciej und Art. occipitalis und N. buccinator durchschnitten. Eiter an der Basis des Schädels.

24 a) und 24 b). 1840. Colson. Frau ron 63 Jahren. Seit einigen Jahren Aneurysma der Carotis communis sin.

19.I.1840. Ligatur der Carotis communis sin. nach Brasdor.

Zunächst Eiterung, dann Reinigung der Wande und Verminderung der Pulsation im aneurysmatischen Tumor. Patientin fühlte sich sehr erleichtert. Plötzlich wurde sie von einer heftigen ophthalmie links ergriffen, gefolgt von beträchtlicher Chemosis. Auf die Chemosis folgte unmittelbar ein kleiner Abscess im oberen Theile des Auges in der Sklera. Dieser Abscess öfnete und schloss sich von selbst. Ein zweiter Abscess bildete sich tiefer unten in der Conjunctiva. Er wurde mit der Lanze geöfnet und schloss sich prompt durch Narbengewebe. Doch die Linse verlor ihre Transparenz und die Sehkrafterloseh auf dieser Seite.

Sonst völlige Heilung der Wunde nach 75 Tagen und Schwinden des Anenrysmas.

X. B. 40 Jahre später September 1881 schreibt Colson, um sein Gewissen zu berubigen und ruhig sterben zu können, wie aus Wahrheitsliebe in der Wissenschaft, dass die Patientin nicht in Folge eines Aneurysmas der Carotis operirt worden und bald darauf gestorben sei, sondern in Folge eines Fungus durae matris, welcher einen grossen Theil der rechten Hirnhälfte zerstört und jedenfalls mit Schuld an dem Untergange des linken Anges gewesen. Auch auf der linken Seite, am Ursprung der linken Carotis, fand sich ein ähnlicher Tumor, welcher die Carotis von allen Seiten völlig einhüllte und von ihr die Pulsation mitgetheilt erbielt und so ganz als Aneurysma imponirte.

25. 1854. Mackenzie-Axenfeld. Ligatur der linken Carotis bei einem jungen Manne. Fünf Tage nach der Ligatur Auftreten von Panophthalmie links. Gleichzeitig Gelenke afficirt, also allgemeine Pyaemie. Nach fünf Monaten Recidiv der Pyaemie, Meningitis, Exitus. 
Die Section zeigte einen infectiösen Thrombus in der linken Carotis. Keine Endocarditis.

26. 1856. Packard-Norris. Mann von 46 Jahren. Messerstich hinter dem linken $\mathrm{Ohr}$ am 3. XI. 1855.

8. XI. Blutung und Bildung einer aneurysmatischen Schwellung.

10. XI. 1855. Ligatur der Carotis communis sin. Verlauf gut.

19. XI. Erysipelas, ausgehend von einer alten Narbe auf der Stirn, in einer Woche abgeheilt.

4. XII. Nachmittags befand sich Patient noch völlig wobl, um Mitternacht Convulsionen. Puls rapid schwach. Athmung schwer, Schlucken unmöglich. Bewasstsein gestört. Linkes Auge war starr, glasig (glassy) und stark entzündet. Das rechte Auge normal. Convulsionen kehrten in ungleichen Intervallen zurück.

5. XII. Mitternachts wurde Patient ruhig and blieb so bis zu seinem Tode am 6. XII. Mittags.

Section. Aneurysmatischer Sack mit drei Oeffnungen, eine für die Jugularvene and zwoi für die Occipitalarterie. Jugularis int. war eine Strecke weit verstopft. Carotis communis und die Stelle der Ligatur durch feste Coagula verstopft. Ligatur selbst lag lose in schmieriger Masse. (The Ligature itself lying lossely in the slough.) Das ganze Hirn war etwas erweicht. Oberer und vorderer Theil der linken Hemisphäre nond der hintere Theil der rechten waren gänzlich in eine teigige Masse zerbröckelt. Es fand sich anch ein Erguss in die Ventrickel.

27. 1871. Hopmann. 23jähriger Manu. Gesichtsschuss, Kugel war am unteren Ende des Jochbeines eingedrungen, Latte den Grumen zerrissen und war drei Centimeter unter balb des linken Gehörganges ausgefahren. Starke Blutung. Neun Mal in den folgenden Tagen heftige Nachblutungen aus der Gaumenwunde.

19. VII. 1870. Ligatur der Carotis communis sin.

Am 22. VII starke Blutung aus der Ligaturwonde. Am Abend vorher soll die verbindende Schwester den Eiter zu stark ausgedrückt haben.

Als unmittelbare Folge der Operation batte Patient zwei Tage lang Cebelkeit und Erbrechen, fermer Ohrensausen rechterseits, Stimnlosigkeit, Vermehrung der Schlingbeschwerden, Unfähigkeit den rechten Arm zu heben, sowie überhaupt theilweise Lähmung der ganzen rechten Seite. Das Alles besserte sich nach und nach etwas, und Patient erholte sich langsam, 
Ende September: Entlassung. Unterbindungswunde bis auf eine linsengrosse Stelle geschlossen. Auf der Reise Schüttelfrost.

Am 10. X. schwoll nach dreitägigem Unwohlsein die Unterbindungsstelle ziemlich rasch an und ergoss nach 24 Stunden, nachdem sie geplatzt, in stossweisen Absätzen viel Blut. Sieben. heftige Nachblutungen in den nächsten 14 Tagen.

24. X. Abermalige Aufnahme im Spital, Patient anaemisch erschöpft.

Noch sechs Mal Blutungen und alle Versuche zum Stillen vergebens. Deshalb Operation: Spaltung des Sackes, Blutung im Strahl. Tamponade des Sackes mit Sehwämmen.

31. X. Patient apathisch fiebernd. Puls minimal irregulär, kaum zählbar, anbaltend Uebelkeit und Erbrechen. Brustschmerzen links. Husten mit Auswurf und pneumonischem Sputum.

Das rechte duge heftig panophthalmitisch entzündet. Parese des rechten Gesichtes und der rechten Körperhälfte. Aphonie. Aus der Wunde fliesst stinkender Eiter und Blut.

Desinfection mit Carbolsänrekrystallen. Bala Besserung der Wunde und Schwinden der verschiedenen Symptome pyämischer Vergiftung. Die Lähmungen dauerten noch längere Zeit an. Die Panophthalmie hatte zur Phthisis bulbi geführt. Auge Januar 1871 enucleirt.

28. 1875. Ensor. Mann von 50 Jahren. Aneurysma der Anonyma.

8. IX. 1874. Ligatur der Carotis communis dext. und Subclavia. Kein merklicher Effect im ersten Moment, Wunde eiterte bald.

18. X. Puls intermittirend schwach. Ohrenschmerz rechts. Miosis rechts. Sonst Besserung der Aneurysmasymptome.

31. X. Nach Erkältung am 25. X., nach vorausgegangenem Schüttelfrost und Blutung aus der Carotiswunde, sehr lästiger Hustenanfall in der Nacht. Oedem in der linken Hand und etwas in den Füssen.

1. XI. Bintung.

5. XI. Erneute Blutung. Puls schwach. Oedem des rechten Augenlides seit $2-3$ Tagen. Cornea heute wolkig getrübt, ist im Begriffe zu Grunde zu gehen.

9. XI. Cornea hat nachgegeben. Glaskörper und Linse sind ausgetreten und Auge zusammengefallen. Gesicht nach links verzogen.

10. XI. Blutung, Puls schwach intermittirend.

12. XI. Exitus im Coma.

v. Graefe's Arehiv für Ophthalmologie. L. 3. 
Section: Pleuritis rechts. Viel Flüssigkeit an der Hirnbasis, Hirnsubstanz bleich und weiss; Art. communicans post. rechts obliterirt und zu einem feinen fibrösen Faden reducirt.

29. 1882. Edmunds-Axenfeld. Mann von 32 Jahren mit Halswunde. Ligatur der linken Carotis communis. Fünf Tage nach der Ligatur Auftreten von Panophthalmie links. Wiederholte Nachblutungen. Eitrige Metastasen im linken Hirn. Exitus am 14. Tage nach der Operation in Folge von Nachblutungen.

Die Section zeigte zerfallene Thromben in der linken Carotis. Keine Endocarditis.

30. 189\%. Tailhefer. 30jähriger Mann. Strumaoperation. Nach 13 Tagen Nachblutung aus der Carotis communis sinistra. Fassen des ganzen Gefässnervenstranges mit Klemmpincette. Sofort Frstickungsanfälle und Brechen. Nach 20 Stunden Aphasie, Hemiplegie rechts und Coma, aus dem Patient erst nach 48 Stunden erwachte. Sechs Tage lang hohes Fieber. Nach zwölf Tagen Panophthalmie links. Später Heilung, nur Aphasie blieb zum Theil bestehen.

IV. Strabismus.

31. 1858. Watson. 1853. Ein junges Franenzimmer erhielt einen Stich in den Hals über der linken Clavicula. Starke Blutung. Ligatur der Carotis communis sin. Blutung stand selbst nach der alsbald darauf vorgenommenen Ligatur der Vena jugnl. int. noch nicht. Die Art. Subclavia nicht zu finden, man legte daher eine Ligatur rum ein in der Näbe des letztgenannten Gefässes vorgezogenes Stück Fascie, worauf die Blutung stand. Am nächsten 'Tage geringe Reaction.

Am Nachmittag des dritten Tages erschwertes Athmen, stotternde Sprache, Erweiterung der rechten Papille, starke Somnolenz. Abends die ganze Körperhälfte gelähmt, Strabismus, schwacher rapider Puls. In der Nacht Tod.

Section: Blotung aus der zerschnittenen Vertebralis. Hirnsubstanz anscheinend theilweise erweicht. Doppelseitige Pleuritis mit reichlichem sero purulentem Erguss.

32. 1858. A. Ehrmann-J. Eh rmann. Mann von 20 Jahren. Verletzung. Ligatur der Carotis communis sin. 1858. Wenige Stunden nachher constatirte man völlige rechtsseitige Hemiplegie. Erhöhung der Sensibilität des Gesichtes links; Strabismus divergens des, linken Auges.

Am vierten Tage Dysphagie, Dyspnoe, Exitus. 
Die Gefahren der Ligatur der grossen Halsschlagadern etc. 529

Seit der Operation hatte der Patient kein Wort mehr gesprochen.

Section: Oberflächliche Venen des Hirns links mehr gefült als rechts. Consistenz des Hirns unverändert. Leichte Punktirung (Piqueté léger) der weissen Substanz. Durch die Verletzung war die Vertebralis und Jugularis int. durchtrennt worden.

33. 1869. Beck. Präventive Ligatur der Carotis communis sin. bei einer Frau, der ein kopfgrosser Markschwamm exstirpirt wurde.

Die physiologischen Erscheinungen beim Zuschnüren des Gefässes waren folgende: Blässe des Gesichts, kalter Schweiss der linken Gesichtshälfte. Zunächst Sehliessen der Augen, später rollte sich beim Oeffnen der linke Augapfel nach aussen und oben. An dem Bulbus konnte sonst nichts wahrgenommen werden, auch waren die Geisteskräfte in keiner Weise gestört.

Exitus erst später durch Carcinommetastasen.

34. 1891. Zimmermann. Mann von 38 Jahren. Seit einem Jahr entwickelte sich langsam eine ampnllenartige Erweiterung der Carotis int. links mit verschiedenen lästigen Symptomen.

9. XII. 1890. Ligatur der Carotis communis und int. sin.

Mittags $2 \mathrm{Uhr}$ : Patient liegt in narkotischem Zustande ruhig da und reagirt auf äussere Reize nur wenig.

Abends: rechts Facialisparese, Hemiplegie, Anaesthesie, links Parese des Hypoglossus.

Ophthalmoskopischer Befund: linke Papille undeutlich begrenzt, etwas verwaschen, röthlichgelb verfärbt. Gefässe zeigen keine Veränderung in ihrer Füllung.

Abends 8 Uhr: zunehmender Sopor. Schluckbeschwerden. Pupille rechts enger als links, träge Reaction auf Lichteinfall.

10. XII. Wunde reactionslos. Tiefes Coma. Rechts totale Facialisparalyse und Lagophthalmus. Links Ptosis, Pupille ad maximum dilatirt. Strabismus nach oben und aussen. Reflectorische Pupillenstarre. Rechte Pupille stark verengt, gleichfalls reactionslos. Incontinenz von Blase und Mastdarm. Puls verlangsamt, kräftig, 64 in der Minute, Respiration tief, regelmässig, 18 in der Minute. 
Den ganzen Tag Coma. Abends Cheyne-Stock'sches Phänomen, und unter zunehmender Pulsfrequenz Exitus.

Section: Ascendirende Thrombose in der Carotis int. and Art. fossae Sylvii, Ramus communicans ant., Art. corp. callosi linkerseits. Beginnende Hirnerweichung im Gebiete der inneren Kapsel, Hirnoedem und Stauung in den Piavenen links. Geringe Herzbypertrophie.

\section{Taria.}

3อ̆. 1838. Christianus Henricus Bnenger. Bei einem 34 Jahre alten Manne fand sich ein diffuses Aneurysma der Arteria temp. superficialis sin. und zum Theile auch der Arteria frontalis und occipitalis, welches viele Beschwerden machte.

Am 10. V. 1819 machte Buenger die Ligatur der Carotis communis sin., worauf die aneurysmatischen Arterien collabirten und sowohl local, als auch im ganzen Kopfe auf längere Zeit Ruhe einkehrte. Nach vielen Mouaten schwollen die aneurysmatischen Arterien bis zu Hirngyrusgrösse, theils zu grösseren Säcken von Nenem an. Es wurden deshalb ligirt: ein Ast der Arteria temporalis sup. sin., die Arteria maxillaris int. und die Arteria temporalis sup. dest.

Gleichzeitig wurde die Compression des ganzen aneurysmatischen Gebietes ausgeübt. Leider wurde dieselbe rom $\mathrm{Pa}$ tienten uicht lange genug ausgehalten, so dass eine röllige Heilung nicht zn Stande kam. - Es fielen jedoch die erweiterten Arterien ziemlich zusammen und so konnte constatirt werden, dass durch ein grosses Loch im Schädel eine Verbindung von Arteria temp, sup. and Meningea media existire.

Trotzdem das Leiden nicht gehoben war, wurde mehrere Jahre nichts weiter unternommen, da alle in Erwägung gezogenen Maassnahmen zu gefährlich erschienen.

Im September 1823 platate auf der höchsten Protuberanz des Aneurysmas eine dort entstandene Pustel nach einer Terletzung mit dem Nagel. Es ergossen sich etwa 6 Unzen Blut im Strahle. Kälte brachte die Blutung zum Stehen.

Im Januar 1824 öffnete Patient selbst, um Selbstmord zu begehen, das Aneurysma etwa zwei Daumen breit mittelst eines Messers. Das Blut brach in daumenbreitem Strahle hervor and Patient war dem Verbluten nahe, nur mit Mühe konnte er durch Compression und Naht rom Tode gerettet werden. Verlust an Blut: 2 Pfund. 
Die Gefahren der Ligatur der grossen Halsschlagadern etc. 531

2. Februar 1824. Neue enorme Blutung aus der alten klaffenden Wunde. Blutveriust circa 2 Pfand.

Am 9. und 16. Febr. erneute Blutungen, daher endlich am 19. Febr. 1824: Ligatur der Carotis communis dext. Sofort nach der Operation konnte kein Einfluss derselben auf die Sinnesorgane bemerkt werden, nur dass Patient, um deutlich zu sehen, die Augen mehr anzustrengen schien, dass die Pupillen weiter, und die Augen starr waren wie Glas. Patient zeigte ausserdem eine eigenartige his jetzt noch nicht bei ihm beobachtete Ruhe und war vom Ende des zweiten Tages nach der Operation an bis zum siebenten Tage seines Verstandes nicht mächtig, äusserst elend and besass einen kleinen frequenten Puls. Er naum weder Speise noch Trank zu sich, und man erwartete seinen Tod.

Am fünften Tage nach der Ligatur, als Patient in der höchsten Lebensgefahr schwebte, wurde ein um den Kopf gehender Compressionsverband angelegt, (tornaculum peculiare applicarimus), theils um die Congestion zu verhindern, theils um die zusammengefallenen Aneurysmata zu comprimiren und zur Obliteration zu bringen, und eine leichtere Beobachtung der Wunde zu ermöglichen.

Nachdem dieser Verband vom Morgen bis Abend gelegen hatte, wurde das obere Augenlid des rechten Auges gehoben, um die Pupille zu inspiciren, und da fand sich das Auge bleich and trübe und die Cornea gequollen ohne Injection. Das andereAuge bot ausser einer weiten Pupille und eines schlaffen, wie entseelten Aussehens - was auf den Sopor des Patienten zurückzuführen war — keine Veränderung.

Stärkende Flüssigkeiten, mit welchen die Augen gewaschen wurden, hielten die zunehmende Verdunklung des rechten Auges nicht auf.

Am sechsten Tage nach der Ligatur wurde die Cornea, durch welche der Glaskörper vorzubrechen schien, dicker und schien aufgelöst in eine Art Brei. Zugleich entstanden dunkelblane Gefässe in der Conjunctiva, welche gleich wie die Lider anschwoll.

Am siebenten Tage allgemeine Besserung. Bewusstsein kehrte wieder und Patient begann wieder wie ror der Ligatur über die Compression, sehr wenig aber über das Auge zu klagen. 
Weiterer Verlauf gut, ausser für das Auge. Pus salubre in den Wunden. Endlich völlige Heilang.

36. 1859. Nunneley. Mann von 31 Jahren mit $\mathrm{Ex}$ ophthalmus pulsans links, einige Wochen nach einem Schlage auf das linke Auge entstanden.

26. X. 1852. Punction der Lider. Blutung in feinem Strahl und als Folge Chemosis und Blutinfiltration der Conjunctiva.

3. XI. Zunahme aller Symptome und daher Ligatur der Carotis communis sin., vier Monate nach dem Unfall. Bald allgemeine Besserung. Pulsation und Geräusche hörten auf und Auge nach drei Wochen nahezu in seinem natürlichen Zustande. Auch die Sehschärfe besserte sich.

27. I. Nach einem Excesse trat ein Recidiv aller Erscheinungen ein.

Nach mehreren Aderlassen Besserung.

23. II. Entlassung.

21. VI. Patient fast völlig normal, linkes Auge erkennt Gegenstände aber nur undeutlich in Umrissen.

Sommer 1857: Patient völlig geheilt. Auge äusserlich normal, aber cataractös und ohne Projection. (The eye was then natural, except cataractous; there was neither congestion nor projection).

37. 1880. Hirschberg-Flatten. 25. II. 1880. Seit zehn Tagen Exophthalmus pulsans links nach vorausgegangenem Trauma. Auge besass noch ein mittleres Sehvermögen. A ugengrund war normal. Augapfel unbeweglich. Exophthalmus sehr stark. Cornea unempfindlich. Euorme Schmerzen.

Zunächst zwei Tage lang - (3. und 4. III. 1880) subcutane Ergotininjectionen, worauf die Pulsationen aufhörten, ohne dass der Exophthalmus sich verringerte.

Am 5. III. 1880 kehrten die Pulsationen wieder, gleichzeitig erfolgte ganz plötzlich eine völlige Erblindung des linken Angapfels.

8. III. 1880. Ligatur der Carotis communis sin. Pulsationen schwanden.

Ophthalmostropische Untersuchung zeigte, dass die Arterien der Netzhaut fadenförmig waren und dass zablreiche Blutungen in der Netzhaut besonders nahe dem Centrum sich fanden. Sehnerv fast normal. Heilung per primam.

Acht Tage nach der Operation: Auge blind, wenig 
Die Gefahren der Ligatur der grossen Halsschlagadern etc. 533

vorgetrieben, unbeweglich, unempfindlich. Blutungen der Netzhaut wie zuvor. Arterien weiter.

Juli 1880: Ptosis und Beweglichkeitsstörung des linken blinden Augapfels gering. Empfindlichkeit der Cornea noch etwas herabgesetzt. Atrophische Excavation des Sehnerven. Netzhautarterien nicht verengt. Keine Protrusion.

38. 1886. Arimond. 44jähriger Mann. Anenrysma der Anonyma.

20. XI. 1884. Ligatur der Carotis communis dext. nach Brasdor. Vor der 0peration fand sich im rechten Auge am Rande der Papille deutlich sichtbarer Arterienpuls. Nach der Operation war derselbe verschwunden. Am folgenden Tage aber war er wieder da.

22. XII. Heilung per primam.

39. 1890. von Frey. 26jähriger Mann. Seit zwölf Tagen ein Aneurysma traumaticum der Carotis communis sin.

2. V. 1890. Ligatur der Carotis communis sin. Während der Operation heftige Blutung, welche nur mittelst Compression durch sechs Hände gestillt werden konnte.

Nach der Operation Patient anaemisch, aber ganz munter. Stimme heiser.

Mittags ist am linken Auge eine nicht unbeträchtliche Ptosis zu bemerken. Die nächsten zwei Tage glatter Verlauf.

13. V. Deutliche Verengerung der linken Papille. Röthung der linken Gesichtshälfte und vermehrte Schweisssecretion, auf dieser Seite. Ptosis besteht fort.

Wundverlauf ungestört. Laryngoskopische Untersuchung zeigte eine Lähmung des linken Thyreoepiglotticus, und völlige Paralyse des linken Stimmbandes. Später lüngsame Besserung der Heiserkeit.

40. 1891. Zimmermann. Frau von 45 Jahren. Seit vier Monaten Exophthalmus pulsans mässigen Grades links, nachdem einige Wochen zuvor der Kopf leicht an einen Thürpfosten angestossen war. Im Beginu der Erkrankung heftige Kopfschmerzen und Lähmung des linken Armes, welche Symptome nach wenigen Wochen wieder verschwanden.

Nachdem drei Wochen lang täglich fünf Stunden ohne Erfolg Digitalcompression geübt worden war, wurde am 26. V. 1878 die Carotis communis sin. ligirt. 
Die subjectiven Symptome nach der Ligatur, Kopfschmerz, Flimmern vor dem linken Auge, Uebelkeit (vom Chloroform) gingen in den ersten drei Tagen nach der Operation vorbei und die Wunde heilte per primam.

Am zwölften Tage nach der Ligatur linksseitige Abducenslähmung, die mit der Zeit sich zurückbildete. Wundverlauf reactionslos. Keine weiteren Hirnsymptome. Völlige, dauernde Heilung.

41. 1991. Zimmermann. Mann von 54 Jahren war zu wiederholten Malen wegen Carcinoma linguae operirt. Bei der dritten Operation am 14. X. 1887 musste, da die nenen Tumoren fest mit der Theilungsstelle der Carotis verwachsen waren, die Carotis communis sin., dann die Carotis ext. und int. sin. ligirt werden. Dabei wurde kein Einfluss auf Puls und Respiration beobachtet.

15. X. Rechte Seite völlig lahm. Reflexe erloschen, nur Kitzeln der Fusssohle löst leichten Reflex aus. Patient ist apathisch und reagirt nicht auf Zureden. Urin muss durch Catheter entleert werden. Wunde reactionslos.

17. X. Zustand der Somuolenz der gleiche. Catheter noch immer nöthig. Seit beute im rechten Bein zeitweise leichte Zuckungen, namentlich boim Kitzeln der Fusssohle. Cornealreflex seit gestern Abend links völlig erloschen. Pupille etwas weiter af dieser Seite als rechts, reagirt aber auf Licht. Beginnende Pneumonie beiderseits.

18. X. Nach zunehmendem Kräfteverfall Exitus.

Section: Ascendirende Thrombose der Carotis int. sin., mit Ausbreitung der Thromben in der Arteriae fossae Sylvii sin. nnd Corporis call. Ischaemische Nekrose im Gebiete der linken Stammganglien, der Capsula int., des Stabkranzes nnd des Schläfenlappens. Frische Meningitis convexitatis. Doppelseitige Schluckpnenmonie mit fibröser Pleuritis.

42. 1898. Uhthoff. Uhthoff hatte Gelegenheit eine ältere Patientin während des unmittelbaren operativen Eingriffes der Carotisunterbindung zu ophthalmoskopiren.

Es zeigte sich eine deutiche voräbergehende $A b-$ blassung der betreffenden Papille und mässige Verringerung der Retinalgefässe. Die Störungen glichen sich aber nach relativ kurzer Zeit wieder aus. 
Die Gefahren der Ligatur der grossen Halsschlagadern etc. 535

\section{Literaturverzeichniss.}

1) Julius Friedländer, Ueber die Ligatur der Carotis. Inaug.Dissert. Dorpat 1881. Fall 137.

2) C. B. Günther, Lehre von den blutigen Operationen am menschlichen Körper. Abth. 5. Operationen am Halse. Fall 111.

3) Sédillot, Gaz. médic. 1842. p. 567. Günther, l. c. Fall 55. Ehrmann, Des effets produits sur l'encephale par l'oblitération des vaisseaux artériels qui s'y distribuent. Paris 1860.

4) Kuhlii, Opusc. academ. scripsit Clarus 1842. p. 51 specimen 1 quaestion chirurg. part. 14. C. Pilz, Zur Ligatur der Carotis communis nebst einer Statistik dieser Operation. Archiv f. klinische Chirurgie. Bd. IX. S. 257.

5) Bertherand, Gazette médicale de l'Algérie 1857. No. 1. p. 1. Ehrmann, loc, cit. Fall XL. III. C. Pilz, loc cit. Fall 80.

6) J. Jolly, Archives générales de Médecine 1866. Vol. II. p. 24. Tom 8. De l'ulcération de la Carotide interne consécutive à la carie du Rocher.

7) Jüngken, Varices Blutaderknoten, Telangiektasiae, Telangiektasien. Berliner klin. Wochenschr. 6. Jahrg. 1869. S. 65 u. 73.

8) Axenfeld, Bericht der 27. Versammlung der ophthalmologischen Gesellschaft in Heidelberg 1898 in der Discussion des Vortrags von Siegrist. S. 22 u. mündliche Nittheilung.

9) H. Majo, London Med. and Physic. Journ. Vol. 38. Dec. Pilz, 1. c. Fall 24.

10) A. Molina, Caso di aneurisma della carotide primativa al destro lato curato colla allacciatura., del dott. A. Molina. Annali universali di Medicina 1828. Vol. XLVII. p. 423.

11) Sisco, Annali universali di Medicina 1829. Vol. LII. S. 362.

12) G. C. Blackman n, Ligatur of both Primitive Carotids. American Journal of the medical sciences. New-Series Vol. XV. 1848. S. 357.

13) A. Robert, La Lancette française. Gazette des Hôpitaux civils et militaires 1851. 24. année No. 33. p. 130.

14) Mussey, Americ. Med. Journ. 1853. N. S. 52. Pilz, loc. cit. Fall 439: a u. b. Ehrmann, loc. cit. Fall VI.

15) Jüngken, Deutsche Klinik 1853. S. 167 (diese Angabe datirt von Pilz. Daselbst nichts zu finden). Pilz, loc. cit. Fall 151.

16) Dropsy-Burnotte, Gazette médicale de Paris 1856. p. 229. Annales médicales de la Flandre occidentale 1855-56. Observation d'anevrisme de l'artère carotide primitive gauche; Ligature à sa partie inférieure; guérison.

17) Hueter, Journ. d. v. Langenbeck's Klinik. 1862 (?). No. 525. Pilz, 1. c. Fall 128.

18) M. Partridge, Ligature of the common carotid artery for bleeding from a punctured Wound behind the ramus of the jew; death from supra-glottic oedema. Under the care of M. Partridge. Lancet 1864. II. p. 659.

19) Jüngken, Persönliche Mittheilung an Pilz. Pilz, l. c. Fall 150.

20) K. King, Aneurism at root of neck: Ligature of right carotid and subclavian arteries by $\mathrm{K}$. King. British medical Journal 4. Dec. 1880. p. 878 .

21) Zimmermann, Ueber Gehirnerweichung nach Unterbindung der 
Art. Carotis communis nebst statistischen Beiträgen. InauguralDissertation. Heidelberg 1891. Fall 1.

22) Wardrop, Case of a rare Aneurismal disease of the temporal arteries and ligature of the Carotid. Lancet Vol. XII. 1826-28. p. 762 a. 798. Vol. XIII. p. 47.

23) Delpech, Montpellier 1831. Günther, 1. c. N. 87.

24a) M. Colson, Anévrisme de l'artère carotide primitive traité par la ligature faite au dessus de la tumeur. Bulletin de l'Académie royale de médecine. Vol. VI. 1840. p. 8.

24 b) M. Colson, Communications. Bulletin de l'Académie de Médecine. 2. Série. Tome X. Juillet à Décembre 1881. p. 1085.

25) Mackenzie, Pract. Treat. of the Diss. of the eye. London. S. $301.589 \mathrm{ff}$.

Axenfeld, Ueber die eitrige metastatische Ophthalmie etc. v. Graefe's Arch. f. Ophthalm. Bd. XL. 3. Abth. S. 38.

26) Packard-Norris, Case of wound of the occipital artery and jugular Vein. -- Ligatur of Carotid artery. The American Journal of the medical sciences. Vol. XXXI. 1856. p. 396.

27) B. Hopmann, Fall von Aneurysma traumaticum der Carotis communis dext. etc. Berl. klin. Wochenschr. 1871. Nr. 35.

28) Ensor, Aneurism of the arteria innominata. Lancet 1875. I. p. $192-193$. II. p. 164 .

29) W. Edmonds, Panophth. suppur. after Ligat. of the A. carot. commun. Transactions of the Ophthalm. Society of the United Kingdom. Vol. II. London 1882. Axenfeld, 1. c. S. 42 a. 36.

30) E. Tailhefer, Gazette hebdomadaire, 1897. Nouvelle Série. Tom. II. No. 13. p. 73.

31) J. Watson, Schmidt's Jahrb. d. ges. Med, 1858. Bd, 98. S. 76.

32 A. Fhrmann; 1858. J. Ehrmann, 1. c. S. 39. Fall XXI.

33) B. Beck, Arch. f. klin. Chirurgie. XI. S. 281. 1869. Nachtrag zu Pilz Aufsatz zur Ligatur der Art. Carotis comm.

34) Zimmermann, I. c. Fall 4. S. 40.

35) C. H. Buenger, Prima Carotidi Communi utrique Corporis humani prospero cum eventu applicata ligatura, qua vita aegri serrata et Aneurysma ejus late diffusum etc. Marburgi 1838.

36) Nunneley, An acount of three cases of Aneurism of or within, the orbit ete. Medico-Chirurgical Transactions. Vol.42. p.165. 1859

37) Hirschberg, Ein Fall ton pulsirendem Exophthalmus. Centralblatt f. Augenheilk. 1880. S.221. Juliheft. - Heildelberger Congressbericht 1898 . \$. 24.

J. Flatten, Ein Fall von Aneurysma der Art. ophthalmica und Carot. int. geheilt durch Ligatur der Carotis communis. Inaug.Dissert. Berlin 1880.

38) Arimond, Ueber die Brasdor-Wardrop'sche Behandlungsweise der Aneurysmen. Inaug.-Dissert. Berlin 1886.

39) ₹. Frey, Zur Casuistik der Getässverletzungen. Wiener klin. Wochenschr. III. Jahrg. Nr. 47. II. Fall. S. 909. 1890.

40) Zimmermann, 1. c. S. 3. 1891.

41) Zimmermann, 1. c. Fall 3. S. 36. 1891.

42) Uhthoff, Bericht uber die 27 . Versammlung der ophthalmologischen Gesellschaft Heidelberg 1898 in der Discussion des Vortrages ron, Siegrist. 9.22 . 
Die Gefahren der Ligatur der grossen Halsschlagadern ete. 537

Kritische Besprechung der referirten Fälle.

Die Carotisligatur kann, wie aus dem Vorausgegangenen ersichtlich, auf verschiedene Weise das gleichseitige Auge schädigen.

I. Was die Gruppe der bleibenden oder doch äusserst lange dauernden Sehstörungen des gleichseitigen Auges betrifft, so ist über deren Ursache noch gar nichts bekannt. Keiner dieser Fälle wurde eingehender und nur zwei mittels des Augenspiegels, aber mit negativem Resultate untersucht, (Fall 6, ausser leichter Verengung der Netzhautgefässe soll nichts Auffälliges vorgelegen haben. Fall 8 zeigte normalen ophthalmoskopischen Befund mit normaler Pupillenreaction), so dass wir noch keine Anhaltspunkte besitzen zur Beurtheilung der Genese dieser Sehstörungen.

Die Hemianopsie, welche Axenfeld (Fall 8) nach einer Carotisligatur beobachtet hat, ist nach der Ansicht dieses Autors entweder durch eine Tractusembolie oder durch apoplectiforme Processe in der inneren Kapsel etc. hervorgerufen worden. Das betreffende Hirn wurde noch nicht untersucht.

Was aber die begleitenden Umstände und die Art dieser Fälle betrifft, so möge kurz folgende Tabelle recapituliren:

\begin{tabular}{|c|c|c|c|}
\hline Nr. & $\begin{array}{l}\text { Altcr } \\
\text { und } \\
\text { Geschlecht }\end{array}$ & Diagnose & Ausgang \\
\hline 1. & M. 51 . & Aneurysma Allonymae. & Hemiplegie Exitus. \\
\hline 2. & M. 22 . & $\begin{array}{l}\text { Aneurysma der Carotis nach } \\
\text { Messerstich. }\end{array}$ & Heilung. \\
\hline 3: & M. 19. & $\begin{array}{l}\text { Aneurysmatische Geschwulst } \\
\text { nach Stich in Hals. } \\
\text { Enorme Blutung. Eiterung. }\end{array}$ & $\begin{array}{l}\text { Himerweichung Pyae- } \\
\text { mie. Exitus. }\end{array}$ \\
\hline 4. & M. 53. & $\begin{array}{l}\text { Aneurysma anast. occipitale. } \\
\text { Blutung. Ligatur der } 2 . \\
\text { Carotis. }\end{array}$ & $\begin{array}{l}\text { Parese des rechten Ar- } \\
\text { mes. Heilung. }\end{array}$ \\
\hline 5 . & M. 30 . & $\begin{array}{l}\text { Schusswunde in Kiefer. BIu- } \\
\text { tung. }\end{array}$ & Heilung. \\
\hline 6. & M. 47 . & $\begin{array}{l}\text { Eiterfluss aus Ohr. Enorme } \\
\text { Blutung. }\end{array}$ & Heilung. \\
\hline 7. & M. 25. & $\begin{array}{l}\text { Telangiektatische Geschwulst. } \\
\text { Anaemie. }\end{array}$ & Heilung. \\
\hline 8. & M. 60 . & Carcinom. Arteriosklerose. & Exitus. Hemiplegie. \\
\hline
\end{tabular}


Vor Allem handelt es sich hier nur um Männer mit einem Durchschnittsalter von 38 Jahren. Bei 5 von den 8 Fällen waren heftige Blutungen der Ligatur vorausgegangen und hatten einen mehr oder weniger hohen Grad von Anaemie hinterlassen. Bei einem sechsten Falle (Fall 2) war eine Blutung, wenn auch nicht angegeben, so doch selbstverständlich. Die zwei übrigen Fälle waren: ein Aneurysma der Anonyma bei einem 51 jährigen und ein Carcinom bei einem arteriosklerotischen 60jährigen Manne. Beide zeigten schwere Hirnsymptome und starben in Folge der Ligatur.

Vier von den acht Patienten zeigten Hirnsymptome nach der Ligatur, der eine nur eine Parese eines Armes, die drei anderen schwere, auf welche der Exitus folgte.

II. Was die $13 \mathrm{Mal}$ beobachteten vorübergehenden Sehstörungen nach Carotisligatur betriftt, so möge folgende Tabelle auch diese Fülle kurz zusammenfassen:

\begin{tabular}{|c|c|c|c|}
\hline$N r$ & $\begin{array}{c}\text { Alter } \\
\text { und } \\
\text { Gescblecht }\end{array}$ & Dingnose & Atsgang \\
\hline 1. & M. 23. & $\begin{array}{l}\text { Blutung aus syphilit. Clcus des Schlund- } \\
\text { kopfes. }\end{array}$ & Heilung. \\
\hline 2. & W. 29. & $\begin{array}{l}\text { Lues. Vereiterung von Cervicaldrüsen. } \\
\text { Aneurysma dex Carotis. }\end{array}$ & Heilung. \\
\hline 3. & M. 17. & $\begin{array}{l}\text { Stich in Hals, Blutung. Traumatisches } \\
\text { Aneurysma. }\end{array}$ & Heilung. \\
\hline 4. & M. 15. & Blutungen nach Nasenpolypoperationen. & Heilung: \\
\hline 5. & W. 19 & $\begin{array}{l}\text { Aneurysma cirsoides der Stime. Viele } \\
\text { Blutangen. }\end{array}$ & Heilung. \\
\hline 6. & M. 19 . & $\begin{array}{l}\text { Naevus vasculosus in regione auris. Hef- } \\
\text { tige Blutungen. }\end{array}$ & Heilung. \\
\hline 7. & M. ? & Aneurysma anast. traumat. Blutungen. & Heilung. \\
\hline 8. & W. 25. & Aneursyma der Carotis durch Brechact. & Heilung. \\
\hline 9. & M. 58. & $\begin{array}{l}\text { Nachblutung nach Exstirpation eines } \\
\text { Tumors. }\end{array}$ & Heilung. \\
\hline 10. & M. 21. & $\begin{array}{l}\text { Stichwunde hinter dem Kimbacken, viele } \\
\text { Blutungen und Abscesse. }\end{array}$ & Exitus. \\
\hline 11. & M. ca. 35. & Stichwunde, Blutung. & Heillung, \\
\hline 12. & M. 40 . & $\begin{array}{l}\text { Aneurysma der Carotis, Ligatur der Ca- } \\
\text { rotis communis und Subclavia. }\end{array}$ & Heilung. \\
\hline 13. & M. 69. & $\begin{array}{l}\text { Clcerirtes Halscarcinom, Eiterumg, enorme } \\
\text { Nachblutungen. }\end{array}$ & Exitus. \\
\hline
\end{tabular}


Wie aus der Tabelle ersichtlich, handelt es sich hier meist um ganz junge Leute mit einem Durchschnittsalter von 30 Jahren. Dieses Alter ist speciell durch den 13. Fall mit 69. Jahren wesentlich erhöht. Auffallend ist, dass hier beinahe in allen Fällen mehr, oder weniger starke Blutangen, sei es nun in Folge der Verletzung oder der Operation oder in Folge von Geschwüren oder Gefässgeschwülsten, der Ligatur vorausgingen. Nur bei Fall 2, 8 und 12 ist von Blutung nichts angegeben. Auch die zwei Patienten (9 und 10), bei denen die Sehstörung längere Zeit andauerte, waren durch heftige vorausgegaugene Blutungen anaemisch. Von diesen 13 Fällen starben nur zwei, beide wohl in Folge einer Infection. Fall 13 war zudem im Alter von 69 Jahren.

Nach alledem beruhen die vorübergehenden Sehstörungen nach Carotisligatur zweifelsohne auf vorübergehenden Circulationsstörungen im enteprechenden Sehorgan, wie solche auch beim Thierexperimente und bei den Compressionsversuchen beim gesuaden Menschen nachgewiesen wurden. Diase Circulationsstörungen waren in unseren Fällen beinahe sämmtlich durch vorausgegangene Blutungen und der hierdurch veranlassten Anaemie des Patienten in ihrer Entstehung begünstigt. Auch bei den Patienten 9 und 10 ist die länger dauernde Sehstörung offenbar auf die auch bei diesen zwei Fällen sich findende allgemeine Anaemie mit ihren Folgen: Herzschwäche etc., zurückzuführen. Hierfür spricht auch das eigenthümliche Verhalten der Sehstörung bei Fall 6, welche erst dann vom Patienten bemerkt wurde, als or aufzustehen begann, und also an das Herz und die Circulationskraft grössere Ansprüche gemacht wurden. Es erinnert dies an eine Mittheilung von Savory, - Med. Chirurg. Transactions 1856 - nach der bei einer jungen, äusserst schwachen, elenden Frau, bei welcher die Section später unter Anderem eine völlige Thrombose der Arterien der linken Seite des Halses nachwies, sich bedeutende Sebstörungen einstellten, sobald die Patientin sich aus ihrer lingenden Lage erheben wollte.

III. Die entzündlichen Erkrankungen und Zerstörungen des gleichseitigen Auges sind wohl ausnahmslos eine Folge einer Infection des Operationsgebietes, mag nun dasselbe schon vor der Operation - Fall 23, 26, 27 und 29 - durch eine vorausgegangene Verletzung oder während der Operation Fall 22, 24 und 28 - durch mangelhaft gehandhabte Anti- 
sepsis inficirt worden sein. Die Infection der Operationswunde führte zu Infection und eitrigem Zerfall der Thromben und so zu metastatischer Panophthalmie mit (- Fail 25, 27, 28 und 29 -) oder ohne allgemeine Pyaemie.

Tabelle der Patienten mit entzündlichen Erkrankungen des Auges naeh Carotisligatur.

\begin{tabular}{|c|c|c|c|c|}
\hline $\mathrm{Nr}$. & $\begin{array}{l}\text { Geschlecht, } \\
\text { Alter }\end{array}$ & Diagnose & Ausgang & $\begin{array}{l}\text { Zeit des Auf- } \\
\text { tretens der } \\
\text { Panophthalmie }\end{array}$ \\
\hline 1. & M. 22 . & $\begin{array}{l}\text { Pulsirende Gefässge- } \\
\text { schwulst des Kopfes } \\
\text { nach Trauma. }\end{array}$ & Heilung. & Am 10. Tag. \\
\hline 2. & M. 21 . & $\begin{array}{l}\text { Bajonnettstich in Hals } \\
\text { mit Aneurysmabildung } \\
\text { und Blutung. }\end{array}$ & $\begin{array}{l}\text { Exitus } 10 \text { Tage } \\
\text { nachher. Eiter } \\
\text { an Schädelbasis. }\end{array}$ & $\begin{array}{l}\text { Innerhalbron } \\
10 \text { Tagen. }\end{array}$ \\
\hline 3. & W. 63. & $\begin{array}{l}\text { Fungus durae matris, } \\
\text { Eiterung der Wunde. }\end{array}$ & Heilung. & ? \\
\hline 4. & M. jung. & Pyaemie. & $\begin{array}{l}\text { Exitus nach } 5 \mathrm{Mo-} \\
\text { naten an Recidiv } \\
\text { der Pyaemie. }\end{array}$ & 5 Tage. \\
\hline 5. & M. 46. & $\begin{array}{l}\text { Messerstich hinter dem } \\
\text { linken Ohr. Blutung } \\
\text { tu. Aneurysmabildung, } \\
\text { Erysipel. }\end{array}$ & $\begin{array}{l}\text { Exitus, Hirner- } \\
\text { weichung. }\end{array}$ & 24 Tage. \\
\hline 6. & M. 23. & $\begin{array}{l}\text { Gesichtsschuss, starke } \\
\text { Blutung, viele Nach- } \\
\text { blutungen. }\end{array}$ & $\begin{array}{c}\text { Heilung, Pyae- } \\
\text { mie. }\end{array}$ & 3 Monate. \\
\hline 7. & M. 50. & $\begin{array}{l}\text { Aneurysma der Innomi- } \\
\text { nata, Ligatur ron Caro- } \\
\text { tis communis nond Sub- } \\
\text { clavia. Eitermo. }\end{array}$ & $\begin{array}{l}\text { Exitus, Pleuritis, } \\
\text { Meningitis. }\end{array}$ & 2 Monate. \\
\hline 8. & M. 32. & $\begin{array}{l}\text { Halswunde, Nacbblutung } \\
\text { nach der Ligatur. }\end{array}$ & $\begin{array}{l}\text { Exitus, eitrige } \\
\text { Metastasen im } \\
\text { Hirn. }\end{array}$ & . 5 Tage. \\
\hline 9. & M. 30. & $\begin{array}{l}\text { Fachblutung n. Struma- } \\
\text { exstirpation. }\end{array}$ & $\begin{array}{l}\text { Heilung m. Apha- } \\
\text { sie. }\end{array}$ & 12 Tage. \\
\hline
\end{tabular}

Vor Allem ist hier zu bemerken, dass bisher niemals nach Carotisligatur eine doppelseitige Panophthalmie beobachtet wurde, stets handelte es sich in den neun bekannten Fällen um eine einseitige Panophthalmie, der Seite der Ligatror entsprechend.

Aus obiger Tabelle geht hervor, dass die neun Patienten, bei denen auf die Ligatur der Carotis communis eine entzündliche 
Die Gefahren der Ligatur der grossen Halsschlagadern etc. 541

Erkrankung, meist Panophthalmie, des gleichseitigen Auges folgte, meist in mittleren Jahren standen. Ihr Durchschnittsalter ist: 35 Jahre. Neben Verletzungen oder Operationén mit Blutungen (vier Fälle) machten Aneurysmen und blutreiche Geschwülste die Ligatur nothwendig.

Die Panophthalmie trat in der Zeit vom fünften Tage bis zu drei Monaten nach der Ligatur auf.

Von den neun Patienten starben fünf mehr oder weniger lange Zeit nach der Ligatur. Von den übrigen vier Patienten litt der eine (Fall 6) nach der Ligatur an allgemeiner Pyaemie und erholte sich nur mit Mühe und unter Zurückbehalten von verschiedenen Lähmungen. Der zweite (Fall 9) zeigte nach der Ligatur schwere Hirnstörungen, von denen er nur langsam und unter Zurückbleiben von Aphasie genas. Nur zwei Patienten wurden völlig gesund. Es zeigt dies, dass Panophthalmie nach Carotisligatur ein übles Prognosticum bedeutet.

IV. Der Strabismus ist fast immer ein Symptom von weitgehenden Veränderungen und schweren Störungen im nervösen Centralorgane. Nur einmal wurde Strabismus - Fall 32 vorübergehend im Momente der Ligatur beobachtet und ist auch da wohl auf eine vorïbergehende Circulationsstörung im Centralorgane zurückzuführen. Die übrigen vier Fälle führten zu Exitus, und bei der Section zeigte sich das Hirn mehr oder weniger schwer geschädigt. Drei dieser Fälle wurden vor dem Tode noch hemiplegisch. (Fall 30, 31 and 23.)

V. Die übrigen acht verschiedenartigen Beobachtungen erfordern eine gesonderte Besprechung.

1. Bei Fall 35 stellte sich bei einem Patienten mit Exopthalmus pulsans, nachdem bereits die Ligatur der Carotis communis sin. gemacht worden war, nach einem Excesse ein Recidiv aller Erscheinungen ein, nach dessen Abheilung das entsprechende linke Ange nur noch sehr undeutlich die einzelnen Gegenstände zu unterscheiden vermochte.

Etwa fünf Jahre später wurde auf dem linken erblindeten Auge eine Cataract constatirt.

Es ist nun sehr fraglich, ob diese Cataract auf Rechnong der Ligatur zu setzen ist, besonders bei den spärlichen Angaben über die Veränderungen des linken Auges in der ersten Zeit nach der Ligatur.

Auffallend muss es andererseits jedem erseheinen, der die Beobachtungen von v. Michel (1) - Cataractbildung bei Arteriosklerose der Carotiden l. c. - kennt, dass Cataract nicht häufi- 
ger nach Ligatur einer Carotis communis oder interna zur Beobachtung kommt.

2. Die Angabe ron Hirschberg (Fall 36), dass er auf die Ligatur der Carotis hin bei einem Patienten mit Exophtlalmus pulsans zahlreiche Blutungen in der Netzhant habe entstehen selien und zwar in Folge der Ligatur, ist, soweit aus der Mittheilung von Hirschberg selbst zu ersehen ist, nicht über alen Zweifel erhaben. Wie uns die Krankengeschichte lehrt, wies am 25. II. 1880 das betreffende linke Auge einen normalen Augengrund and mittleres Sehvermögen auf. Ergotininjectionen brachten die Pulsationen zum Stillstand. Am 5. III. 1880 kelrten die Pulsationen wieder, und gleichzeitig erfolgte ganz plötzlich eine völlige Erblindung des linken Angapfels. Am 8. III. 1880 wurde die Ligatur der Carotis ausgeführt, und kurz nach derselben zeigte der Augenspiegel die erwähnten Netzhautblutungen.

Wie sich der Hintergrund am 5. III. 1880 nach der plötzliehen Erblindung des Auges oder wenigstens in der Zeit rom 5. III. bis 8.11I., dem Tage der Ligatur verhelt, darüber werden keine Angaben gemacht, und doch wäre dies vor Allem zu einer sicheren und klaren Beurtheilung des Falles erforderlich gewesen.

Hirschberg sagte in der Discussion meines Tortrages bei der 27. Versamulung der ophthalmologischen Gesellschaft Heidelberg 1898, Sitzungsbericht, S. 24: "Wenn man unmittelbar nach der Unterbindung der Carotis beim Menschen den Augengrund spiegelt, so findet man die Netzhautschlagadern erlueblich verengert, fadenförmigg, zallreiche Blatungen in der Netzhaut, besonders nahe dem Centrum, die Sehnerven fast normal, wie ich schon vor längerer Z eit veröfentlieht habe" (Centralbl. f. Augenheilkunde, 1888, S. 221).

Diese allgemeine Belyuptung stitzt $\mathrm{Hir}$ chberg lediglich auf seine erwähnte kurze Krankengeschichte. Zieht man nur die Angaben von Hirschberg ${ }^{1}$ ) in Betracht, so ist es gewiss sehr zweifelhaft, ob die centralen "Netzhautblutungen eine Folge der Ligatur der Carotis waren, oder" ob sie nicht vielmehr schon ror

1) J. Flatten hat denselben Fall in einer Inauguraldissertation Berlin 1880 behandeit. (Ein Fall von Aneurysma der Art. ophthalm. und Carotis int. geheilt durch Ligatur der Carotis communis). Flatten giebt an: am 6. III. 1880 ophthalmoskopischer Befund: geringe venöse Stauung. Am 6. III. und 7. III. nochmals Ergotininjectionen, - Wie sich der Hintergrund in diesen zFei Tagen veründerte, sagt auch Flatten nicht. 
der Ligatur bestanden hatten. Man kann daher um so weniger der allgemeinen Behauptung Hirschberg's beistimmen, dass nach der Unterbindung der Carotis beim Menschen zahlreiche Blutungen in der Netzhaut sich finden.

3. und 4. Fall 41 und 37. Die Beobachtungen von Uhthoff und Arimond widerlegen klar die soeben besprochene allgemeine Behauptung von Hirschberg. Uhth off fand nach der Ligalur einer Carotis communis lediglich eine deutliche, aber vorübergehende Abblassung der betreffenden Papille und mässige Verengerung der Retinalgefässe, Veränderungen, die sich relativ rasch wieder ausglichen. Arimond fand, dass ein am Rande der Papille vor der Operation beobachteter Arterienpuls während eines Tages nach der Ligatur der Carotis verschwand. Diese zwei Beobachtungen stimmen ganz mit dem überein, was wir über die physiologisehe Wirkung der Carotisligatur auf das gleichseitige Auge vom Thierexperiment oder den Compressionsversuchen her kennen gelernt haben. Das Verschwinden des Arterienpulses ist offenbar auf die der Ligatur folgende Verminderung des intraocularen Druckes zurïckzuführen.

5. Fall 38 (von Frey) zeigt eine paretische Affection des linken Halsstranges des Sympathicus, wohl durch Quetsebung: bei der Compression des Operationsgebietes, welche zur Blutstillung ausgeübt werden musste, entstanden.

6. Eigenthümlich und unaufgeklärt ist Fall 39, wo sich erst am zwölften Tage nach der Ligatur eine Abducenslähmung: einstellte, mit der Zeit sich aber wieder völlig zurückbildete.

7. und 8. Von besonderem Interesse sind noch zwei Fälle mit Affectionender Hornhaut des gleichseitigen Auges. Der eine Fall 4,0, von Zimmermann, zeigte zwei Tage nach der Carotisligatur die Hornhaut des gleichseitigen Auges vollkommen anaesthetisch, der Cornealreflex war erloschen. Zugleich war die Pupille dieser Seite etwas weiter. Der Patient ging drei Tage später an einer Schluckpneumonie zu Grunde, und die Section wies einen ascendirenden Thrombus in der Carotis int. sin. nach, der sich in die Arteria fossae Sylvii und corporis callosi erstreckte. Ferner zeigte sich Nekrose im Gebiete der linken Stammganglien.

Die Anaesthesie der Hornhant ist wohl in diesem Falle anf eine centrale Läsion der Bahnen oder Kerne des Trigeminus zurückzuführen. Diese Beobachtung, das Fehlen des Oornealreflexes, ist allenfalls von grosser Wichtigkeit für die Beurtheilung von anderweitigen Affectionen der Hornhant nach Ligatur der gleichseitigen Carotis communis oder interna, z. B. Ulcerationen ete. 
Einen solchen Fall stellt uns Nr. 34 vor, bei dem man wirklich im Zweifel sein kann, worauf die Zerstörung der Hornhaut, beim Fehlen einer primär entzündlichen Reizung, zurückzuführen ist. Man kann sich den breiigen Zerfall der Hornhaut kaum anders erklären, als durch eine Keratitis neuroparalytica. Hier hatte wohl auch der Compressivverband und die ungewöhnliche Anaemie des Patienten an der Genese des Hornhantleidens illren Antheil. Der mehrtägige comatöse Zustand des Patienten spricht für schwere Störungen der Circulation im nervösen Centralorgane.

Dies sind also die Affectionen des Sehorganes, welche bisher bei Ligatur der Carotis communis oder interna zur Beobachtung kamen.

Ein Theil derselben entspricht ganz dem, was wir als physiologische Wirkung der Ligatur der Carotis nach den Erfahrungen, welche uns die Compressionsversuche und das Thiexexperiment an die Hand geben, bezeichnet haben: so die rasch vorübergehenden Sehstörungen, die vorübergehenden leichten Veränderungen in der Fuillung der Netzhautgefässe. (Fall 37 und 41.) Diese Sehstörungen wurden offenbar durch die zumeist bestehende Anaemie begünstigt.

Bei einem kleinen Theile der Fälle ist es sehr fraglich, ob die Ligatur der Carotis mit der Affection des gleichseitigen Auges in einem causalen Zusammenbange steht, so z. B. beim Falle von Hirschberg 36 und Nunneley 35.

Soweit wir bei den übrigen Fällen einen Einblick in die Ursachen der Affectionen des gleichseitigen Auges haben, müssen wir gestehen, dass alle tieferen Störungen nicht der Ligatur als solcher zur Last gelegt werden können, also nicht gleichsam eine physiologische Wirkung der Ligatur darstellen, sondern dass sie vielmehr Complicationen derselben bedeuten, die bedingt sind durch aussergewöhnliche pathologische Verhältnisse,

1. durch Infectionen: alle Panophthalmieen,

2. durch Läsion des Sympathicus während der Operation (Fall 38), 
Die Gefahren der Ligatur der grossen Halsschlagadern etc. 545

3. durch pathologische Processe im Hirn und in den Hirngefässen in Folge der verschiedensten Ursachen, so z. B.: Infectionen, Durchtrennung der Arteria vertebralis, hohes Alter mit Gefässdegenerationen, Anaemie und Herzschwäche, Ascendirende Thrombose in der Carotis interna etc.

Da nun auf der einen Seite die Ligatur der Carotis communis bei relativ gesunden Menschen, das heisst bei solchen mit Nervenkrankheiten oder Elephantiasis faciei, niemals zu irgend welchen Symptomen des gleichseitigen Auges geführt hat, auf der anderen Seite alle bekannt gewordenen Sehstörungen nach Carotisligatur, so weit wir Einsicht in deren Entstehung gewinnen konuten, (bei einer gewissen Anzahl derselben ist dies wegen durchaus. mangelhafter Angaben und ungenügender Untersuchungen sowohl des Auges intra vitam als auch der anatomischen Präparate bei den Sectionen völlig unmöglich), auf Complicationen der Carotisligatur zurückzuführen sind, so dürfen die nach Carotisligatur bisher beobachteten Störungen des Sehorganes nicht dazu benützt werden, um die Behauptung zu beweisen, dass die blosse Unterbrechung der Circulation im Gebiete einer Carotis für das gleichseitige Auge von. wesentlichem Einflusse sei.

Die praktisch wichtige Frage, wann Complicationen der Carotisligatur, welche allenfalls auch zu Augenstörunger. Anlass geben können, zu fürchten sind, was für Momente dieselben bedingen, ferner was gethan werden kann, um dieselben so viel wie möglich zu vermeiden, dies alles soll im dritten Theile dieser Arbeit besprochen werden.

\section{Literaturverzeichniss des I. Theiles.}

1) Miche1, Das Verhalten des Auges bei Störungen im Circulationsgebiete der Carotis. Beiträge zur Ophthalmologie, als Festgabe: Friedrich Horner gewidmet. 1881. S. 1. 
2) M. W. v. Schultén, Experimentelle Untersuchungen über die Circulationsverhältnisse des Auges und über den Zusammenhang zwischen den Circulationsverhältnissen des Auges und des Gehirns. v. Graefe's Arch, f. Ophthalm. Bd. XXX. Abth. 3.

3) Hans Virchow. Ueber die Gefässe der Chorioidea des Kaninchens 1881, Separatabdruck aus den Verhandlungen der phys.med. Gesellehaft zu Würzburg. N. F. XVI. Bd.

4) ML. Jacobi, Die Seelenstörungen in ihren Beziehungen zur Heilkunde.

5) J. Ehrmann, Des effets produits sur l'encéphale par l'oblitération des vaisseaux artériels qui s'y distribuent. Paris 1860.

6) Kussmaul und Tenner, Untersuchungen über Ursprung und Wesen der fallsuchtartigen Zuckungen bei der Verblutung sowie der Fallsucht überhaupt. Untersuchungen zur Naturlehre des Menschen und der Thiere, von J. Moleschott. III. Bd. 1857.

7) Wadsworth und Putnam, Intraocular circulation, rhythmical changes in the venous pulse of optic disc. Transactions of the Americ ophthalm soc. 1878. S. 435.

8) Leber, Die Circulations - and Emährungsverhältnisse des Auges. Graefe-Sämisch, Handbuch der Augenheilkunde. Cap. VIII. S. 352 .

9) Pilz, Zur Ligatur der Arteria Carotis communis nebst einer Statistik dieser Operation. Arch. f. klin. Chirurgie. Bd. IX. S. 257. 1868.

10) T. Friedländer, Ueber die Ligatur der Carotís. Inaug.-Dissert. Dorpat 1881.

11) C. B. Günther, Lehre von den blutigen Operationen am menschlichen Körper. Abth. 5: Operationen am Halse.

12) H. Sattler, Pulsirender Exophthalmus. Graefe-Sämisch, Handbuch der Augenheilkunde. VI. Bd. XI. Cap. 2. Theil. S. 745.1880.

13) Nüller - Erdmann, Zur Casuistik des pulsirenden Exophthalmus. Inaug.-Dissert. Haile a. S. 1891.

14) E. Keller, Beitrag zur Casuistik des Exophthalmus pulsans. Inaug.-Dissert. Zürich 1898.

15) Schmidt's Jahrbücher der gesammten Medicin. 1880-1896.

16) Jahresbericht über die Leistungen und Fortschritte der ges. Medicin ron Rud. Virchow und Aug. Hirsch. 1880-1897.

17) J. Flatten, Ein Fall von Aneurysma der Art. ophthalmica und Carotis int, geheilt durch ligatur der Carotis communis. Inaug. Dissert Berlin 1880.

18) Busch, Niederrheinische Gesellschaft für Natur- und Heilkunde in Bonn. Sitzung v. 15. XI. 1880. Berliner klin. Wochenschr. 1881. \$. 377 .

19) Treves, Axillary Aneurism treated by Antiseptic Ligature of third part of Subclavian Artery. Lancet 1881. 12. Febr. S. 251.

20) C. T. Dent, Innominate Anewrism treated by Simultaneous distal ligature of the Carotid and Subclavian Arteries, with remarks etc. Lancet. I. March 26. 1881, p. 501.

21) H. Dauchez, Anevrysme de la crosse de l'aorte ayant simulé un anevrysme de l'artère Carotide primitive etc. Le Progrès medical. 1882. S. 366 . 
Die Gefahren der Ligatur der grossen Halsschlagadern etc. 547

22) H. Marsh, Ligature of the Right Subclavian and Carotid Arteries. for aneurism of the Aorta. Lancet. I. 17. Febr. 1883. p. 275.

23) Ch. Heath, Ligature of the Common Carotid Artery for anenrism of the external carotid. Lancet I. 17. Febr. 1883. p. 275.

24) Messiter, Case of ligature of the left common carotid artery for haemorrhage. Lancet I. 13. Januar 1883. p. 61.

25) R. Harrisun, Woud of neek; secondary haemorrhage, ligature of common and external Carotid arteries; Recovery. Lancet I. 24. Febr. 1883 . p. 318.

26) Aly, Curschmann und Schede, Aerztlicher Verein zu Hamburg, Vortrag von Aly: übes einen Fall von Aneurysma der Aorta ascendens, bei dem die Art. subcl. und Carotis communis unterbunden wurden. Discussion. Deutsche med. Wochenschr. 29. V. 1884 . S. 349 .

27) F. Franke, Ein Fall von Entfernung eines Fremdkörpers durck Oesophagotomie. Inaug.-Dissert. Greifswald 1885.

28 J. Scriba, Beiträge zur Aetiologie und Therapie des Aneurysma. Deutsche Zeitschr. f. Chirurgie. 22. Bd. 1885. S. 513.

29) Siegmund Reis, Ueber die nach Unterbindung der Arteria carotis communis vorkommenden Gehimerscheinungen. Inaug.-Dissert. Würzburg 1885.

30) Stadelmann, Eine Carotisunterbindung. Münch. med. Wochenschrift. 7. IX. 1886. S. 635 .

31) C. Maydl, Ueber die Prognose der Hemipiegie nach Carotisligatur. Allgemeine Wiener med. Ztg. Nr. 17 u. 181886.

32) Arimond, Ueber die Brasdor-Wardrop'sche Behandlungsweise der Aneurysmen. Inaug.-Dissert. Berlin 1886.

33) F. Cramer, Beitrag zur Kenntniss der Struma maligna. Archiv f. klinische Chirurgie. Bd. 36. S. 259. 1887.

34) V. Ullrich, Zur Casuistik der Unterbindungen des Truncus. anonymus. Inaug.-Dissert. Greifswald 1887.

35) A. Selenkow, Ein Fall von Ligatur der Carotis communis in diphtherisch-scarlatinöser Abscesshöhle, mit Ausgang in Genesung. St. Petersburger med. Wochenschrift. N. 8. S. 61. 1887.

36) J. Schmitt, Statistische Bemerkungen über Ligaturen der Ca-rotis communis. Inaug.-Dissert. Würzburg 1887.

37) J. Rosenstirn, Die Brasd or'sche Operation bei Aneurysmen. des Arcus Aortae und der Anonyma. Archiv f. klin. Chirurgie. Bd. 34. S. 6. 1887.

38) H. B. Hewetson, A case of haemorrhage due to erosion of the left internal carotid artery, ligature of common carotid etc. Lancet 1. 26. May. p. 1026. 1888.

39) W. Boeck, Ein Beitrag zur Caswsitik der Unterbindung der Carotis communis. Inaug.-Dissert. Berlin 1888.

40) Köhler, Aneurysma arcus Aortae. Unterbindung der linken. Carotis communis am 7. Juli, der linken Subclavia am 27. Juli 1887. Heilung der Unterbindungswunden per primam. Vorübergehende Besserung. Tod am 14. September 1887 durch Durchbruch nach aussen. Deutsche Zeitschr. f. Chirurgie. Bd. 28. S. '245. 1888.

41) A. Henschel, Ein Fall von Angioma arteriale racemosum. Inaug,Dissert. Greifswald 1890. 
42) R. v. Frey, Zur Casuistik der Gefässverletzungen. II. Fall. Wiener klinische Wochenschr. III. Jahrg. Nr. 47. S, 909. 1890.

43) J. Rans oh off, Ruptur der Arteria meningea media ohne Fraktur; Ligatur der Arteria Carotis communis bei secundärer Blutung. Arch. f. klin. Chirurgie. Bd. XLII S. 229. 1891.

44) W. Zimmermann, Ueber Gehirnerweichung nach Unterbindung der Art. Carotis communis. Inaug.-Dissert. Heidelberg 1891.

45) F. Dienemann, Ein Beitrag zur Casuistik der arteriell-venösen Aneurysmen. Inaug.-Dissert Erlangen 1892.

46) Karewsky, Operation eines Aneurysma der Carotis communis dext. Berliner klin. Wochenschr. S. 225. 1892.

47) Jacob Hans, Die peripherische Unterbindung der Halsarterien bei Aneurysmen des Arcus aortae und der Art. anonyma. Inaug.Dissert. Berlin 1892.

48) Gebhard, Ueber operative Behandlung des intrathoracischen Aneurysma. Berliner klin. Wochensehr. S. 1026. 1893.

49) H. Lipps, Ueber die Unterbindung der Carotis externa. Arch.f. klin. Chirurgie. Bd. XLVI. S. 1. 1893.

50) S. H. Woodward, Exophthalmie pulsatile; rupture de la carotide gauche dans le sinus caverneux. Ligature de la carotide primitive etc. Annales d'oculistique. CXV. p. 282. 1896.

\section{Theil.}

\section{Eigene Beobachtungen.}

I.

Der erste Fall war ein Mann von 47 Jaluren mit Carcinom tes Zungengrundes, welches auf die Tonsillengegend iibergegriffen hatte. Die Operation wurde am 10. October 1893 von Dr. de Quervain, erstem Assistenten der Kocher'schen Klinik in Bern, ausgeführt.

Schnitt in der Submaxillargegend rechts - vergl. Operationslehre ron Kocher, II. Autage, S. 83 - Ausräumung der Submaxillardrüsen, praeventive Ligatur der Carotis ext nahe an der Theilungsstelle und der Arteria thyreoidea sup., von der die Arteria lingualis abging. Eindringen durch den Mundboden auf die Zunge, Luxation derselben nach unten, Exstirpation des Carsinoms mit Messer und Thermokauter, Tamponade der Wunde. Hierauf Sondenernährung. Glatter, ungestörter Verlauf während sieben Tagen. Am achten Tage Nachts zwei Uhr trat nach leichtem Husten eine starke arterielle" Blutung aus der Wunde auf, die etwa drei Minuten andauert. Bej Ankunft des Arztes war die Blutung spontan gestillt. Eine blutende Stelle war nirgends in der Wunde nachweisbar. Der Patient war sehr anaemisch, sein Puls klein, frequent und nnregelmässig; ein ausgesprochener Collaps war jedoch nicht vorhanden. Sensorium frei. 
Die Wunde wurde gereinigt, die Beine wurden hochgelagert und Stimulantien verabreicht, nachdem subcutan eine Salzsodalösungsinfusion ausgeführt worden war. Patient wurde nach sorgfaltiger Tamponade den Rest der Nacht überwacht.

Am folgenden Morgen wurde, um weiteren schwereren Blutungen vorzubeugen, die Arteria carotis communis und interna ligiert. Der Puls des Patienten war noch immer sehr schwach, sonst Status idem. Rechts wurde in die Vena mediana cubiti gut 1/2 Jiter - eine Salzwasserinfusion gemacht. Puls darauf besser, aber immer noch 120 .

Bei der nun folgenden Ligatur fanden sich folgende Ver* hältnisse:

Es zeigte sich in unmittelbarem Anschluss an die Ligaturstelle der Carotis externa eine usurierte Stelle der Carotiswand, die durch einen nicht frischen Thrombus verschlossen war. Es war nämlich bei der Operation des Carcinoms nicht möglich gewesen, die Ligaturstelle der Carotis ext. mit Gewebe zu bedecken.

Die Stelle war also der, wenn auch noch so leichten, Oberflächeninfection einer offenen Pharynxwunde ausgesetzt, und das genügte offenbar, nm eine Usur mit einem kleinen Wanddefect herbeizuführen. Die Blutung war spontan dadurch gestanden, dass sich der schon vorhandene Thrombus ventilartig in die Oeffinung legte.

Die Ligatur der Carotis communis und interna dextra wurde also unter Cocainanaesthesie am 17.X. 1893 vorgenommen. Im Momente der Ligatur wurde Patient blass, cyanotisch. Puls und Respiration setzten aus. Sensorium plötzlich ganz benommen und die Pupillen erweiterten sich, die linke mittelweit, die rechte fast maximal. Sofort wurden die Beine hocbgehalten. Nach etwa zwei Minuten wurden Puls und Respiration wieder bemerkbar, die Pupillen enger und beiderseits gleich. Das Sensorium kehrte wieder und die Cyanose nahm ab. Verband.

In den folgenden Tagen war der Puls raseh, was auf die Anaemie zurückgefülırt wurde. Es zeigte sich auch leichte Temperatursteigerung.

Schon am Tage der Ligatur der Carotis communis gab Patient an, ex sehe am rechten, der Ligatur entsprechenden Auge nichts melir, und der Augenspiegel zeigte am 19. Oetober bei der ersten von mir vorgenommenen ophthalmoskopischen Untersuchung das typische Bild der Embolie der Centralarterie der Netzhaut. 
Die Papille war aufgelockert, weisslich verfärbt und von ganz unregelmässiger, unscharfer Begrenzung. Auch die Netzhaut zeigte im hinteren Abschnitte des Auges diese weissliche Verfärbung, ganz besonders intensiv rings um die Papille und in der Gegend der Macula, in welcher der charakteristische kirsehrothe, scharf umschriebene Punkt hervorstach.

Ganz eigenartig war das Verhalten der Netzhautgefässe. Sowoll in den Arterien, als auch in den Venen, die beide sehr dünn waren, fand sich eine unterbrochene Blutsäule. In den Venen lagen die einzelnen Blutsäulen bewegungslos, durch hellere Zwischenräume von einander getrent. In allen Arterien aber, die stellenwejse weiss berandet erselienen, marschirten die einzelnen Blutsäulchen in mässig schnellem Tempo einige Secunden peripheriewärts, dann hielt plötzlich alle Bewegung inne und kurz. daranf traten alle den Rückweg gegen die Papille zu an', um nach kurzer Pause von Newem wieder peripheriewärts zu gleiten, ete. Diese Bewegung war mit dem Arterienpulse nicht synchron.

Dieser Zustand dauerte drei Tage, bis zum 22. October. Am 21. October war die weissliche Verfarbung um die Papille bedeutender, und auch in der Maculagegend hatte die weissliche Netzhauttrïbung erst jetzt ihren Hölepunkt erreicht.

22. October: Die durch leere oder hellere Parthieen von einandel" getrennten Blutcylinderchen marschiren jetzt continuirlich in mässiger Geschwindigkeit, so dåss im umgekehrten Bilde jedes einzelne Cylinderchen verfolgt werden kann, und zwar eilen dieselben in allen Arterien centrifugal, in den Venen centripetal. Die weissliche Trubung hat rings um die Papille abgenommen, und ilhe Grenzen treten deutlicher hervor. Auch in der Maculagegend bat die weisse Verfärbung abgenommen, besonders dicht unterhalb derselben ist die Netzhant viel klarer, und die dortigen Gefässe sind nicht melı in so intensiven grauweissen Schleier gehüllt.

23. X. Patient ist sehr schwach. Es wird eine Pnenmonie gefurrehtet. Abends 6 Uhr: Patient sehr elend, collabirt und muss kräftig stimulirt werden. Puls 120, klein. Temperatur 38, o. Herzschwäche. Injectionen von Campheröl.

Ophthalmoskopisch zeigt sich keine Spur melrr von Circulation in Arterien und Venen. Die Blutsäulchen liegen in beiden bewegrngslos da. Einige Arterien bilden schon theilweise weissliche Stränge. Die weisse Netzhauttrübung ist überall wieder vermehrt. 
Wunde und Lunge normal, nur eine Stelle hinten am rechten Mittellappen zeiot unbestimmtes, abgeschwächtes Athmen. Kaum etwas Rasseln.

23. X. Abends 7 Uhr: Patient unrulig, sinkt beim Aufheben immer zusammen. Puls aussetzend. Dyspnoe, Oyanose, kein Husten mehr. Campler, Digitalis, Cognac wurden verabreicht.

24. X. Morgens 1 Uhr: Exitus.

Der erkrankte Bulbus wurde schon acht Stunden nach dem Tode enucleirt und in Müller'scher Lösung conservirt. (Die Leiche war sofort nach dem Tode in ein kaltes Zimmer gebracht worden, wo die Leichenerscheinungen sich weniger rasch einstellen; es war zudem Winter.)

Das Sectionsprotokoll von Prof. Langhans lautete:

Grosser schlanker Körper, stark abgemagert. Livores mässig. Grüne Verfärbung an Brust, Bauch und Schultern. Todtenstarre vorhanden. Auf der rechten Seite unter dem Unterkiefer eine grosse weitklaffende Wunde in der Mittellinie, $2 \mathrm{~cm}$ unter dem Unterkiefer beginnend und hinten $3 \mathrm{~cm}$ unter dem Obre am äusseren Rande des Sternocleidomast. endend. Klafft in der Mitte $4 \mathrm{~cm}$. Man sieht weit in Mund und Rachen hinein. Die Wände mit Eiter bedeckt, die Gewebe also nicht gut zu erkennen. Im unteren Mundwinkel die Epiglottis, darüber die hintere Pharynxwand (glatt), nach vorne ein grosser Rest der Zunge. Der Unterkiefer an der unteren Kante und an der inneren und äusseren Fläche freigelegt, aussen rauh. Eine kleine Operationswunde am inneren Rande des Sternocleidomast., $3 \mathrm{~cm}$ lang, $2 \mathrm{~cm}$ klaffend. Die Sonde dringt nur $1 / \mathrm{gm}$ in der Richtung gegen die Trachea durch eine schmale Spalte vor.

Pectoralis ziemlich gut entwickelt. Panniculus schwach, aber hellgelb. Zwerchfell rechts am Rande der fünften Rippe, links im fünften Intercostalraume. Leberrand in der Mammillarlinie $4 \mathrm{~cm}$ über dem Rippenbogen. Magen etwas eng. Dünndärme eng. Im Abdomen wenig gelbes Serum.

Rechte Lunge ziemlich stark retrahirt, oben hinten Adhaesionen, einige Tropfen klares Serum. Linke Lunge oben vorne adhaerend, Spitze frei, Serum wie rechts.

Im Herzbeutel stark rothe Flüssigkeit - 5,0 $\mathrm{cm}^{3 \cdot}$-- , Herz etwas breit, ziemlich schlaff, Spitze vom linken Ventrikel gebildet. Links etwas Cruor, rechts etwas Speckhaut. In den grossen Gefässen eine grössere Blutmenge namentlich in der Cava inferior, zum Theile dünnflüssig, Blutmenge: $70,0 \mathrm{~cm}^{3 .}$. Linke 
und rechte Aortenklappe mit einander auf die Länge von $8-9 \mathrm{~mm}$ verwachsen und hier verdickt, sonst die Aortenklappen zart. Die übrigen Klappen normal. Foramen ovale spaltförmig offen. Muskulatur links $9 \% / 2 \mathrm{~mm}$, rechts $3-4 \mathrm{~mm}$. Muskulatur etwas blass, im Septum leicht getrübt.

Mikroskopisch: Geringe Verfettung der Wand beider Ventrikel, besonders im Septum.

Milz ziemlich gross und weich. Follikel micht deutlich. Gewicht $150 \mathrm{~g}$. Aorta abdominalis enthält ziemlich viel Blut. Wand normal. Linke Nebenniere etwas fettarm. Linke Niere ohne Veränderungen. Rechte Nebenniere und Niere wie links.

Linker Hoden stark atrophisch, Scluittfläche stark weisslich, sehnig, Tunica verwachsen. Rechts leichte Hydrocele. Hoden etwas stärker braun.

Duodenum mit galligem Inhalte. Im Magen sehr viel Inhalt von eigelber Farbe. Schleimhaut blass.

Leber ziemlich gross. Auf dem rechten Lappen eine tiefe Einschnurung bis an den vorderen Raud, dem Ligamentum suspensorium hepatis parallel, in der Tiefe mit weisser Serosa ausgekleidet.

Schnittfläche: Trübung in deri peripheren Theilen der Acini. Unter der Narbe bindegewebiger Zug mit Gallengängen und grösseren Venen, welcher direct durch die Leber durchgeht und die untere Fläche erreicht. In der Galleublase braune Galle.

In der Carotis dext. ein Thrombus, welcher unter der Clavicula beginnt, bier mit einem freien cylindrischen Ende mit quer gerippter Oberfiäche etwa $1^{1 / 2} \mathrm{~cm}$ lang. Dieses cylindrische Ende ragt frei in das Lumen hinein. Dann folgt ein vollständig obturirender, blatrother Thrombus. Jenseits von der Unterbindungsstelle obenfalls eiu blutrotber Thrombus, weich. Der Thrombus setzt sich in die Subclavia fort.

Im Oesophagus viel Mageninhalt. Im oberen Theile des Larynx viel Eiter, ferner eitriger Belag an der hinteren. Wand der Trachea. Schleimhaut blass. Zäpfchen gespalten. Tonsille atrophisch. Von der Zunge ist das rechte lintere Drittel bis über die Mittellinic entfernt. Querschnitt durch die Muskulatur zeigt blassbraune Farbe, aber keine Eiterung. Thyreoidea ohne Knoten. An der linken Lunge oben ein fester Knoten, auf dessen Schnittfiache in der Mitte kleine Höhlen mit käsig aussehenden Massen, in der Peripherie schwarzes, scluwieliges Gewebe. Im Oberlappen klare, blatige, schaumige 
Die Gefahren der Ligatur der grossen Halsschlagadern etc. 553

Flüssigkeit abzustreifen. Schnittfläche glatt und glänzend. Im Unterlappen dasselbe, nur etwas blutreicher. Gewebe überall vollständig zu comprimiren, nicht brüchig. Rechte Lunge gross, Schnittfläche wie links. In den Bronchien beiderseits etwas zäher Schleim in dünner Lage. Schleimhaut normal.

Schädel etwas kurz, links hinten etwas schwächer entwickelt. Dura stark gespannt.

Im Sinus longitudinalis etwas Speckhaut. Dura innen links sehr feucht. Weiche Häute etwas anaemisch, sehr viel Liquor. Windungen nicht abgeplattet. Rechts Dura wie links. Viel Liquor. Namentlich die feinen Gefässe über den Windungen gut injicirt. Am Stirnlappen Blutgehalt wenig geringer als hinten.

In der Carotis interna dext. ein rother Thrombus, der dieselbe völlig ausfült. An der Basis sammelt sich viel blarer Liquor. Der Thrombus in der Carotis dext. erstreckt sich bis zur Arteria fossae Sylvii und Corpus call. und $5 \mathrm{~mm}$ weit in die ziemlich weite Communicans post.

Die Basilaris, Vertebralis und Profunda cerebri sind mit flüssigem Blute gefüllt. Die Thromben sind mit der Wand nicht fest verklebt, scheinen das Lumen nicht vollständig verschlossen zu haben. Seitenventrikel ziemlich weit, klare Flüssigkeit darin. Im vorderen Schenkel der inneren Kapsel sind rechts Gefässöffnungen etwas weit.

Diesem Protokolle habe ich hinzuzafügen, dass die Hirngefässe keine Abnormität in ihrer Anordnung aufweisen, und. dass sich nur Spuren von Arteriosklerose fanden, ferner dass der Thrombus sich continuirlich von der Ligaturstelle hinauf in die genannten Hirngefässe erstreckte.

Die Section wies also einen von der Ligaturstelle ausgehenden ascendirenden Thrombus in der Carotis interna nach, der sich in die Arteria fossae Sylvii, Arteria corporis callosi and Arteria communicans post. fortsetzte.

Die von mir weiterhin ausgeführte anatomisch-mikroskopische Untersuchung zeigte auf sagittalen Serienschnitten durch die centrale Partie $(2 \mathrm{~cm})$ des Sehnerven nebst Carotis interna, dass die letztere ganz von einem rothen Thrombus ausgefüllt war, der sich noch etwa $6 \mathrm{~mm}$ in das Anfangsstück der Arteria ophthalmica hinein erstreckte, wo er kegelförmig zugespitzt endete.

Fig. 2 (Taf. XVIII) zeigt einen solehen Sagittalschnitt. 
Da die Ophthalmica einen leicht gebogenen. Verlauf hat, ist sie auf diesem Schnitte nicht in ihrer ganzen Ausdehnung längs getroffen worden, sondern es ist nur das Anfangsstück und eine mehr periphere Partbie derselben zu sehen. Während das Anfangsstïck den kegelförmig sich zuspitzenden Thrombus enthält, ist das periphere Stück, wie die dazwischen nur auf den übrigen Serienschnitten sichtbare Parthie der Ophthalmica, frei von obturirender Masse and enthält normales Blut.

Die Wand der Ophthalmica ist überall völlig normal. Nirgends eine Spur von endarteriitischen Veräuderungen.

Die Carotis interna zeigt nur an einer Stelle, da wo die eine Gefässwand sich concav einstülpt, eine kleine halbmondförmige arteriosklerotische Wucherung.

Der Thrombus in der Carotis interna und Ophthalmica besteht zum grössten Theil aus zusammengepressten rothen Blutkörperchen, aus Lenkocyten, die an einzelnen Stellen sich besonders zahlreich angesammelt haben, wie aus dem Bilde selbst zu ersehen ist, und aus Fibrin, dass im grossen und ganzen keine regelmässige Anordnung aufweist, sondern eher unregelmässig, netzförmig angeordnet ist. An einzelnen Parthieen, besonders längs der Gefässwand, speciell im Anfangstheile der Ophthalmica, findet sich oft eine der Gefässwand parallele faserförmige Gestaltung des Fibrins, an andern Stellen kommen wieder eher zwiebelschaalenförmige Schichtungen vor, welche in der Richtung der Gefässachse auf einander aufgetürmt sind ${ }^{1}$ ).

Der periphere Theil des Sehnerven sammt nächster Umgebung wurde nun bis fast zam Bulbus in Querschnitserien zerlegt, das kleine dem Bulbus anhaftende, peripherste Stiick des Sehnerven mit dem Bulbus in Längsschnittserien, und da zeigte sich, etwa $1^{\mathrm{s}} / 4 \mathrm{~cm}$. von dem kegelförmigen Ende des Thrombus in der Arteria ophthalmica entferat, ein Pfropf, der das Lumen der Arteria fast ganz ausfüllt, doch ringsherum von der völlig normalen Gefüsswand durch eine bald dünnere

1) Die Schnitte wurden vor der Fibrinfärbung nach der von Weigert für Schnitte, die in Nüller'scher Lösung fixirt worden waren, angegebenen Methode mit Oxalsäure behandelt. Beiträge zur Kenntniss der normalen menschlichen Nenroglia ron Carl Weigert. S. 139. Festschrift zum 50jährigen Jubilürm des ärztlichen Vereins zu Frankfurt a. MI, 1895. 
bald dickere Blutsehicht getrennt ist, also nirgends direct mit der Gefässwand in Verbindung stebt. (Taf. XIX, Fig. 3 und 4).

Dieser Pfropf setzt sich in die in gerader Richtung abzweigende Arteria centr. retinae fort, während der rechtwinklig abbiegende und sich dann verzweigende Hauptstamm der Arteria ophthalmica frei bleibt. (Taf. XIX, Fig. 5 und 6.) Kurz vor dem Eintritte der Arteria centralis retiuae in den Sehnerven endet der Pfropf. (Taf. XX, Fig. 9.)

Von der Eintrittstelle der Centralarterie in den Sehnerven an bis zur Papille besitzt die Centralarterie ein völlig freies Lumen und zeigt in keiner Weise irgend welche pathologischen Wandveränderungen.

Die Richtigkeit dieser Angaben erhellt aus der Einsicht der Figuren 3 bis 6 und 9, welche einzelne Querschnitte der genannten Querschnittserie zur Darstellung bringen und zwar vom Centrum gegen die Peripherie zu. Die den Bildern beigefügten Erklärungen geben über das Nöthige Aufschluss.

Aus den Bildern dieser, wie der zuerst erwähnten sagittalen Serienschnitte wurde das Uebersichtsbild (Fig. 10, Taf. XX) frei construirt, welches deutlich und anschaulich die Lage des obturirenden Pfropfes zeigt.

Erst in der Arterie centralis retinae liegt der Pfropf der Gefässwand, anfangs nur auf einer Seite (Taf, XIX, Fig. 6.) später in seinem ganzen Umfange eine Strecke weit $-2,5 \mathrm{~mm}-$ eng an und zeigt hier insofern Verbindung mit der völlig normalen Arterienwand, als das Endothel der letzteren Sprossen in ihn hineinsendet, (Taf. XX, Fig. 8).

Was die Zusammensetzung dieses Pfropfes betrifit, so besteht derselbe zumeist aus zusammengepressten rothen Blutkörperchen und einer mässig grossen Zahl von Leukocyten, die meist an einzelnen Stellen angebäuft sind, Fibrin findet sich in der centralen wie peripheren Parthie des Pfropfes regelmässig angeordnet, in ersterer an den Randtheilen des Pfropfes ringförmig, der Gefässwand concentrisch, in letzterer mehr längs gerichtet, der Achse des Gefässes parallel.

Die kleinere etwa $2,5 \mathrm{~mm}$ in der länge messende (der schwarz gemalten Stelle des Uebersichtsbildes, (Taf. XX, Fig. 10). die mit: "Embolus" bezeichnet ist, entsprechend) Parthie des obturirenden Pfropfes, welche im Anfangstheile der Arteria centralis retinae liegt, zeigt das Fibrin nicht regelmässig wie im 
übrigen Pfropfe geschichtet, sondern ganz unregelmässig, netz. förmig angeordnet.

Dies ist die gleiche Parthie des obturirenden Pfropfes, welche anfänglich einer Seite der Gefässwand innig anliegt, während ihre freie Fläche von einem eigenen Endothelhäutchen (Taf. XIX, Fig. 6 und Taf. XX, Fig. 7) überzogen ist, das den Pfropf so gegen das kleine halbmondförmige Lumen des Gefässes mit dem normalen Blutinhalte abschliesst. Es ist ferner die gleiche Parthie, welche etwas mehr peripheriewärts in ibrer ganzen Circumferenz der Gefässwand innig anliegt und in welche diese deutlich Endothelsprossen sendet (Fig. 6, 7 und 8). Im Uebrigen weist die Gefässwand selbst nirgends pathologische Veränderungen irgend welcher Art auf.

\section{Epikrise.}

Bis auf den hentigen Tag kamen, wie auch schon zum Theil aus den neweren Arbeiten von Haab (1) und Reimar (2) zu ersehen ist, 21 Fälle von Erblindungen unter dem bisher als typisch geltenden ophthalmoskopischen Bilde der Embolie der Centralarterie zur anatomischen Untersuchung. Unter diesen 21 Fällen finden sich drei, welche von den genannten Autoren bei ihrer Aufzählung der bis heute anatomisch untersuchten Emboliefälle der Centralarterie der Netzhaut nicht mitgerechnet wurden.

1. Ein Fall von Michel (3 und 32) ${ }^{1}$ ) aus dem Jahre 1881, in dem sich nur eine Thrombose der Carotis interna fand.

2. Ein Fall von Uhthoff $\left.(4)^{2}\right)$ bei dem sich eine Thrombose der Carotis interna und des Anfangsstückes der Ophthalmica zeigte.

3. Ein Fall von * Michel (5 und 32) $\left.{ }^{3}\right)$. Hier fand

1) Beiträge zur Ophthalmologie als Festgabe Friedrich Horner gewidmet. 1881. S. 16.

$\left.{ }^{2}\right)$ Vortrag am internationalen med. Congress in Rom. Heidelberger Ophthalmologencongress 1898. S. 21.

3) Ceber Thrombenbildung im Stamme der Arteria centralis retinae. Heidelberger Ophthalmologencongress 1898. S. 243. Fall 1. 
sich angeblich eine Thrombose der Arteria centralis retinae vor der Lamina cribrosa.

Bei einer Anzahl dieser 21 Fälle nun - Loring-Delafield (6), Popp (7), Hirschberg(8) - wurde ein obturirender Pfropf innerhalb der allerdings nur partiell untersuchten Centralarterie nicht gefunden.

Gleichfalls nicht bei den Fällen von v. Michel und Uhthoff, obgleich hier die Centralarterie in ihrem ganzen Verlauf zur Untersuchung kam.

Bei einer weiteren Anzahl der Falle fehlen entweder nähere Angaben über den sogenannten Embolus, wie uiber die Arterienveränderungen völlig, oder sind wenigstens so unvollständig, dass diese Fälle bei der Beantwortung der Frage nach dem thatsächlichen Vorkommen von Embolieen der Centralarterie der Netzhaut nicht mit Sicherheit verwerthet werden können. Das gleiche gilt von mehreren Fällen, die durch entzündliche Erkrankungen des Auges complicirt waren, bei denen somit keine reinen Fälle der sogenaunten Embolie der Centralarterie vorlagen.

Andere Fälle wurden von den Autoren, welche dieselben mittheilten, von vornherein nicht als Embolieen, sondern als Thrombosen der Centralarterie angesprochen, so die Fälle von Ridley (31) und von v. Michel (5 u. 32).

Bei den übrigen, anatomisch untersuchten Fällen ist nach Reimar(2) und Haab(1) und neuerdings auch nach v. Michel (32) auch nicht einmal eine Embolie anatomisch völlig sicher nachgewiesen worden, und stets ist ein ge-

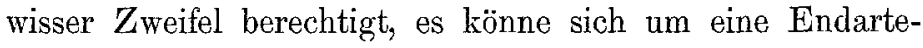
riitis oblit. mit ihren Folgen handeln.

Nach alle dem ist unser vorliegender Fall von ganz hervorragend wissenschaftlichem Interesse, besonders da er einen frischen Fall von sogenannter Embolie der Centralarterie darstellt, bei dem wir es noch nicht mit secundären Umwandlungen des Embolus und der umgebenden Gefäss- 
wand $\mathrm{zu}$ thun haben, welche in der Regel eine sichere anatomische Diagnose fast zur Unmöglichkeit machen.

Klinisch zeigt das vorliegende, an eine Carotisligatur sich anschliessende Augenleiden das charakteristische Bild einer sog. Embolie der Centralarterie.

Die acute Erblindung wurde schon am Tage der Operation rom Patienten bemerkt. Bedenkt man, dass einseitige Erblindungen oft längere Zeit von sonst völlig gesunden Patienten unbeachtet bleiben, so wird man sich nicht wundern, wenn einem Patienten, kurz nach einer eingreifenden Operation, auf welche unvorhergesehener Weise unmittelbar eine einseitige Erblindung erfolgte, diese Erblindung nicht im Momente ihrer Entstehung, sondem erst nach mehreren Stunden zum Bewusstsein kommt. Es ist daher die Vermuthung wohl nicht unbegründet, die Erblindung sei bei unserem Patienten im Momente der Ligatur, zu gleicher Zeit mit den während der Ligatur beobachteten Hirnsymptomen erfolgt, dem Patienten aber erst einige Stunden später, nachdem er sich etwas erholt, zum Bewusstsein gekommen.

Der ophthalmoskopische Befund des erblindeten Auges trug alle Merkmale, welche wir für das charakteristische Bild der Embolie der Centralarterie fordern: enge Gefässe, speciell enge Arterien, abgeblasste und verschwommene Papille, weisslicbe Netzhauttribung, welche in der Maculagegend ihren Höhepunkt erreichte und daselbst den typischen, runden, kirschrothen Fleck erkennen liess. Eigenthümlich war in unserem Falle nur das Circulationsphänomen. Ein ähnliches von diesem Unfange wurde bis hente bei gleichartigen Fällen noch niemals beobachtet.

Die unterbrochene Blutsäule, welche ein Zeichen einer äusserst abgeschwächten Circulation darstellt, wurde schon öfters bei sog. Embolie der Centralarterie gesehen, aber, so viel ich weiss, meist mur in den Venen. Das Phänomen einer rückläufigen Circulation wurde sehr selten, immer 
Die Gefahren der Ligatur der grossen Halsschlagadern etc. 559

aber nur in einzelnen Aesten grösserer Arterien, niemals in dieser Ausdehnung beobachtet.

Die Thatsache, dass die in den Arterien centrifugal marschirenden Blutsäulchen stets nach kurzer Pause gezwungen wurden, den Rückweg nach der Papille zu anzutreten, zeigt nur, wie schwach die Circulation in den Arterien war, da sie nicht genügte, den Widerstand in den Capillaren zu überwinden. Sie zeigt zugleich, wie vollständig der Verschluss der Centralarterie gewesen sein muss.

Worauf die abwechselnd vor- und rïckläufige Bewegung der Blutsäulchen im Arteriensysteme beruhte, ist schwer anzugeben. Ich begnüge mich damit, diese Thatsache als absolut sicher zu constatiren und die Vermuthung auszusprechen, es möchten die Netzhautarterien selbst in Eolge eines durch die Anaemie gesetzten Reizes durch leichte, fortschreitende Contractionen ihrer Muskulatur diese eigenthümliche Hin ond Herbewegung ibres Inhaltes bewirkt haben. Diese merkwürdige Art der Blutbewegung ist in der Physiologie unter dem Namen „Mouvement de va et vient" bekannt und kommt da zu Gesicht, wo eben eine extreme Verlangsamung des Blutstromes eingetreten ist und sich bereits in weiter belegenen Gefässtheilen Stockung eingestellt hat $^{1}$ ).

Am vierten Tage nach der Unterbindung der Carotiden fand sich eine langsame, aber constante, regelrechte Circulation in Arterien wie Venen vor, jedoch immer noch in unterbrochener Blutsäule. Es scheint nunmehr die Circulationskraft gewachsen zu sein, so dass sie im Stande war, vielleicht durch kleinste Anastomosen vom Circulus Zinnii aus Blut in das Arteriensystem der Netzhaut, und von da durch die Capillaren in die Netzhautvenen zu treiben. Die Circulationskraft war aber immer noch nicht

1) Landois, Lehrbuch der Physiologie des Menschen. 8. Auf. 1893. S. 178.

จ. Graefe's Archiv für Ophthalmologie. L. 3. 
so stark, um wenigstens in den Arterien, geschweige denn im ganzen Gefässsysteme der Netzhaut, die unterbrochene Blutsäule durch eine continuirliche zu ersetzen.

Am sechsten Tage war die Circulationskraft ganz gesunken, denn ron einer Circulation war an diesem Tage keine Spur mehr zu entdecken. Es waren offenbar entweder auch die geringen Anastomosen noch völlig verlegt worden, oder der nicht völlig obturirende Pfropf in der Centralarterie hatte das Lumen gänzlich verlegt, oder endlich, was hier bei dem eingetretenen Collaps des Patienten und dem bald folgenden Tode desselben am wahrscheinlichsten ist, die Herzkraft war bedeutend gesunken und nicht mehr im Stande, durch die geringen Anastomosen auch nur eine schwache Circulation in der Centralarterie aufrecht zu erhalten.

Interessant ist, dass am fünften Tage nach der Ligatur; als eine regelrechte Circulation, was ihre Richtung betrifft, wieder hergestellt war, die weissiche Verfärbung der Netzhaut um die Papille und in der Maculagegend merklich zuriickging, um am folgenden Tage gleich wieder in verstärktem Maasse aufzutreten, nachdem die Netzhautcirculation völlig zum Stillstand gelangt war.

Wir haben es hier also mit einem typischen klinischen Falle von sog. Embolie der Centralarterie der Netzhant zu thun, welcher sich nur dadurch von anderen bisher beschriebenen Fällen auszeichnet, dass die Circulationskraft im Gefässsysteme der Netzhaut von Anfang an ganz auffallend schwach war, was seinen Ausdruck in einer Agglutination der Blutsäule, nicht nur in den Venen, sondern selbst in den Arterien, fermer in einem völligen Stillstand der Circulation in den Venen fand. Diese äusserst schwache Circulationskraft besserte sich nicht, wie in den meisten der bisher beschriebenen Fällen ron sogen. Embolie der Centralarterie, ganz bedeutend in den folgenden Tagen, sondern erlahmte nach Irurzer, kaum merklicher Kräftigung 
Die Gefahren der Ligatur der grossen Halsschlagadern ete. 561

vollkommen. Auch war von Anfang an das Auge völlig erblindet, um auch später nicht die geringste Spur von Lichtempfindung mehr zu erhalten.

Was die Resultate der anatomischen Untersuchung der Arterien der Orbita betrifft, so konnte die Verlegung des Anfangstheiles der Arteria ophthalmica, welche auf den sagittalen Serienschnitten durch das centrale Opticusende sammit Carotis interna gefunden wurde, das ophthalmoskopische Bild der Embolie der Centralarterie und die damit eng verknüpfte acute Erblindung des betreffenden gleichseitigen Auges nicht erklären; denn abgesehen davon, dass zur Zeit des Todes des Patienten, also sechs Tage nach erfolgter Frblindung, der Thrombus erst $6 \mathrm{~mm}$ weit im Anfangstheile der Ophthalmica vorgedrungen war, also zur Zeit der Erblindung daselbst wohl noch gar nicht existirte, sprechen gegen eine solche etwaige Annahme ziemlich klar die Untersuchungen von Elschnig(15).

Elschnig zeigte in einer grösseren Arbeit, dass sowohl eine langsam, wie aeut auftretende Obturation des Anfangsstückes der Ophthalmica, seltene Fälle von grosser Herzschwäche vielleicht ausgenommen, keine auffallende Störung im Gebiete der Augengefässe der gleichen Seite hervorzurufen im Stande sei. Er bewies dies an der Hand von zahlreichen, sowohl eigenen als auch aus der ganzen Literatur gesammelten, Sectionsprotokollen, in denen sich eine Obturation des Ursprunges der Arteria ophthalmica fand, ohne dass intra vitam sich irgend welche ophth. Veränderungen oder Functionsstörungen des betreffenden Auges gezeigt hätten. Ferner bewies er seine Behauptung durch eine grosse Menge von Injectionsversuchen. Er injicirte bei eröffnetem Schädel, als die Carotis interna vollständig von der Ophthalmica abgetrennt war, Farbstofflösungen von der Carotis externa oder Maxillaris externa aus, und fand, dass durch alle diese Arterien, selbst bei niedrigem Injectionsdrucke, die Ophthalmica der gleichen wie der entgegengesetzten Seite mit sämmtlichen Aesten leicht und völlig genügend gefüllt werden kann, so dass also die Annahme berechtigt ist, die genannten Gefässe seien so mannigfach durch Anastomosen mit einander verbunden, dass von einer Carotis 
externa, ja Maxillaris externa aus, jederzeit leicht die in ihreu Anfangstheile durch Thrombose, ja selbst Embolie obturirte Ophthalmica derselben wie der entgegengesetzten Seite sammt ihren Aesten mit Blut reichlich versehen werden könne.

Die Fälle von Michel ${ }^{3}$ und Uhth of ${ }^{4}$, bei welchen nach einer Erblindung unter dem typischen ophthalmoskopischen Bilde der Embolie der Centralarterie, trotzdem dass angeblich die Centralarterie in ihrem ganzen Verlaufe untersucht wurde, kein Embolus, noch sonst eine obturirende Masse in der Centralarterie, sondern bloss ein Thrombus in der Carotis interna, welcher im Falle von Uhthoff auch noch den Anfangstheil der Ophthalmica auffüllte, gefunden wurde, sind einzig in ibrer Art. Auf den Fall von v. Michel werden wir später zurückzukommmen Gelegenheit baben. Derselbe kann hier weiter keine Berücksichtigung finden, da er nach des Autors eigenen Worten aus nenester Zeit (Literaturverzeichniss No. 32, S. 8) wohl ungenügend anatomisch untersucht war.

Was den Fall von Uhthoff betrifft, so ist mir derselbe nur aus einer persönlichen Mittheilung des Autors and aus dessen kurzen Angaben bei der Discussion meines Vortrages am 27. Ophthalmologen-Congresse in Heidelberg 1898 bekannt.

Es bandelte sich da um eine Thrombose der Carotis interna, welche sich nach oben bis über die Abgangsstelle der Arteria ophthalmica fortsetzte. Es fand sich klinisch Amaurose des gleichseitigen Auges unter dem bekannten Bilde der $\mathrm{Ab}$ sperrung der arteriellen Blutzufuhr zur Retina. Anatomisch Ironnte im ganzen Orbitalgebiete weder im Bereiche der Arteria ophthalmica, (ibr Anfangsstitek ausgenommen), noch im Bereiche der Arteria centralis retinae eine thrombotische oder embolische Verstopfung nachgewiesen werden. Es war also hier allem Anscheine nach die Verlegung der Arteria ophthalmica an der Abgangsstelle aus der Carotis im Stande gewesen, die Erblindung des gleichseitigen Anges unter dem ophthalmoskopischen Bilde der sog. Embolie der Centralarterie bervorzubrigen.

Uhthoff sagte damals von seinem Falle: ,ich glaube nun allerdings, dass dieses Verhalten nicht der Regel entspricht; ich habe einen Fall ron Carotis-Thrombose anch bis über die Abgangsstelle der Arteria ophthalmica hinaus klinisch untersucht und anatomisch, und hier waren weder Erblindang noch die ophthalmoskopischen Veränderungen der Ischaemie der Netzhaut eingetreten. Dies differente Verhalten erklärt sich meines Erachtens wohl aus den gelegentlich unzureichenden Anastomosen 
Die Gefahren der Ligatur der grossen Halssehlagadern etc. 563

im vorderen Gebiete der Arterie ophthalmica mit der Maxillaris interna und externa u. s.w. In der Regel werden diese Anastomosen ausreichen, um die Function des Auges zu erhalten, gelegentlich aber kann es zur Erblindung kommen, wie in dem angezogenen Falle".

Es folgt also aus alledem, dass eine Erblindung eines Auges unter dem ophthalmoskopischen Bilde der sog. Embolie der Centralarterie in der Regel nicht durch eine Thrombose des Anfangsstiickes der Arteria ophthalmica kann erklärt werden. Der einzige bekannt gewordene und genau untersuchte Fall gegen diese Regel, jener von Uhthoff, wird von Uhthoff selbst als ganz aussergewöhnlich bezeichnet.

Meine weiteren Befunde bei dem Studium der Querschnitte durch den peripheren Theil des Sehnerven sammt Umgebung müssen wohl folgendermaassen gedeutet werden: Bei der Ligatur der Carotis communis oder interna wurde ein Stuickchen des bereits von der ersten präventiven Ligatur der Carotis ext. her existirenden Thrombus, der durch sein ventilartiges Anlegen vor die am siebenten Tage nach der Carcinomoperation entstandenen Usur der Carotis communis die heftige Nachblutung zu spontanem Stillstand gebracht hatte, losgerissen und in den Anfangstheil der Arteria centralis retinae geschleudert. Auf diesen primären Embolus im Ursprungstheile der Centralarterie haben sich nun in den folgenden Tagen secundär peripher-wie centralwärts thrombotische Massen aufgelagert.

Für diese Auffassung spricht:

1. die acute totale Erblindung unter dem charakteristischen ophthalmoskopischen Bilde der acuten Verlegung der Centralarterie der Netzhaut wohl sofort nach der Ligatur der Carotis communis der gleichen Seite,

2. die bereits begonnene Organisation eines kleinen 
Stiickes des obturirenden Pfropfes der Centralarterie und die Lage dieses Stiickes gerade im Ursprungstheile der in gerader Richtung von der rechtwinklig umbiegenden Ophthalmica sich abzweigenden Centralarterie.

Erst im Anfangstheile der Centralarterie beginnt nämlich der obturirende Pfropf sich anfänglich nur auf einer Seite, dann aber bald im ganzem Umfange der Gefässwand eng anzulegen, und diese sendet Sprossen ihres Endothels in ihn hinein (Taf. XTX, Fig. 6, Taf. XX. Fig. 8). Dort, wo der Pfropf in dieser Gegend der Gefässwand nicht völlig anliegt, grenzt ein eigenes Endothelhäutchen die obturirende Masse gegen das schmale, halbmondförmige Lumen zu ab (Taf. XX, Fig. 7).

Diese secundären organisatorischen Teränderungen: Endothelwucherungen in den Pfropf hinein und Umwachsung des partiell freiliegenden Pfropfes mit einem Endothelhäutchen, finden sich an keiner anderen Stelle der oburirenden Masse in der Ophthalmica und Centralarterie, und auch im Ursprungstheile der letzteren nur in einer Länge von etwa $2,5 \mathrm{~mm}$. Bis solche secundäre Processe sich ausbilden, müssen seit der Entstehung der Thrombose oder des Embolus, zum. Mindesten nach den Arbeiten von Baumgarten (16) sechs bis acht Tage rerflossen sein. Diese Anfänge von Organisation deaten "also darauf hin, dass das besprochene und im Uebersichtsbilde, (Taf. XX, Fig. 10, mit "Embolus" bezeichnete Stiuck des Pfropfes schon älteren Datums ist and mindestens sechs bis acht Tage an Ort und Stelle gelegen hat, also in seiner Entstehung gerade mit der Zeit des Auftretens der Erblindung unter dem beschriebenen ophthalmoskopischen Bilde $d$. h. mit der Ligatur der Carotis selbst zusammen fällt.

3. Die Anordnung des Fibrins innerhalb der obturirenden Masse. Während dasselbe im ganzen Pfropfe eine regelmässige, für Thromben charakteristische Schichtung zeigt, in den centralen Parthieen concentrisch der Gefäss- 
Die Gefahren der Ligatur der grossen Halsschlagadern ete. 565

wand, in den peripheren mehr der Gefässwand parallel, ist das Fibrin innerhalb der kleinen Parthie im Anfangsstücke der Centralarterie, welche beginnende Organisation aufweist, von unregelmässiger meist netzförmiger Anordnung.

4. Die völlige Integrität der Gefässwand sowohl der Arteria ophthalmica wie der Centralarterie, das absolute Fehlen jeglicher Gefässveränderung endarteriitischer Art, welche entweder direct oder indirect durch Thromben zu Gefässverlegung hätte Anlass geben können.

Reimar(2) schreibt in seiner erst vor Kurzem erschienenen Arbeit über Embolie der Arteria centralis retinae, S. 349, wo er die Hauptergebnisse seiner Abhandlung nochmals zusammenfasst:

„Bei wirklicher Embolie oder Thrombose der Centralarterie müssen wir totale Erblindung und körnigen Zerfall der Blutsäulen der zugehörigen Retinalgefässe erwarten."

Beides ist in unserem Falle eingetroffen. Die Bedenken ferner, welche Haab(1) und Reimar(2) gegen die Richtigkeit der Diagnose: Embolie der Centralarterie, in den meisten Fällen geltend machen, finden auf unseren Fall durchaus keine Anwendung.

Wir hatten es hier nicht mit prodromalen Erblindungsantällen zu thun, es trat keine Wiederanfüllung der fast blutleeren, engen Netzhautgefässe ein, es fehlt hier nicht eine Quelle der Embolie wie bei manchen bekannten Fällen ron sog. Embolie der Centralarterie, und endlich wir fanden weder mit dem Ophthalmoskop intra vitam, noch mit Hilfe des Mikroskopes irgend welche Veränderungen an den Gefässen der Netzhaut oder der Orbita.

Daher erklärt die Diagnose: „Embolie im Ursprungstheile der Centralarterie mit secundär peripher- wie centralwärts aufgelagerter Thrombose" allein völlig ungezwungen alle klinischen Erscheinungen und anatomischen Befunde unseres Falles.

Eine Embolie ist zu dem durchaus nichts Ungewöhn- 
liches nach Ligatur der Caratiden. Zu wiederholten Malen fand ich bei dem Studinm der chirurgischen Literatur der Carotisligatur als Ursache einer auf die Ligatur folgenden Hirnerweichung die Embolie einer Hirnarterie angegeben, welche anatomisch zweifellos nachgewiesen worden war. Oft handelte es sich um septische Embolieen mit ihren Folgen. Auch Axenfeld dachte bei der ron ihm nach Carotisligatur beobachteten Hemianopsie, Fall 8, an eine etwaige Embolie in der Tractusgegend auf dem Wege der Arteria communicans post.

Sodann beruhen $j$ anch die nach Carotisligatur beobachteten und bereits zu Beginn dieser Arbeit besprochenen Panophthalmieen auf kleinsten Embolieen mit septischem Material.

Schliesslich muss noch hervorgehoben werden, dass in unserem Falle der Embolus, nicht wie in allen bisher anatomisch untersuchten ähnlichen Fällen, soweit eine obturirende Masse iberhaupt zu Tage gefördert wurde, sich unmittelbar vor der Lamina cribrosa, also dicht hinter dem Bulbus fand, sondern dass derselbe in $\mathrm{Ur}$ sprungstheile der Centralarterie sass, eine Localisation, an welche schon Hirschberg(8) dachte.

Es ist nach meiner Ansicht leichter zu verstehen, dass ein Embolus von einer gewissen Grösse im Anfangstheile der Centralarterie schon festgehalten werde, als dass er ungehindert die zwei rechtwinkligen Biegungen der Centralarterie bei deren Eintritt in den Sehnerven passire und bis zur. Lamina cribrosa vordinge.

Endlich folgt aus meinem Befunde, dass in Zukunft cine Embolie der Centralarterie nicht in Abrede gestellt werden darf, wenn nicht die ganze Centralarterie bis zu ihrem Ursprunge auf Serienschnitten untersucht ist, und wenn man sich begnügt hat lediglich das dem Bulbus anhaftende periphere Stück des Sehnerven zu untersuchen. 
Die Gefahren der Ligatur der grossen Halsschlagadern etc. 567

Fassen wir die Resultate unserer Untersuchung zusammen, so ergiebt sich:

1. dass die Ursache der Erblindung unseres Patienten nach Ligatur der Carotis communis und interna in einer Embolie des Anfangsstückes der Arteria centralis retinae zu suchen ist, auf welche sich secundär, peripher-wie centralwärts, thrombotische Massen aufgelagert haben,

2. dass der Embolus im Momente der Ligatur von dem bereits existirenden Thrombus in der Carotis ext. und communis losgerissen wurde.

Prof. v. Michel äussert in einer erst vor kurzem erschienenen Arbeit $\left.{ }^{1}\right)$ Zweifel an der Richtigkeit meiner Diagnose Embolie des Anfangsstückes der Centralarterie in dem mitgetheilten Falle. Fir sagt daselbst wörtlich: „So kann ich mich auch nicht mit der Deutung eines von Siegrist in jüngster Zeit veröffentlichten Falles einverstanden erklären. Es scheint mir kein zwingender Grund zur Annahme eines Embolus gegeben $\mathrm{zu}$ sein, umsoweniger als der Thrombus sich in die Arteria centralis retinae fortsetzte, wenn er auch kurz vor dem Eintritt derselben in den Sehnerven endete und noch weiter in die Arteria fossae Sylvii, Arteria corporis callosi und Arteria communicans posterior. Ich muss mich vielmehr für einen thrombotischen Verschluss aussprechen, auch im Hinblick darauf, dass anfänglich der Pfropf nur auf einer Seite der Arteria centralis retinae sich befand. Bei der vorhandenen Thrombenbildung im Gebiete der Carotis und wenigstens auch des Anfangsstückes der Arteria centralis retinae konnte die Circulationsstörung jenseits der rechtwinkligen Eintritts- bezw. Umbiegungsstelle der Arterie in den Sehnerven umsomehr zn einer Thrombose führen, da ja die genannte Stelle unter normalen Verhältnissen schon ein natürliches Stromhinderniss darstellt."

Die von v. Michel gegen meine Ansicht angeführten Gründe können mich nicht bestimmen, meine Diagnose zu ändern.

1) "Ueber Erkrankungen des Gefässsystems der Arteria und Vena centralis retinae". Zeitschr. f. Augenheilk. Bd. II. S. 9. 
Es standen v. Michel bisher allerdings nur meine etwas knapp gebaltenen vorläufigen Mittheilungen meines Vortrages am Heidelberger Ophthalmologen-Congress 1898 zur Verfügung. Dies mag vielleicht Schuld sein, dass meine Befunde von ihm missverstanden wurden.

Als Gründe gegen meine Auffassung führt v. Michel an:

1. Dass der Thrombus sich in die Arteria centralis retinae fortsetzte, wenn er auch kurz vor dem Eintritte derselben in den Sehnerven endete und noch weiter in die Arteria fossae Sylvii, Arteria corp. callosi und Arteria communicans post.

Ich habe hierauf zu erwidern, dass der Thrombus der Carotis interna sich keineswegs, wie v. Michel meint, in die Centralarterie fortsetzte, denn dieser ascendirende Thrombus hatte, wie auf Fig. 2 zu sehen, acht Tage nach der Erblindung des Patienten, beim Tode desselben, erst das Anfangsstück der Ophtalmica erreicht. Was sich in der Centralarterie bis zu deren Eintritt in den Sebnerren fortsetzte, war lediglich der secundär auf den primären Embolus im Aufangsstück der Centralarterie aufgelagerte Thrombus, wie dies deutlich aus dem Uebersichtsbild, Fig. 10, zu ersehen ist. Schon eine Strecke weit vor dem Einrittt der Centralarterie in den Sehnerven verlegte dieser secundäre Thrombus nar noch zum Theil das Lumen der Arterie (aus Fig. 9 ersichtlich). Er zeigt also eine Abnahme, eine Verjüngung gegen die Eintritts. stelle der Arterie in den Sebmerven zu und ist am stärksten entwickelt dicht am peripheren Rande des als Embolus bezeichneten Theiles des Gesammtpfropfes im Ursprungstheile der Centralarterie, indem or das ganze Gefasssltimen ausfüllt. Dass dies Verhalten des secundären Thrombus, wie die Thatsache, dass der Thrombus der Carotis sich später im Laufe von acht Tagen auch in die Arteria fossae Silvii etc. fortpflanzte, gegen die Anffassung des Pfropfes im Anfangsteile der Centralarterie als Embolus sprechea soll, ist mir nicht recht erklärlicb.

2. Futhrt v. Michel gegen meine Ausicht an, dass der von mir als Embolus bezeichnete Propf anfänglich nur anf einer Seite der Centralarterie völlig anlag. Es scheinen mir jedoch diese von mir beschriebenen Verbältnisse bei einem Embolus durchaus uatürlich zu sein, aud das Gegentheil wäre mindestens eigenartig. Es scheint, dass ich mich bei meinem Vortrag etwas zu undeutlich ausgedruckt habe. Es handelt 
sich hier nicht um ein Aufsitzen des Pfropfes auf einer Seite der Gefässwand, während die andere Seite des Gefässes mit einem grossen Theile des Lumens völlig frei ist, sondern es bandelt sich um Verhältnisse, wie sie auf Fig. 6 deutlich genug abgebildet sind. Fs ist doch kaum anzunehmen, dass der Embolus so in das Lumen der Arterie eingekeilt worden wäre, dass er an seinem distalen wie proximalen Ende, gleich wie in der Mitte das Gefässlumen völlig verlegt, sondern nichts ist wahrscheinlicher, als dass eben die Enden des Embolus sich etwas zuspitzen oder dass das proximal nachdrückende Blut anf einer Seite eine ksleine Strecke weit eine feine Lücke zwischen Embolus und Gefässwand hat bohren können, und dass dann nach dieser kleinen Lücke za das Endotbel den Propf gegen die etwas freiliegende Gefässwand zu abzugrenzen suchte, Verhältnisse, wie sie prächtig aus Fig. 6 und $7 \mathrm{zu}$ ersehen sind. Beistehende Abbildung erklärt die Sache am besten. $\mathrm{E}$, die schattirte Masse, bedeute den im Anfangstheile der Centralarterie liegenden $2^{1 / 2}$ Millimeter langen Embolus, wie er meinen Be-

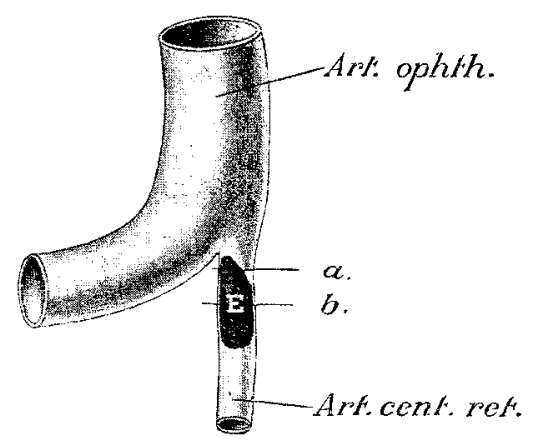
funden entspricht.

Die ersten Querschnitte nun, welche durch a gehen, werden den Embolus nur auf einer Seite (wie es auf Fig. $6 \mathrm{zu}$ sehen ist) an der Gefässwand haftend zeigen, die weiteren mehr peripheren Querschnitte, z. B. durch $b$ zeigen den Embolus in seiner ganzen Circumferenz der Gefässwand eng anliegend.

Nach meiner Auffassung ist dieser Befund durchaus bei Embolie natürlich und kann nicht mit Recht gegen die Diagnose Embolie verwerthet werden. Reimar verlangt aus rein theoretischen Gründen von einem Embolus, dass seine Enden sich conisch zuspitzen und nicht allseitig der Gefässwand anliegen, und das theoretisch von ihm construirte Bild stimmt völlig überein mit dem nebenbei von mir abgebildeten.

3. Sagt v. Michel: „Bei der vorhandenen Thrombenbildung im Gebiete der Carotis und wenigstens auch des An- 
fangsstückes der Arteria centralis konnte die Cireulationsstörung jenseits der rechtwinkligen Eintritts- bezw. Umbiegungsstelle der Arterie in den Sohnerven umsomehr zu einer Thrombose führen, da ja die genannte Stelle unter normalen Verhältnissen schon ein natürliches Stromhinderniss darstellt."

Hierauf ist nochmals geltend zu machen, dass für die im Anfangsstücke der Centralarterie gelegenen Massen jeder Beweis fehlt, dass sie ein ,Thrombus" waren, und dass v. Michel, wenn er dieselben von vornherein als Thrombus bezeichnet, in seiner Beweisführung gegen meine Diagnose Embolie einfach voraussetzt, was zu beweisen wäre.

Dass die Verlegung der Carotis und des Ursprungstheiles der Centralarterie Gelegenheit zu Thrombenbildung jenseits (also peripher) der rechtwinkligen Eintritts- bezw. Umbiegungsstelle der Arterie in den Sehnerven abgeben könne, will ich durchaus nicht bestreiten, anf das Entschiedendste muss ich aber betonen, dass in meinem Falle das Lumen der ganzen Centralarterie ron der Papille centralwärts bis zur Eintrittsstelle der Arterie in den Sehnerven vollkommen frei war, und nirgends anch nur Spuren endarteriitischer Veränderungen oder thrombotischer Verstopfung aufwies, sondern nur etwas Blut enthielt. Ich hebe hervor, dass diese Angabe auf dem genauesten Studium einer durchaus lückenlosen Serie von Querschnitten berubt.

Ich habe die ganze periphere Partie des Opticus vom Eintritt der Centralarterie bis nahe zur Papille in eine ltackenlose Querschnittsserie zerlegt. Das kleine an dem Bulbus haftende Stück des Sehnerven wurde in eine Serie von Längsschnitten zerlegt und lässt aụch da auf keinem Schnitte Spuren von Thromben oder endarteriitischen Erkrankungen erkennen.

Ich mass daher die ron r. Michel geltend gemachte, rein hypothetische Annahme von peripheren Thromben ju der Centralarterie, für meinen Fall, unbedingt zurückweisen.

Seit dem Jahre 1859 wurden beinahe alle Fälle von mehr oder weniger acuten Erblindungen eines Auges unter dem ophthalmoskopischen Bilde der arteriellen Ischaemie nach dem Vorgange vou v. Gunefe als Embolieen der Centralarterie der Netzhaut aufgefasst. Nachdem in der letzten Zeit $\mathrm{Haab}$ und andere mit Reclt davor gewarnt, alle diese Fälle auf eine Embolie zurückzuführen, suchte Reimar (2) in seiner trefflichen Arbeit sehr geschickt den Nachweis zu führen, dass. 
alle bisher beschriebenen Fälle von sog. Embolie der Centralarterie auf einer Verlegung des Gefässlumens in Folge von Endarteriitis obliterans beruhen, oder dass da, wo dieser Nachweis nicht direkt $z u$ führen sei, doch grosser Verdacht für eine solche Genese der Erblindung bestehe.

v. Michel(32), der in neuester Zeit einige Fälle von Thrombose der Centralarterie $z u$ beobachten Gelegenheit hatte (deren Diagnose aber keineswegs einwandfrei ist, denn es ist doch kaum zu verstehen, dass z. B. ein Thrombus in der Centralarterie nach fünf Wochen langem Bestand - Fall 1 - noch nicht eine Spur von Organisation aufweist) ist seinerseits geneigt, alle Fälle von sog. Embolie, so gut es sich durchführen lässt, durch eine Thrombose der Centralarterie zu erklären. Wie weit sein Betreben hierin geht, möge der folgende Fall illustriren. Dieser Fall erfordert so wie so eine eingehendere Besprechung, denn v. Michel schickt denseiben, da er mit dem meinigen eine gewisse Aehnlichkeit aufweist, seinen kritischen Bemerkungen über meine Embolie-Diagnose gleichsam als Stütz- und Ausgangspunkt voraus.

Es handelt sich um einen 49 jährigen Mann, dessen Krankengeschichte $\mathrm{v}$. Michel im Jahre $\mathbf{1 8 8 1}$ in den Beiträgen zur Ophthalmologie als Festgabe Friedrich Horner gewidmet - S. 16 - mittheilt.

Dieser Patient hatte seit 14 Tagen eine ziemlich rasch auftretende Abnahme des Sehvermögens des rechten Auges bemerkt (Fingerzählen in $1^{1 / 2} \mathrm{~m}$ ). Ophthalmoskopisch fand sich sehr schwache Füllung der Arterien und verhältnissmässig starke der Venen. Während einer Beobachtung verschwand sogar für kurze Zeit die Blutsäule sowohl in den arteriellen, als auch in den venösen Netzhautgefässen. Die allgemeine Untersuchung ergab Emphysem, Hypertrophie des rechten Ven. trikels und nahezu völlige Thrombose der rechten Carotis. Nach Verlauf von einigen Tagen wurde zugleich mit der Feststellung der völligen Pulslosigkeit der rechten Carotis das ophthalmoskopische Bild der sog. Embolie der Arteria centralis retinae beobachtet. 15 Monate nach der ersten Beobachtung erfolgte der Tod.

Die Section zeigte eine Thrombose der Carotis communis und des Anfangsstückes der Carotis interna, während das Lumen der Carotis ext. frei war. „Weder (S. 23) in der Arteria ophthalmica noch in der Arteria centralis retinae oder ihren Verzweigungen wurden irgend- 
welche Veränderungen trotz der sorgfältigsten Untersuchung gefunden."

v. Michel glaubte damals, das ophthalmoskopische Bild der sog. Embolie der Centralarterie könne in diesem Falle lediglich durch die in Folge der Thrombose der Carotis hervorgerufene Anaemie in den arteriellen Verzweigungen der Retina erzeugt worden seio (S. 22) oder falls man unbedingt eine Verstopfung des Lumens der Centralarterie annehmen zu müssen für nöthig halte, so könne man annehmen, dass vom Thrombus der Carotis sich ein Partikel gelöst und in die Arteria centralis retinae wirklich gelangte, allmählich aber resorbirt wurde (S. 23).

$\nabla$ on diesem selben Falle schreibt nun $r$, Michel in seiner neusten Arbeit (uiber Erkrankungen des Gefässsystem der Arteria und Vena central. retinae etc. Zeitschrift für Augenheilkunde, Bd. II, Heft 1, S. 8):

"Wenn bei der mikroskopischen Untersuchung angeblich keine Veränderungen an der Arteria centralis retinae gefunden wurden, so kann dieser Mangel wohl nur einer ungenügenden Untersuchung zugeschrieben werden, da im Hinblick auf die durch die Untersuchung des Falles I (dieser neuesten Arbeit) gewonnene Erfahrung und dem vorliegenden Befund an der Carotis die Annahme wohl als sicher betrachtet werden darf, dass das beobachtete Bild der Arteria centralis retinae durch eine Endarteriitis prolifera, bezw. Thrombenbildung auf der Basis einer solchen Veränderung hervorgerufen wurde."

Ich glaube, Jederwann würde mir zustimmen, wenn ich bei diesem y. Michel'schen Falle mit dem gleichen Rechte die Diagnose: "Embolie der Centralarterie, ausgehend von dem Thrombus der Carotis" stellte und dabei, wie v. Michel annähme, dass bei der ungenügenden Untersuchung dieses Falles dieser Erabolus übersehen worden sei. Es ist dies zum Theil eine Auffassung, welcher v. Nichel seiner Zeit durchaus nicht so abhold war, und gegen welche auch in keiner Weise ernstliche Z Weifel können geltend gemacht werden. Einzig die allmählich zunehmende Sehstörung könnte für die Diagnose "Thrombose" in's Gewioht fallen.

Dass Erhrankungen der Carotis interna eine Quelle für eine Embolie der Centralarterie abgeben können, kann nicht bestritten wexden. Im Referate über die Dissertation von Kern in Jahre 1892 im Jahresberichte über die Leistungen 
Die Gefahren der Ligatur der grossen Halsschlagadern etc. 573

der Ophthalmologie findet sich folgende Stelle: "Kern betont, dass in der Züricher Augenklinik einige Krankheitsfälle beobachtet wurden, die unter dem Bilde der Embolia arteriae centralis retinae verliefen, obne dass am Herzen oder sonst am Körper ein sicherer Ausgangspunkt für den Embolus nachgewiesen werden konnte." An dieser Stelle fügte der Referent, Prof. v. Michel, in Klammern die Bemerkung bei: ( "wurde regelmässig die Carotis untersucht?"). Es zeigt dies, dass auch v. Michel damals die Ansicht hegte, es könne die Carotis gelegentlich die Quelle einer Embolie der Centralarterie abgeben.

Ob nun aber ein Fall, wie der soeben mitgetheilte and von v. Michel gegen mich angefürte, geeignet ist, als Ausgangspunkt für eine Kritik meiner durchaus gewissenhaften Untersuchungen und deren Resultate zu dienen, möchte ich bezweifeln. -

Ich bin ganz überzeugt, dass nur ein kleiner Theil der bisher beschriebenen Fälle von sog. Embolie der Centralarterie wirklich auf eine Embolie dieser Arterie zurückzuführen ist und dass ganz gewiss ein grosser Theil derselben auf Verschluss des Gefässlumens durch endarteritische Wucherung, and vorübergehende secundäre Spasmen, seltener auch durch einen Thrombus zu Stande kommt. Ich glanbe aber, dass es unrecht ist, allen diesen Fällen von sog. Embolie der Centralarterie ein und dieselbe Diagnose aufzwängen zu wollen, denn warum sollte nicht auch in der Centralarterie, wie in den anderen Körperarterien, speciell wie in den übrigen Aesten der Carotis interna Embolieen vorkommen können, wenn auch allerdings seltener, als man bisher annahm, besonders wenn eine Quelle für eine Embolie so naheliegend ist, wie bei einer Thrombose der Carotis interna, an welcher noch mit Ligaturen herumgearbeitet wird, wie in meinem Falle.

Weiter bin ich der Ansicht, man könne mit der Kritik auch zu weit gehen, wenn man zur Annahme und Berechtigung einer Diagnose absolut zwingende gleichsam mathematische Beweise fordert, die einmal auf diesem Gebiete nicht zu haben sind. Ich glaube, dass diejenige Diagnose mit gutem Recht angenommen werden darf, welche einerseits alle Befunde am besten and ungezwungensten erklärt, gegen welche anderseits auch keine stichhaltigen Bedenken geltend gemacht werden können. Diese Postulate erfüllt aber in meinem Falle allein die Diagnose: Embolie der Centralarterie. 
Bevor ich die Diagnose: "Embolie des Anfangsstückes der Centralarterie mit secundär centralwärts wie peripheriewärts aufgelagerten Thromben" bei meinem Falle aufgebe, hätte ich doch gerne eine befriedigende Antwort auf folgende Fragen ron grundlegender Bedeutung, Fragen, welche v. Michel bei seiner Kritik meiner Diagnose völlig unberücksichtigt liess.

1. Warum findet sich in Anfangstheile der Centralarterie in einer Ausdehnung von $21 / 2 \mathrm{~mm}$ inmitten des obturirenden Pfropfes dieser Arterie beginnende Organisation, in den anderen Theilen des Pfropfes dagegen nicht?

2. Warum findet sich in diesem $21 / 2 \mathrm{~mm}$ langen obturirenden Pfropfe, welcher beginnende Organisation aufweist, das Fibrin unregelmässig, netzförmig angeordnet, wäbrend es peripheriewärts und centralwärts eine regelmässige geschichtete Anordnung aufweist, wie sie für Thromben charakteristisch ist?

3. Ist es Zufall, dass das kleine im Beginne der Organisation befindliche Stück des obturirénden Pfropfes mit unregelmässiger Fibrinanordnung gerade im Anfangstheile der Centralarterie sich findet, welche in gerader Richtung von der rechtwinklig umbiegenden Ophthalmica sich abzweigt?

4. Wie krommt es, dass in meinem Falle die Erblindung sofort eine absolute und rom ersten Momente der Beobachtung bis zum Tode (nur an einem Tage wurde vorübergehend äusserst abgeschwächte Circulution mit Agglutinationserscheinungen beobachtet) keine Cireulation in den Retinalgefässen mehr zu constatiren war, während bei allen, nach dem Urtheile von v. Michel als typisch geltenden Fällen von Thrombrose der Centralarterie (ich meine die vier von v. Michel(32) selbst yor kurzem publicirten), die Sehschärfe niemals pöllig erlosch und immer noch eine gewisse nicht unbedeutende Circulation in den Retinalgefassen fortbestand, da niemals, wie in meinem Falle Zerfall der Blutsäule sich einstellte.

5. Wie kommt es, dass die sofortige absolute Erblindung unter dem ophthalmoskopischen Bilde der totalen Aufhebung der Netzhautcirculation bei meinem Falle röllig mit dem ubereinstimmt, was $R$ eimar (2) in seiner letzten Arbeit als theoretisches Postulat für eine wirkliche Embolie der Centralarterie fordert?

6. Wie kommt es, dass die Thrombrose, welche in der Centralarterie getroffen wurde, $21 / 2 \mathrm{~mm}$ peripher vom Anfangstheile der Centralarterie das Lumen ganz erfüllte, gegen die 
Eintrittsstelle der Arterie in den Sehnerven zu aber sich langsam verjüngte und zuletzt das Lumen der Arterie nur noch partiell verlegte? Hier kann doch nicht gut angenommen werden, dass diese obturirende thrombotische Masse an dem zugespitzten Ende, etwas vor der Eintrittsstelle der Centralarterie in den Sehnerven, ihren Anfang nabm, sondern man muss schliessen, dass der Ausgangspunkt centraler lag und peripher kurz vor der Einrtittsstelle der Arterie in den Sehverven das zugespitzte Ende.

7. Warum aber begann denn diese Thrombose im centralen Theile der Centralarterie und nicht peripher von der rechtwinkligen Umbiegungsstelle der Arterie bei ihrem Eintritt in den Nerven, wo v. Michel sie fordert und sie auch in allen seinen Fällen von sogenannter Thrombose der Centralarterie thatsächlich fand? Wie anders lässt sich diese Ursprungsstelle in meinem Falle erklären als durch die secundäre Auflagerung auf einen primären, in das Anfangsstück der Centralarterie eingefahrenen Embolus? An einen ron der Carotis aus ascendirenden Thrombus, dies muss ich nochmals betonen, kann nicht gedacht werden, da beim Tode des Patienten dieser Thrombus erst das Anfangsstück der Ophthalmica erreicht hatte.

8. Ist die Embolie in unserem Falle denn etwas unmögliches? Findet sich denm nicht eine sehr naheliegende Quelle der Embolie, und ist der Vorgang, wie es zu einer Embolie kommen konnte, denn so schwer zu verstehen, oder ist nicht vielmehr bei Berücksichtigung aller Verhältnisse eine Embolie der Centralarterie das Wahrscheinlichste? Das sind Fragen, auf welche ich vor allem eine Antwort wünsche, da dieselben bei der Beurtheilung meines Falles von fundamentaler Wichtigkeit sind.

Ich muss unbedingt, so lange diese Fragen nicht in einer Weise beantwortet sind, welche die Diagnose "Embolie" ausschliessen, auf meiner Diagnose: "Embolie des Anfangstheiles der Centralarterie mit secundär central wie peripher aufgelagerten Thromben", festhalten.

\section{Der hintere Bulbusabschnitt:}

Die Untersuchung des hinteren Bulbusabschnittes speciell der Netzhaut lehrte, dass die pathologischen Verände- 
rungen lediglich in den inneren Schichten derselben localisirt waren.

Diese Veränderungen sind:

1. Abhebungen der Limitaus interua dureh glasige Scholleu und Kugeln, die oft fein granulirt sind.

2. Auflockerung und seröse Durchtränkung der Nervenfasersehicht. Da, wo dio Tervenfaserbündel quer getroffen sind, in der Gegend der Papille (Taf. XX, Fig. 11-13) findet man die einzelnen Bündel durch glasige, homogene Massen von einander getrennt. Statt der vormalen Faserquerschnitte sieht man unregelmässige Tröpfchen und myelinartige Figuren.

3. Cystische Hohlräume zwischen den Stützfasern (Taf. XX, Fig. 11), speciell häufig rings un einzelne Retinalgefässe.

4. In der Umgegend der Papille ist an den Ganglienzellen eine dentliche Anomalie nicht nachweisbar. In einiger Entfernung davon finden sich auffallend viel blassgefärbte Kerne. Dio Contouren der Zellen sind hier undeutlicher und ihre Zahl scheint verringert.

5. Die innere granulirte Schichte, wie die innere and äussere Körnerschichte zeigt lieine pathologischen Veränderungen. Die Zwischenkörnerschichte dagegen zeigt stellenweise einzelne cystische Hoblräume.

Stäbchen und Zapfen, soweit ersichtlich, normal, ebenso wie das Pigmentepithel im ganzen Gebiete der Netzhaut, auch in der Maculagegend.

Die Forea centralis weist ausser den Abhebungen der Membrana limitans interna eine merkliche Schwellung und Auflockerung der Zapfenfaserschicht in ein System ron kleinen, blasigen Hohlräumen auf (Taf. XX, Fig. 14).

6. Die Foveola centralis erscheint, so weit ersichtlich, nicht pathologisch verändert, ebensowenig wie die Aderhaut, welche ausser stellenweisen leichten Infiltrationen in den Lymplscheiden einzolner Aderhautgefässe durchaus normale Verhälitnisse anfiveist, sowohl an der Peripherie wie in der Gegend der Macula lutea.

Was die Grefässe der Netzhaut betrifft, so zeigen sich nirgends abnorme Verhältnisse. An einzelnen, besonders längsgetroffenen Gefässen ist deutlich zu seben, wie der Inhalt derselben streckenweise von rothen Blutkörperchen, streckenweise nur yon geronuener feinkörniger Substanz mit einzelnen Vacuolen gebildet ist, was vielleicht der Agglntination, weicbe intra ritam 
Die Gefalren der Ligatur der grossen Halsschlagadern otc. 577

beobachtet wurde, entspricht, Verhältnisse, wie sie eben auch bei älteren Leichenaugen beobachtet werden. Thrombosen finden sich nirgends, and nirgends Gefässerlkrankungen irgend welcher Art.

\section{Papille and Nervus opticus:}

Die Centralvene im Sehnervenstamme ist anf der ganzen Länge zusammengefallen. Sie enthält neben einzelnen rothen Blutkörperchen, noch eine grössere Anzahl von weissen Blutkörperchen.

Die Centralarterie ist stellenweise leer, streckenweise mit rothen Blatkörperchen, streckenweise mit geronnenem Plasma, das mehrere randständige Vacuolen enthält, gefüllt. An einer Stelle wechseln kleine Cylinderchen von rothen Blutkörperchen mit kleinen leeren Zwischenräumen, Es finden sich ferner im Lumen stellenweise, meist randständig, amorphe kleine, rothe Körperchen. (Blutfarbstoffe?)

Der Sehnerv selbst und seine Scheiden sind normal, der Kemgehalt des Nerven nicht vermehrt. An einzelnen Stellen sind die Sehnervenbündel in nächster Umgebung der Centralgefässe deutlich aufgelockert.

Sobald die Nervenfaserbündel durch die Lamina cribrosa in den Bulbus getreten sind, werden sie durch zahlreiche kleine cystische Hohlräume etwas auseinandergedrängt und aufgelockert.

Die ganze Sehnervenpapille zeigt eine solche Auflockerung durch zahlreiche grössere und kleinere Hohlräume, die zum Theil mit geronnener Substanz gefült sind. Die Limitans interna ist gleich bei ihrem Beginne in der Nähe der Papille in toto seicht abgehoben, und unter ihr finden sich geronnene Massen.

Ausserhalb des Bulbus in der Umgebung der Eintrittsstelle des Sehnerven finden sich die Lymphscheiden einzelner weniger kleiner Ciliararterien leicht infiltrirt. In den Ciliarnerven, welche die Eintrittsstelle des Sehnerven umgeben, finden sich ziemlich zahlreiche Ganglienzellen, bisweilen nur vereinzelt, bisweilen in grösseren Ansammlungen, bis zu fünfzehn.

Epikrise:

Die anatomische Untersuchung eines Bulbus bei frischer Enibolie der Centralarterie ist von hohem wissenschaftlichem Interesse, denn bis jetzt gelangte noch kein Bulbus bei Embolie der Centralarterie in diesem frischen Stadium der 
weisslicher Netzhauttribung zur anatomischen Untersuchung; es stehen sich daher die Ansichten über die anatomische Grundlage dieser Netzhauttrübung, wie über das anatomische Substrat des typischen kirschrothen Fleckes in der Maculagegend noch immer feindlich gegenüber.

v. Graefe(1.7) hielt die weisse Netzhauttrübung für den Ausdruck einer Zersetzung des Netzhautgewebes - wahrscheinlich fettigen Zerfalls - mit consecutiver Infiltration mit Körnchenzellen.

Die Mehrzahl der Ophthalmologen hält sie für die Wirkung eines Oedems der Nervenfaserschichte, und nenere Autoren, vor Allem Elschnig(18), lehnen sich wieder mehr an die v. Graefe'sche Ansicht an und halten sie für den Ausdruck einer Nekrose der Netzhaut.

Elschnig sagt l. c. S. 133: ,Durch die Absperrung der arteriellen Blutzufuhr der Netzhant wird also eine Nekrose der von der Centralarterie versorgten Gebirnschichte bewirkt, welche in einem körnig-fettigen Zerfall der nervösen Elemente, allmäblicher Aufsangung des gebildeten Detritus, Uebergang in einfache Atrophie besteht."

Es zeigten nun unsere eigenen Präparate:

1. Abhebungen der Limitans interna durch glasige homogene Schollen und Kugeln, die oft fein granulirt waren.

2. Auflockerung und seröse Durchtränkung der Nervenfaserschichte und in der Maculagegend und deren Umgebung auch der Zwischenkörnerschichte.

Von einer Infiltration durch Körnchenzellen und Rundzellen wurde nirgends eine \$pur beobachtet.

Es ist also vor Allem ein Oedem mit Infiltration oder das massenhafte Auftreten von Körnchenzellen nicht für die Ursache der Netzhauttrübung anzusprechen.

Schwieriger scheint mir die Frage, ob bei Embolie ein Oedem der Nervenfaserschichte oder eine Nekrose der nervösen Elemente der Gehimschichte die weissliche Netzhauttrübung verursache.

Die Thatsache, dass die gesammte Nervenfaserschichte, wie die Zwischenkörnerschichte, in der Gegend der Macula 
Die Gefahren der Ligatur der grossen Halsschlagadern ete. 579

aufgelockert und mit seröser geronnener Flüssigkeit durchtränkt ist, scheint doch die Vermuthung zu rechtfertigen, es handle sich hier vor Allem um ein Oedem dieser Schichten. Erklärt würde dasselbe dadurch, dass das Plasma des in den Venen stagnirenden Blutes durch die in ihrer Ernährung gestörten und so absterbenden Gefässwände hindurch in das sie umgebende Gewebe austrete und daselbst zu der beschriebenen Auflockerung und serösen Durchtränkung der Gewebselemente Anlass gäbe. Schwache anastomotische Zuflisse capillärer Natur, die ja meist existiren, speciell in der Umgebung der Papille, können im Verlauf von ein bis zwei Tagen die Trübung bedeutend vermehren, da dieselben nicht über genügende Kraft verfügen, ihr zugeführtes Blut durch die Capillaren in die Venen und weiter zu treiben. So kann es kommen, dass sowohl von den Venen - der intraoculare Druck hindert den Austritt des venösen Blutes aus dem Bulbus - als auch von den durch capilläre anastomotische Zuflüsse gespeisten Arterien aus Blutflüssigkeit durch die absterbenden Gefässwände in das umgebende Gewebe auszutreten vermag.

Unsere Präparate zeigen jedoch, ausser diesen als Oedem gedeuteten Veränderungen, auch einen Zerfall der Nervenfasern selbst zu unregelmässigen Tröpfchen und myelinartigen Figuren, sowie eine beginnende Nekrose der Ganglienzellen, und es ist doch sehr wohl denkbar, dass diese acut auftretenden Nekrosen der nervösen Elemente gleichfalls ihren Theil an der ophthalmoskopisch sichtbaren Netzhauttrübung haben. Andererseits lässt die Thatsache, welche Wagen m an n (19) berichtet, dass rollständige Durchschneidung des Sehnerven sammt den Netzhautgefässen, keine Netzhauttrübung beim Kaninchen bedingt, berechtigte Zweifel daran aufkommen, ob wirklich eine acute Nekrose der inneren Netzhautschichten eine ophthalmoskopisch wahrnehmbare Trübung der Netzhaut bewirken könne. Denn eine solch acute Nekrose der inneren Netzhautschichten 
tritt zweifelsohne auf, nach Durchschneidung des Sehnerren sammt den Centralgefässen.

In Weiteren spricht dieser Befund ron Wagenmann wenn nicht für, so doch keineswegs gegen die Auffassung, dass die Netzhauttrübung bei Embolie der Centralarterie auf einem Staungsoedem der Nervenfaserschichte beruhe, denn wir haben bei der Durchschneidung der Centralgefässe nicht nur die Centralarterie wie bei deren Embolie für den Blutstrom unwegsam gemacht, sondern auch die Centralvene durchschnitten, aus welcher nun leicht das venöse Blut des Bulbus ablaufen kann, wodnrch ein Oedem vermieden wird.

Dem entspricht auch die Erscheinung, dass bei diesem Experimente Arterien wie Venen bis weit in die Netzhaut hinein blutleer erscheinen, wälnrend bei Embolie der Centralarterie die Venen fast immer in der Netzhaut weiter werden.

Es ist daher die Annahme nicht ungerechtfertigt, es sei die Netzhauttrübung bei Embolie der Centralarterie vor Allem und wesentlich auf ein Oedem der gesammten Nervenfaserschichte sowie der Zwischenkörnerschichte der Maculagegend zurückzuführen, es könne aber auch der Nekrose der nerrösen Elemente der Gehirnschichte der Netzhaut ein wenn auch nicht wesentlicher Einfluss auf die Genese der Retinatribung zukommen.

Die Beobachtung bei unserem Falle, dass die weissliche Netzhauttribung bis zum vierten Tage stetig zunahm, vom fünften Tage an aber, als eine schwache Netzhautcirculation, allerdings langsam und mit unterbrochener Blutsäule sich wieder hergestellt hatte, bedeutend zuriickging, um am sechsten Tage, als die Circulation vollständig stille stand, von Neuem in erhöhtem Maasse aufzutreten, kam haum anders als durch ein Oedem als Träger der Netzhauttrïbung erklärt werden.

Fünf Tage völliger Anaemie der Netzhaut mussten genügen, um die nervösen Elemente der Gehirnschichte unbedingt zum Absterben zu bringen. Die geringe Verbesse- 
Die Gefahren der Ligatur der grossen Halsschlagadern etc. 581

rung der Circulation am fünften Tage konnte die Nekrose der Nervenfasern nicht mehr aufhalten, wohl aber konnte sie auf das bestehende Oedem der Netzhaut einen günstigen Einfluss ausüben.

Wagenmann (19) sagt: - 1. c. S. 99 - „Da die Netzhauttrübung stets nach verhältnissmässig kurzer Zeit zurückgeht, so kann man sie kaum auf eine tiefer gehende anatomische Verïnderung der Netzhaut beziehen. Denn hinge sie z. B. mit der Degeneration der Nervenfasern zusammen, so wäre nicht zu verstehen, wesshalb sie frïher zurïckginge als die Degeneration beendet ist."

Also auch die letztgenannte ophthalmoskopische Beobachtung spricht datür, dass die Netzhauttrïbung bei Embolie der Centralarterie nicht ausschliesslich auf eine Nekrose der nervösen Netzhautelemente zurückzuführen sei, sondern vor Allem auf ein Oedem der Nervenfaserschicht.

Wie ist nun der charakteristische lirschrothe Fleck in der Maculagegend zu erklären?

Die einen Autoren halten ibn fur eine Blutung in der Netzhaut - Blessig (20), - andere für eine Blutung in der Aderhaut, bedingt durch collaterale Fluxion - Steffan (21) während wieder andere ihn für den Ausdruck einer ChorioRetinitis ansprechen - Nettleship (1L) - , sind neuere Autoren der Ausicht, er konme durch eine eigenartige Umwandlung des der Maculagegend imnewohnenden gelben Pignentfarbstoffes zu Stande - Fischer (22) -.

Elschuig (18) lässt ibn dadurch entstehen, dass die Parthie der Fovea centralis, welche frei von der getrübteu Nervenfaserschichte ist, die normale rothe Farbe der Aderhaut ungehindert lindurchschimmern lasse. Diese rothe Färbung werde durch Veränderungen des Pigmentepithels der Maculagegend, welche Elschnig bei Embolie der Centralarterie als constant ansieht, in noch dunklerer Nüance erscheinen.

Nuël(23), von dem die neueste anatomische Arbeit über den Gegenstand herrührt, glaubt, der kirsehrothe Fleck sei der Ausdruck einer capillaren Hyperaemie der Maculagegend.

Die Mehrzahl der Ophthalmologen ist jedoch nach dem Vorgange von $v$. Graefo der Ansicht, es beruhe der rothe 
Fleck der Maculagegend daranf, dass eben die nächste Umgebung der Fovea centralis oder dieselbe selbst, in Folge ibrer anatomischen Structur frei ron Trübung bleibe und so den rothen Hintergrund der Aderhaut ungehindert hindurchseheinen lasse. Derselbe erscheine durch den Contrast mit der rings ihn umgebenden weisslichen Netzhauttrübung um so dunkler.

Die Mehrzahl der späteren Publicationen, welche die v. Graefe'sche Ansicht vertreten, wie meine eigene vorläufige Mittheilung, welche ich am 27. Ophthalmologencongresse in Heidelberg über don Gegenstand machte, enthalten in Folge der bei den einzelnen Autoren nicht immer übereinstimmenden Begriffe, welche wir mit "Fovea centralis" oder "Macula" oder "Foveola" verbinden, eine gewisse Unklarheit über die Grösse des Bezirkes, welcher dem rothen Fleck bei Embolie der Centralarterie znkommen soll.

Wir müssen doch unter "Fovea centralis" jene centrale Parthie der Netzhaut verstehen, welche eine grubenartige Vertiefung darstellt, während "Macula lutea " jenen Bezirls der" Netzhaut bezeichnet, welcher deutlich den gelben Farbstoff enthält, durch den die centrale Netzhaut ausgezeichnet ist. Fovea centralis and Macula lutea sind durchaus nicht immer miteinander identisch. Ferner giebt es aber noch im Centrum der grubenartigen Einsenkung der Netzhaut, also im Centram der Fovea centralis ein kleines Grübchen, dessen Concavität merklich die der Umgebung übersteigto Dieses centrale Grübchen bezeichnete Dimmer als: "Foveola".

Sowohl in den Lehrbüchern, als auch in mannigfachen Specialarbeiten wird bei der Besprechung des rothen Fleckens bei Embolie mit dem Worte "Macula" allem Anseheine nach meistens das bezeichnet, was eigentlich die Forea centralis ist und mit dem Worte: "Fovea centralis" was eigentlich "Foveola" heissen sollte. Es wird aber auch Fovea centralis mit Macula lutea verwechselt und angegeben, dass der rothe Fleck bei Embolie der Centralarterie an Stelle dor Macula lutea sich finde.

Einige Proben mögen die Richtigkeit dieser Aeusserung bestätigen. So sagt z. B. Leber, dass bei Embolie der Centralarterie der rothe Fleck immer mit der Fovea centralis zusammenfalle. Aehnlich drückt sich v. Michel und Panas aus. v. Michel sagt in seinem Lehrbuche, II. Auflage, S. 442: "Der rothe Fleck, entsprechend der Fovea centralis, ist nicht als eine Blutung, sondern im Wesentlichen als eine Contrast- 
Die Gefahren der Ligatur der grossen Halsschlagadern etc. 583

erscheinung aufzufassen". Panas erlüärt in seinem Lehrbuche, S. 623: "La fovea se détache comme un point rouge cerise apoplectique".

Fuchs dagegen veriegt wie $\mathrm{Haab}$ den rothen Flecken in das Centrum der Fovea. Fuchs schreibt in seinem Lehrbuche neueste 7. Auflage, S. 484: "Entsprechend der Mitte der Fovea hebt sich vom weiss getrübten Grunde ein lebhaft rother Fleck $\mathrm{ab} . . "$, und $\mathrm{Haab}$ meint in der 2. Auflage seines Atlas und Grundriss der Ophthalmoskopie bei Fig. 32: "In der Mitte der Foveagegend sieht man einen kirschrothen Eleck."

Hosch lässt den rothen Fleck mit der Macula lutea znsammenfallen, indem er in seinem Grundriss der Augenheilkunde 1897, S. 323 schreibt: „Bald wird (bei Embolie der Centralarterie) der centrale Theil der Retina durch Infiltration opak, milchig weiss getrübt, wälrend die Stelle des gelben Fleckes in dunkelrother Farbe vom weissen Grunde sich abhebt."

Wenn Nuel(23) den rothen Fleck auffasst als den Ausdruck einer capillaren Injection der Macula lutea, so vergisst er auf der einen Seite, dass das Centrum der Macula, die Foveola, gefässlos ist, auf der auderen Seite kann er mit dem Ausdrucke Macula nicht das verstehen, was andere Autoren als Centrum der Fovea centralis oder als Foveola bezeichuen.

Ich glaube nun nach alledem, dass es im Interesse eines klaren Verständnisses, welches alle derartigen Verwechslungen ausschliesst, liegt, dass in Zukunft für die einzelnen Bezirke des Netzhautcentrums Bezeichnungen allgemein eingeführt werden, welche nicht misszuverstehen sind. Es sollte, meine ich, nach dem Vorgange von Dimmer mit "Macula Iutea" die gelbe Parthie des Netzhautcentrums, mit „Fovea centralis" die ganze Netzhautgrube, nnd mit "Foveola“ das kleine, intensiver als die Umgebung eingestülpte Centrum der Fovea bezeichnet werden.

Nach den vorzuiglichen, exacten Untersuchungen von Dimmer ${ }^{1}$ ) beträgt nun der horizontale Durchmesser der

1) Beiträge zur Anatomie und Physiologie der Macula lutea des Menschen. Wien 1894. 
A. Siegrist.

Fovea centralis, d. h. jener Parthie der Netzhaut, welehe eine grubenartige Vertiefung aufweist, etwa $1,5-2,0 \mathrm{~mm}$. Es ist demnach die wirkliche Fovea centralis ungefähr gleichgross wie die Sehnervenpapille, oft noch grösser als dieselbe. Nun ist aber der kirschrothe Fleck bei Embolie der Centralarterie bedentend kleiner als die Sehnervenpapille, er kann daher unmöglich mit der wirklichen Fovea centralis zusammenfallen, wie dies bisweilen angenonimen zu werden scheint.

In der Mitte der Fovea centralis findet sich jedoch, wie bereits erwähnt, abermals eine kleine Einstïlpung der imeren Netzhautoberfläche: die sogen. Foveola, die einen Durchmesser von 0,12-0,3, oder wemn ein Fundus Foveae, vorliegt, bis zu $0,7 \mathrm{~mm}$ hat. Diese Parthie würde der Grösse nach viel eher dem rothen Flecken entsprechen und auch gewisse Schwankungen in der Grösse dieses Fleckes erklären. Zugleich ist diese Parthie die diunnste der ganzen Netzhaut.

Rechnet man als mittlere Grösse der Foveola einen Durchmesser ron $0,2-0,3 \mathrm{~mm}$, so würde dieselbe im aufrechten Bilde betrachtet einen rothen Flecken von ungefähr $0.2-0,3 \times 16=3,2-4,8 \mathrm{~mm}$ im Durchmesser betragen, was annähernd der Wirklichkeit entspricht.

Die Mehrzahl der Ophthalmologen hält nun die weissliche Netzhauttrübung bei Embolie der Centralarterie für den Ausdruck eines Oedems der Nervenfaserschichte. Im Gebiete der wirklichen Forea centralis, nimmt aber die Nervenfaserschicht rasch bedeutend an Dicke $a b$, um bald fast völlig zu schwinden. Es müsste demnach, wenn unsere Ansicht von der Identität des rothen Fleckens mit der Foreola richtig ist, die weisse Netzhautverfärbung rings um den rothen Fleck am schwächsten sein, um schon eine gewisse Strecke vor demselben ganz zu verschwinden. Ein Blick auf das ophthalmoskopische Bild lehrt jedoch das Gegentheil, gerade rings um den rothen Fleck ist die Netz- 
Die Gefahren der Ligatur der grossen Halsschlagadern etc. 585

hauttrübung am intensirsten. Es liegt hier also ein gewisser Widerspruch vor, der sich nur lösen lässt, wenn man die bei unseren Präparaten der Foveagegend gefundene Auflockerung der Zapfenfaserschichte in ein System von kleinen cystischen Hohlräumen berïcksichtigt. Diese wohl als Oedem der Zapfenfaserschicht zu deutende Aufquellung trägt jedenfalls mit zu der gerade in dieser Gegend so intensiven Netzhauttrübung bei, (ausser der bedeutenden Dicke von Ganglienzellen - und Nervenfaserschichte in der Umgebung der Forea centralis). Von einem Oedem der Zapfenfaserschichte bei Erblindungsfällen unter dem ophthalmoskopischen Bilde der sog. Embolie der Centralarterie sprechen schon Gowers, Hirschfeld, Wagenmann und Nuël.

Die Foveola allein besitzt keine Trübung, da sie nach Dimmer weder Nervenfaserschichte noch Zapfenfaserschichte aufweist. Durch sie blickt uns also inmitten der weissgetrübten Netzhaut die rothe Farbe der normalen Aderhaut als runder Fleck entgegen, und zwar in Folge des Contrastes mit der weissen Umgebung in saturirter Färbung.

Vergleicht man bei den klassischen ophthalmoskopischen Bildern der sogen. Embolie der Centralarterie die Grösse der Papille und des rothen Fleckes, so wird man eine auffällige Uebereinstimmung mit den Maassangaben von Dimmer und der soeben entwickelten Ansicht über die anatomische Grundlage des rothen Fleckes finden.

Nehmen wir z. B. den Atlas der Ophthalmoskopie zweite Auflage von Dr. Liebreich (Liebreich hat übrigens noch vor v. Graefe als erster die Contrasttheorie für den rothen Flecken bei Embolie der Centralarterie aufgestellt) und messen wir auf Tafel VIII, Fig. 4 die Grösse der Papille, wie die Grösse des centralen rothen Fleckes, so finden wir die Papille: $15 \mathrm{~mm}$ lang, $14 \mathrm{~mm}$ breit, den rothen Fleck: $3 \mathrm{~mm}$ im Durchmesser. Da die Bilder 
in zehnfacher Vergrösserung gezeichnet wurden, so ergiebt sich für die thatsächliche Papillengrösse: $1,5 \mathrm{~mm}$ Länge und $1, \pm \mathrm{mm}$ Breite, für die thatsächliche Grösse der anatomischen Grundlage des rothen Fleckes: ein Durchmesser von $0,3 \mathrm{~mm}$.

Diese Maasse entsprechen ganz den Angaben ron Dimmer über die Grösse der Fovea centralis, resp. Papille einerseits und der Foreola centralis andererseits. Aehnliche gegenseitige Grössenverhältnisse weisen Papille und rother Fleck der meisten übrigen Abbildungen der sogen. Embolie der Centralarterie auf.

Wir können unsere Untersuchungsresultate in folgende Sätze zusammenfassen:

1. Die anatomische Grundlage der weissen Netzhautriabung im Anfangsstadium der Embolie der Centralarterie der Netzhaut besteht vor Allem in einem Oedem der Nervenfaserschicht, sowie in einem Oedem der Zapfenfaserschichte in der Gegend der Macula lutea. Auch der Nekrose der nervösen Elemente der Gehirnschichte der Netzhaut kommt vielleicht ein gewisser wenn auch nicht wesentlicher Einfluss an der Genese der weisslichen Trübung zu.

2. Der charakteristische kirschrothe Fleck in der Maculagegend bei Embolie der Centralarterie kommt dadurch zu Stande, dass die Foveolacentralis - nicht Fovea centralis - frei von jeglicher Trübung bleibt, da sie weder Zapfenfaser-noch Nervenfaserschichte besitzt. Durch diese ungetrübte Foveola schimmert die normale Farbe der Aderhaut unbehindert hindurch und wird durch den Contrast mit der rings sie umgebenden weissen Netzhauttrübung in ihrer Wirkung noch verstärkt. 


\section{Der vordere Bulbusabschnitt.}

Die Untersuchung des vorderen Bulbusabschnittes wies vor allem mässige Hyperaemie der conjunctivalen wie episkleralen Gefässe nach (Taf. XXI, Fig. 15). Thrombosen wurden nirgends beobachtet. Die Umgebung der hyperaemischen Gefässe ist reichlich mit Rundzellen infiltrirt. Hierdurch entsteht rings um die Hornhaut, so weit eben die Conjunctiva bulbi reicht, der Sklera aufliegend und auch etwas deren oberflächlichste Lagen in sich hineinziehend, eine Schichte von etwa $1 / 3$ Skleradicke, in der sich eine hochgradige Rundzelleninfiltration um die erweiterten Gefässquerschnitte findet. Die Rundzellen haben hier ausnahmslos mononucelaren Charakter, einzelne finden sich auch zwischen den Epithelzellen der Conjunctiva. Diese Zellinfiltration gewinnt gegen den Limbus hin an Mächtigkeit und breitet sich dann in den oberfächlichen Hornhautschichten gegen die Hornhantmitte zu aus, wo sie etwas unterhalb und temporal von der Hornhautmitte in den oberflächlichen und mittleren Schichten ein ganz besonders dichtes rundliches Infiltrat von etwa $2 \mathrm{~mm}$ Durchmesser darstellt.

Am Limbus drängt sich die Infiltration mit kleinen neugebildeten infiltrirten Gefässen an vielen Stellen zwischen Epithel und Bowman'sche Membran, wodurch diese oft eine Strecke weit von Hornhautepithel verdrängt wird. Die vom Epithel abgedrängte Bowman'sche Membran ist aber sowohl temporal, als auch nasal, nur ganz in der Peripherie am Limbus erhalten, hört dann ganz plötzlich auf und ist durch das infiltrirte Gewebe ersetzt, um nach einer Unterbrechung von ungefähr 2,0 mm plötzlich wieder in richtiger Lage aufzutauchen. Wir haben so die eigenthümliche Erscheinung, dass ganz am Limbus ein kleines Stück der Bowman'schen Membran durch infiltrirtes Gewebe rom Hornhautepitel abgedrängt, aber noch erhalten ist, dass dann die Bow man'sche Membran etwa 2,0 mm weit centralwärts gegen die Mitte der Hornhaut zu völlig fehlt, und durch infiltrirtes Gewebe ersetzt ist, um dann plötzlich wieder in normaler Lage gegen die Mitte der Cornea zu sich einzufinden.

Wie in der Hornhautmitte, so ist auch am Limbus das Infiltrat dicht, während im dazwischen liegenden Gebiete die Zellenanhäufung geringer ist. Dadurch entsteht deutlich das Bild einer vom Limbus nach der Hornhautmitte fortgeptlanzten Infiltration. 
In centralen Hornhautinfiltrate finden sich die Rundzellen in den erweiterten Spalträumen zwischen den Hornhautlamellen (Taf. XXI, Fig. 16 und 18), wo sie dicht zu Ketten geordnet neben einander liegen. Einige Spalträume scheinen mit einer homogenen, mit Eosin sich leicht rothfärbenden Masse, in welcher die Rundzellen liegen, ausgegossen zu sein. Auch die fixen' Bindegewebszellen sind etwas vermebrt. Was die Art der Rundzellen betrifft, so überwiegen hier die polynucleären Formen. Das Endothel der Descemet'schen Membran ist überall unverändert, nur findet sich auf demselben eine mässige Auflagerung von Rundzellen, meist einkernige. Diese Rundzellenautlagerung ist merklich dichter unter dem centralen Infiltrate der Hornhaut, ebenso wie an den periphersten Stellen der Descemeti. Das Ligamentum pectinatum zeigt ebenfalls eine deutliche Infiltration seines Mascheuwerkes mit Rundzellen (Taf. XXI, Fig. 15).

In einer Zone von etwa $1,5 \mathrm{~mm}$ Breite um das centrale Hornhautinfiltrat zeigt das Epithel eigenthümliche Veränderungen (Taf. XXT, Fig. 17 und 19). Die cylinderförmigen Basiszellen sind sowoll in ihrer Längsrichtung, als auch in der Breite gut um das Dreifache vergrössert und stellen grosse blasenförmige Zellen mit rergrössertem Kern dar. Zwischen ihnen finden sich stellenweise einzelne, gleichfalls sehr in die länge gezogene, aber seitlich zusammengepresste, fast möchte ich sagen, geschrumpfe Zellen, welche oben arkadenförmig sich ansbreiten. Die weiteren, mehr äusseren Schichten des Epithels zeigen gleichfalls bedeuteude Vergrösserung. Der Leib aller dieser gequolienen und vergrösserten Zellen färbt sich fast gar nicht, der vergrösserte Kern sehr schlecht.

Gegen die Mitte des centralen Hornhautinfiltrates zu, nimmt, die Grösse und die Zahl der übereinander liegenden Epithelzellen. immer mehr ab, so dasś bald nur noch eine einzige Zellenreihe, Fig. 18, bald aber keine einzige Zelle menr die Bowman'sche Membran declt Fig. 19. Direkt äber der Mitte des centralen Hornhautinfiltrates, in einem Bezirke von etwa $0,2 \mathrm{~mm}$ im Durchmesser fehit Epithel, wie Bowman'sche Mombran, vollständig. "U" $U^{*}$ in Fig. 16 und 19. Nach dieser centralen defecten Stelle zu verdunnt sich von allen Seiten die Bowman'sche Membran keilförmig. Ein Defect auch im Hornhautparenchym ist hier nicht au erkennen. Mir scheint das $\mathrm{Pa}-$ renchym direct unter diesem Ulcus in kleipster Ausdehnung 
Die Gefahren der Ligatur der grossen Halsschlagadern etc. 589

etwas nekrotisch zu sein, da es sich hier schlechter färbt, und nur noch uudeutlich Zellkerne nachweisen lässt.

Eine Bakterienfärbung blieb erfolglos.

Die Iris ist locker infiltrirt. Das Corpus ciliare aufgelockert und von einer sich zart rosa färbenden Flüssigkeit durchsetzt. Processus ciliaris in gleicher Weise mässig oedematös. Corpus vitreum zeigt ausgesprochen wellig fibrilläre Structur. Der vordere Theil der Lamina fusca chorioideae ist ein klein wenig infiltrirt.

\section{Epikrise.}

Die beschriebene Hornhautaffection muss sich erst in den allerletzten Tagen vor dem Tode des Patienten gebildet haben, da sie noch auf kleinem Gebiete localisirt und intra vitam nicht bemerkt worden war. Da Hornhautaffectionen nach Carotisligatur zu den grössten Seltenheiten gehören, von welchen mir zur damaligen Zeit nichts bekannt war, dachte ich gar nicht daran, die Hornhaut des erkrankten Auges zu Lebzeiten des Patienten eingehender zu prüfen. Erst die anatomische Untersuchung kiärte mich ïher das bestehende Hormhautleiden auf.

Wir haben es, so weit ersichtlich, mit einem beinahe central gelegenen Infiltrate der oberfächlichen und mittleren Schichten der Hornhaut in einer Ausdehnung von etwa $2,0 \mathrm{~mm}$ zu thun. Ueber den Randbezirken dieses Infiltrates ist das Epithel eigenartig verändert, während es uiber den mittleren Theilen desselben einschichtig, niedrig wie vertrocknet und geschrumpft ist und in kleinster Ausdehnung ( $U$, Fig. 16 und 19) ebenso wie die Bowmansche Membran, völlig fehit. Das Parenchym ist an dieser Stelle leicht nekrotisch.

Bei der Frage nach der Genese dieses im Anfangsstadium der Entwicklung begriffenen, beinahe central gelegenen Hornhautgeschwüres musste man vor Allem an eine durch die Carotisligatur verursachte ungewöhnliche Anaemie der die Hornhaut ernährenden Gefässbezirke denken. Weiter kam eine zufällige Verletzung der Hornhaut mit 
nachfolgender Infection der lädirten Stelle in Betracht. Endlich eine durch trophische Störungen erfolgte Erkrankung der Hornhaut, gleichguiltig wie man sich diese trophischen Störungen vorstellen wollte, also eine beginnende sog. Keratitis neuroparalytica.

I. Eine Verletzung der Hornhaut mit nachfolgender Infection der lädirten Stelle konnte nicht angenommen werden, da kein Grund hierfür vorlag. Mit was sollte sich der Patient verletzt haben? Warum hat er selbst die Verletzung nicht bemerkt? Es musste also nach einer weiteren Erklärung gesucht werden.

II. Auch die Erklärang durch Anaemie des vorderen Augenabschnittes musste ron vornherein abgewiesen werden, wenn man an die ausgiebigen Anastomosen dachte, welche das Ciliargefässsystem mit dem Gefässgebiete der Carotis ext, der gleichen wie auch der anderen Seite aufweist.

Es fand sich ja der Hauptstamm der Arteria oplthalmica in seiner peripheren Hälfte frei ron obturirenden Massen, so dass jedeufalls einer grossen Anzahl von Anastomosen der Zugang zum System der Ophthalmica offen stand. In dieser Ansicht wurde man bestärkt, wenn man in Betracht zog, dass in den conjunctivalen wie episkleralen Gefässen nirgends Anaemie oder Stase mit Thrombenbildung beobachtet wurde, sondern überall nur mässige Hyperaemie mit Rundzelleninfiltration, also lediglich leicht entzündliche Erscheinungen.

Den Einfluss einer Anaemie im System der Ciliaparterien auf die Hornhaut hat Wagenmann ${ }^{1}$ ) genau an Kaninchen studirt, indem er beide Arteriae ciliares longae durchschnitt.

Wagenmann fand:

1. Klinisches Bild:

Constant beginnt, meist schon nach einem halben Tage, eine diffuse grauweisse Hornhauttrübung sich zu zeigen, die

1) v. Graefe's Arch. f. Ophthalm. Bd. XXXvi. Abth. 4. 
Die Gefahren der Ligatur der grossen Halsschlagadern etc. 591

gewöhnlich am Rande zuerst einsetzt, sich gegen die Mitte rasch vorschiebt und dann die ganze Hornhaut gleichmässig einnimmt.

Die grauliche Trübung nimmt innerhalb der nächsten Tage an Intensität zu, die Farbe wird mehr grauweiss und milchig, die Conjunctiva ist injicirt, aber obne Secretion. Schon vom dritten Tage an kann man eine beginnende Randvascularisation erkennen, die allmählich zunimmt und circulär vollkommen gleichmässig fortschreitet. Sie schreitet verhältnissmässig schnell nach dem Hornhautcentrum zu vorwärts. Bisweilen, wenn die Vascularisationsschicht stärker geröthet and zogleich dichter und wulstig erscheint, kommt eine Complication mit Ulceration der Hornhaut vor, indem sich das Epithel auf deren Mitte abstösst und ein Ulcus mit käsig aussehendem Grunde entsteht. Dabei beginnt das Auge zu secerniren und der Process nimmt eitrigen Charakter an.

2. Anatomiscbe Veränderungen:

Es kommt sehr bald zu einer enormen Verdickung der Hornhant, welche sich zuerst in der Peripherie bemerbar macht und daselbst am stärksten entwickelt ist. Die dünne Kaninchencornea quillt zu einer mebrere Millimeter dicken Membran auf. Zuerst ist das Centrum noch weniger stark verdickt. Von innen gesehen, springt die Innenfläche der Cornea in den Raum der vorderen Kammer vor und hat nach dem Centrum zu gerichtete Falten, die mittlere Parthie scheint trichterförmig eingesuuken. Das Endothel fehlt völlig.

Mikroskopisch findet man eine starke Aufquellung der Hornhautlamellen, Durchtränkung mit eiweissreicher Flüssigkeit, massenhaftes Auftreten von Fibrin und eine anfangs mässige Einwanderung von Lymphkörperchen. Fibrin findet sich an der Peripherie am reichhaltigsten und nimmt nach dem Centrum za ab. Es wird also die Hornhaut mit einer äusserst fibrinreichen Flüssigkeit von der Peripherie her durchdrängt, und es kommt dann im Gewebe der Hornhaut zur Gerinnung des Fibrins.

Anfangs zeigen sich wenig Lymphkörperchen, in den nächstfolgenden Tagen nimmt die Infiltration der Hornhaut beträchtlich zu. Hand in Hand damit geht das Eindringen ron Gefässen in die Grundsubstanz der Hornhaut. Ueberall, wo Gefässe sind, kommen dichte Züge ron Rundzellen zwischen den Gefässen vor. Auch die an die Vascularisation grenzende centralwärts gelegene Zone ist dicht infiltrirt.

v. Graefe's Archiv für Ophthalmologie. L. 3. 
Tch habe an zwölf Kaninchen die Experimente Wagenmaun's nachgemacht und die entstehende Keratitis parenchymatosa an eigenen Präparaten in den verschiedensten Entwicklungsperioden des Leidens eingehend studirt. Ich kann die Angaben Wagenmann's nur bestätigen.

Hinzufügen möchte ich jedoch, dass die Trübung nach Durchschneidung beider langen Ciliararterien fast immer vou oben und unten in das Hornhautgewebe einzuwandern beginnt.

Erst nach zwei Tagen etwa sieht man dieselbe anch merklich von den Seiten her, nach der Horhautmitte zu, sich ausbreiten.

An der Hand meiner eigenen Präparate kamn ich bestätigen, dass sich zuerst eine mächtige Aufquellung der Hornhaut zeigt. Die Hornhaut wird gut um das sechsfache dicker, and verliert ihr Endothel. Die einzelnen Hornhautlamellen unellen auf, und die ganze Hornhaut wird von der Peripherie, aber auch von der hinteren Hornhautfläche aus, mit einer eiweissreichen fibrinhaltigen Flüssigkeit durchtränkt. In den ersten Tagen zeigt das Hornhautparenchym, ausser den genaunten Veränderungen, speciell in seinen centralen Theilen durchaus keine Infiltration mit Rundzellen.

Nur am Limbus zeigt sich eine kleine Strecke weit eine Einwanderung von Rundzellen in allen Schichten der Hornhaut. Diese Rundzellen haben in der grössten Mehrzahl polynucleären Charakter und entspringen aus. dem am Limbus sich findenden coujunctivalen und episkleralen Gefässen, sowie auch aus den Gefässen des Kammerwinkels. Die aus letzteren Gefässen auggewanderten Zellen dringen dicht vor der Descemet'schen Membrau als dichter Infiltrationsstreifen gegen die Mitte der Hornhaut zu vor.

Am dritten Tage sind bereits zwei Drittel der Hornhant mächtig um das sechs- bis siebenfache angeschwollen, während das Yittelsstück derselben erst etwa die doppelte Dicke der normalen Hornhaut aufweist. Während das Mittelstück in seiner oberflächlichen Hälfte noch normales Aussehen bat, zeigt die tiefere, gegen das Augeninnere zugekehrte Hälfte, wie bereits zum Theil am zweiten Tage schon, Aufquellung, und die Kerne der Hornhantkörperchen sind hier nicht mehr zu färbenl. Das Endothel feblt seit dem zweiten Tage auf der ganzen Descemet'schen Membran. Die Rundzelleninfiltration 
Die Gefahren der Ligatur der grossen Halsschlagadern etc. 593

ist weiter gegen die Hornhautmitte zu vorgedrungen, und zwar sind die Rundzellen, welche unmittelbar auf der Descemeti einmarschiren, viel weiter nach vorne gedrungen, als diejenigen, welche von den Gefässen des Randschlingennetzes ausgehen. Die ersteren wandern in dichtgedrängten Schaaren, immer der Descemeti aufliegend, eine gute Strecke weit in die Hornhaut ein, um dann plötzlich, kurz vor dem Beginn der noch relativ normalen Parthie des Hornhantmittelsturckes sich schräg durch die ganze Hornhantdicke hindurch auf eine kleine Strecke weit auszubreiten.

Am siebenten Tage ist die Quellung der Hornhaut auch im Centrum ganz gewaltig. Diffus in dem mächtig aufgelockerten, mit eiweissreicher Flüssigkeit durchtränkten Gewebe finden sich zerstreut einzelne polynucleäre Rundzellen, ferner zahlreiche spindel- und sternförmige Zellen mit mehreren langen Fortsätzen und grossem Kerne (wohl Abkömmlinge der Hornhautkörperchen), endlich einige andere grosse, blasige, grosskernige Zellen.

Das Epithel zeigt als einzige Veränderung einzelne blasige Vacuolen in den oberflächlichen Schichten, wie stellenweise Vergrösserung einzelner oberflächlichen, sonst flachen Epithelzellen zu blasenförmigen Zellgebilden mit fast wasserLellem Zellleib und grossem, schwach färbbarem Zellkerne.

Fom Rande her dringen nun in allen Hornhautschichten gleichmässig Gefässe in die Hornhautsubstanz ein. Zwischen denselben finden sich zahlreiche polynucleäre Rundzellen. In den oberflächlichsten Schichten zeigt auch jetzt noch die Hornhaut im Centrum annähernd normalen Bau. Man kann hier noch die einzelnen Lamellen unterscheiden, und auch die fixen Hornhautkörperehen zeigen in ihrer Gestalt und Lage noch annähernd normale Verhältnisse. Von der Peripherie aus beginnt nun eine bald ein- bald mehrfache Lage von meist spindelförmigen Zellen, die Descemeti als Endothel zu bedecken.

Am zwölften Tage hat die Aufquellung der Hornhaut bedentend $a b-$, die diffuse Infiltration derselben mit Rundzellen dagegen zugnommen. Die Gefässe sind ein gutes Stück weiter nach dem Centrum der Hornhant vorgerückt, und eine oft mehrfache Lage von spindelförmigen Zellen bedeekt als Endothel wieder die ganze Descemeti. Das Epithel ist nicht mehr wesentlich verändert, stellenweise ist es etwa verdickt.

Den späteren Verlauf lasse ich unberücksichtigt, da er $39^{*}$ 
meinen Zwecken nicht weiter dient. Herrorheben möchte ich nochmals, dass die Trübung der Hornhaut fast immer in den ersten Tagen von oben und unten in die Hornbaut hineinwandert und erst etwas später auch von den seitlichen Theilen aus die Einwanderung beginnt, ferner dass, wie bei der anatomischen Untersuchung deutlich bervortritt, die Aufquellung und Durchtränkung der Hornhautsubstanz nicht nur vom Limbus gegen das Centrum der Hornhaut zil vorrücken, sondern dass dieselben gleichzeitig von den inneren tiefsten Hornbautschichten beginnen und durch die mittleren gegen die oberflächlichen zu sich weiter ausbreiten. So erscheint es fraglich, ob nicht auch von der vorderen Kammer aus, bei dem schon am zweiten Tage nach der Durchschneidung der Ciliararterien constatirten completen Fehlen des Endothels, Flüssigkeit in die Hornhaut eindringe, und zu der mächtigen Trübung. und Quellung derselben beitrage. Solche Quellungen des Hornhautparenchyms bei Laesionen des Endothels sind ja bekannt, und haben Mellinger (31 und 32) dazu geführt, die Keratitis parenchymatosa des Menschen auf eine primäre Erkrankung des Endothels zurtickzuführen.

Aus dem ganzen Krankheitsbilde, wie es hier geschildert wurde, geht nun mit grosser Klarheit hervor, dass dasselbe mit dem bei unserem Patienten nach Carotisligatur beobachteten Hornhautleiden durchaus nichts gemein hat. Tch glaube, dass ich nicht nöthig habe, die allzusehr in die Augen fallenden Unterschiede noch besonders hervorzuheben.

Es folgt daraus, dass die beobachtete Hornhautveränderung nach Ligatur der Carotis communis und interna nicht als eine Folge von Anaemie der die Hornhaut ernährenden Gefässe zu betrachten ist, sondern dass sie auf anderem Wege entstanden sein muss.

Fs bleibt also noch als letzte Erklärung eine Keratitis neuroparalytica übrig.

III. Bevor wir die Gründe prïfen, welche für das Vorhandensein dieser Form von Hornhauterkrankung sprechen, müssen wir zuerst sehen, ob eine Keratitis neuroparalytica nach Carotisligatur überhaupt möglich ist, und 
Die Gefahren der Ligatur. der grossen Halsschlagadern etc. 595

ob ähnliche Beobachtungen nach dieser Operation schon gemacht wurden.

Dass eine einfache Carotisligatur ohne weitere Complicationen zu Störungen der Innervation des Trigeminus führe, ist schwer glaublich bei den wohl ausgebildeten Anastomosen, welche die Gefässe der zwei Hemisphären, mit einander verbinden. Anders ist es aber, wenn in der Carotis interna von der Ligaturstelle aus ein Thrombus hinaufsteigt und zur Verlegung von mannigfachen Hirngefässen führt.

Thatsächlich wurde in einem solchen Falle von Zimmermann - Nr. 40 - die Hornhaut des gleichseitigen Auges völlig anaesthetisch gefunden. Dieser Fall von Zimmermann gleicht zudem in vielem dem unserigen, bei welchem wir es ja gleichfalls mit einer ascendirenden :Thrombose in die Hirngefässe hinein zu thun hatten. Dass zugleich auch der Sympathicus schon dureh den operativen Eingriff lädirt worden sein kann, das zeigen zablreiche Beispiele, in denen nach der Ligatur ohne weitere Complicationen Störungen sich einstellten, die auf Läsionen des Sympathicus zurückzuführen waren; ich erwähne hier nur Fall 2, 5 und 38

Es muss also die Möglichkeit einer Läsion des Trigeminus oder Sympathicus in Fällen, wie dem unsrigen, absolut zugegeben werden.

Die Literatur der Carotisligaturen beim Menschen kennt ausser dem soeben erwähnten Falle 40 von Zimmermann nur noch einen Fall, der mit einer Affection der gleichseitigen Hornhaut einherging. Es ist dies Fall 34 von Buenger, bei dem nach der Ligatur der zweiten Carotis am fünften Tage das gleichseitige Auge bleich und trüb gefunden wurde. $O b$ der Compressionsverband eine Mitschuld trug, bleibt dahingestellt. Die Cornea war ohne Injection der Umgebung gequollen. Die Trübung schritt fort und die Hornhaut zerfiel in eine Art Brei und liess den Glaskörper hindurchtreten. Nun erst entstand Injection der Conjunctiva und Schwellung der Lider.

Einen weiteren Fall theilt Ehrmann l. c. S. 16 bei der experimentellen Ligatur aller vier Hirnarterien eines Hundes mit. Gleich nach der gemeinsamen Ligatur der vier Hirn- 
arterien stellten sich heftige Convulsionen ein, dann fiel das Thier in einen Zustand von Stupor, der etwa fünf Minnten dauerte. Nach einer Viertelstunde ging das Thier wieder bei vollem Bewusstsein herum.

„Pendant 5 jours l'êtat paraissait satisfaisant, il n'y eut aucun symptôme cérébral, mais la cornée de l'oeil droit vint à s'ulcérer; dyspnée; mort le 6. jour."

Welcher Natnr die Hornhautaffection in diesen zwei Fällen war, ist jetzt schwer zu sagen, da die Angaben speciell über den Beginn des Leidens zu ungenügend sind, and eine anatomische Untersuchung fehlt.

Es bleibt noch eine Beobachtung von Savory ${ }^{1}$ ) zu erwähnen, dass bei einer jungen Frau, bei welcher die Section einen Verschluss der linken Subclavia und Carotis ergab, das gleichseitige Auge ein Hornhantgeschwür mit unbekannter Genese aufwies. Ueber die Art des Geschwüres ist leider nur wenig angeführt. Dasselbe ging einher mit Entzündungserscheinungen der Umgebung, vergrösserte sich stetig und führte zum Schwunde der Sehkraft.

Wie stimmt nun die Hornhautaffection unseres Patienten mit dem zusammen, was wir über die sog. Keratitis neuroparalytica wissen?

Ich halte mich im Folgenden an die neueren Arbeiten von Seydel (33) - für den klinischen Befund -- und v. Hippel (34) - für den anatomischen.

1. Die Keratitis neuroparalytica begimnt annäbernd im Centrum der Hornhaut als Epithelveränderung, die bald zu za einem centralen Ulcus fuhrt.

2. Die centrale Nekrose der Hornhaut weist eine Abstufung der Intensität nach der Peripherie zu auf. In den peripheren Theilen findet man einen mehr oder weniger breiten, normal durchsichtigen Hornbautring.

3. Die nächste Umgebung des Geschwüres wird mit Rundzellen infiltrirt. Ebenso zeigt sich Infiltration mit Rundzellen rings um die Gefässe des Kammerwinkels, wie um die Randschlingengefässe der Hornhaut.

4. Bald entsteht Hypopyon, also Rundzellenanhänfung in

1) Med. Chir. Transact. 1856. 
Die Gefahren der Ligatur der grossen Halsschlagadern etc. $\overline{\partial 97}$

der vorderen Kammer und Infiltration der Iris und des Maschenwerkes des Ligamentum pccinatum.

5. Bakterienfärbung ergiebt oft ein negatives Resultat.

Es stimmt also dieses ganz und gar mit dem Befund überein, welchen die Hornhaut unseres Patienten aufwies. Es ist nicht ein Punkt, in welchem eine Abweichung $z u$ verzeichnen wäre.

Die Leukocyteninfiltration der Hornhaut wird wohl, gleich wie das, auch in unserem Falle in seinen Anfängen sich zeigende Hypopyon, aus den Gefässen des Kammerwinkels, der Iris, sowie des Randschlingennetzes geliefert und höchst wahrscheinlich durch den chemotaktischen Reiz ron Mikroorganismen, welche den einmal gesetzten Substanzverlust der Hornhaut zu ihrer Niederlassung benützen, hervorgerufen. Diese Annahme wird dadurch kaum entliräftet, dass im Ulcus keine Mikroorganismen nachgewiesen werden konnten. Auch im Falle ron r. Hippel blieb die bakteriologische Untersuchung völlig resultatlos.

Die Epitbelveränderungen, die sich in unserem Falle zeigten, wurden bisher in ihrer Gesammtheit, soweit meine Literaturkenntniss reicht, noch niemals beobachtet. Dies ist aber kein Grund gegen die von uns aufgestellte Diagnose Keratitis neuroparalytica, da eben auch noch niemals eine Keratitis neuroparalytica in so frischem Stadium zur anatomischen Untersuchung gekommen ist.-- Der einzige anatomisch genau beschriebene $F$ all von reiner Keratitis neuroparalytica rührt von v. Hippel her (nach v. Hippel) und war bereits neun Tage alt und die Hornhaut schon zum grössten Theile zerstört. Immerhin finden wir auch in unserem Falle in den oberen Epithelschichten, speciell über dem centralen Hornhautinfiltrate die von v. Hippel und andereu Autoren schon beschriebene Vertrocknung des Epithels. Ferner erinnert das Verhalten der Bowman'schen Membran in unserem Falle an das eigenthümliche Verhalten dieser Membran im Falle von r. Hippel. 
Nach alle dem kommen wir durch Ausschluss aller denkbaren Hornhautaffectionen für unseren Fall zur Diagnose: Keratitis neuroparalytica. Unser Krankheitsbild stimmt nach dem Vorausgegangenen überdies völlig mit dem überein, was wir bisher über die anatomischen Veränderungen der Hornhaut bei diesem seltenen Hornhautleiden kennen gelernt haben.

\section{II.}

Der zweite Fall betraf einen bisher stets gesunden, kräftigen Mann von 25 Jahren.

Anamnese vom 2. Mai 1894: Im August 1893 fiel derselbe von einer Laube einige Meter boch herunter und schlug dabei mit der linkon Scheitelstirngegend auf eine flache Steinplatte anf. Patient will nicht bewusstlos gewesen sein, sondern stand sofort wieder auf und ging nach Hanse. Am folgenden Morgen waren die ganze Schläfengegend, sowie die beiden linksseitigen Lider stark angeschwollen und blauroth verfärbt, ohne dass Schmerzent irgend wesentlicher Art bestanden. Dazu fiel dem Patienten gleichzeitig ein rythmisches, regelmässig blasendes Geränsch im linken Ohr auf, das seither fortwährend besteht. Ferner machte Patient die Beobachtung, dass das linke Auge stärker vorgetrieben war und dass die aufgelegte Hand eine Pulsatiou fühlte. 14 Tage nach dem Unfall nahm Patient seine Arbeit : wieder auf, ohne in der Bewegung der Augen irgendwie behindert zu sein. Auch von einer Veränderung der Sehschärfe will er nichts bemerkt haben. Erst von den Momente eines kleinen Unfalles an ein kleines Steinsplitterchen flog dem Patienten in das linke Auge, nno lädirte leicht und oberflächlich die Hornbaut im unteren Quadranten - glaubt er, eine etwas geringere Sehschärfe zu haben, und diese Beobachtung fübrte ihn auch zum Arzte. Blutung aus Mund, Nase oder Ohr hat nie stattgefunden. Status praesens rom 2. Mai 1894: Das linke Auge des Patienten prominirt dentlich im Vergleich zum rechten, so dass der Lidschluss nur knapp möglich ist. Die Bewegungen des Bulbus sind völlig normal und gehen in normaler Ausdehnung, wie anf der gesunden Seite ror sich. Zahlreiche deut- 
liche, subconjunctivale Gefässe sind sichtbar. Die Cornea zeigt in der Lidspaltenzone eine kleine Macula. Sonst weist sie keine Veränderungen auf und spiegelt überall gut.

Die Pupille ist eine Spur weiter als auf der rechten Seite. Sie reagirt aber gut, direct und consensuell auf Lichteinfall.

Sehschärfe: od. 1,0 mit $+0,5 \mathrm{sph}$.

os, $0,5 \mathrm{mit}+2,5 \mathrm{sph}$.

Ophthalmoskopischer Befund: Die Papille ist scharf begrenzt, etwas blass. Venen mässig verbreitert, etwas geschlängelt. Arterien vielleicht etwas enger als normal. Sonst ist nicht Besonderes im Hintergrunde zu sehen. Derselbe ist, wie ich ausdrücklich bemerken möchte, diffus roth, nicht getigert und lässt nirgends eine Spur von Chorioidealgefässen oder vou Unregelmässigkeiten in der Pigmentirung erkennen.

Perimetrische Veränderungen wurden nicht gefunden. Die auf das Auge aufgelegte Hand fühlt deutlich über dem Bulbus eine Pulsation, die bei Compression der Carotis sinistra sofort verschwindet. Am ganzen Schädel hört man ein mit dem Pulse der Carotis synchrones blasendes Geräusch, am stärksten an der linken Schläfe und über dem linken Auge.

Ueber dem rechten Auge ist das Geräusch schwächer als auf dem Schädel. Bei Compression der Carotis sin. verschwindet das Geräusch am Schädel sofort. Compression der Carotis dext. hat keinen Einfluss, doch bleibt bei Compression der linken Carotis ein leichtes, wie fernes systolisches Blasen, das durch Compression der rechten Carotis auch noch verschwindet. Das Geräusch rührt also fast ausschliesslich vom Kreislaufe der linken Carotis her.

Die Allgemeinuntersuchung ergiebt: Gut aussehender, kräftiger, junger Mann von guter Ernährung. Appetit gut. Stublgang in Ordnung. Keine Cyanose. Puls 78, regelmässig, ziemlich kräftig. Lungenbefund normal. Herz: Dilatation nach der rechten Seite hin, Grenze $1 \mathrm{~cm}$ rechts vom Sternalrand. Spitzenstess in der Mammillarlinie sehr deutlich in einer Ausdehnung von $3-4 \mathrm{~cm}$. Deutliches systolisches Blasen über der Sternummitte, ron da überall hin abnehmend. Abdominal nichts Besonderes.

Die Diagnose musste nach dieser Anamnese und dem vorausgehenden Status mbedingt auf traumatischen Exophthalmus pulsans, d. h. auf traumatische Ruptur der Carotis 
interna innerhalb des Sinus cavernosus gestellt werden. Der Patient wurde am 10. Mai 1894 auf die chirurgische Klinik des Herrn Prof. Kocher verlegt, um daselbst durch Ligatur der Carotis behandelt zu werden.

Krankengeschichte: Am 21. Mai 1894 wurảe von Prof. Kocher unter Cocainanaesthesie die Ligatur der Carotis ext. und int. sinist. ausgeführt. Es wurde die Carotis ext. wie int. unterbunden, um einen etwaigen Collateralkreislauf ron der Arteria carotis ext. der anderen Seite her zu verhüten.

Schnitt parallel dem horizontalen Kieferast, einen Finger breit unter dem Kieferwinkel. Eingehen vor dem Sternocleidomastoidens anf die Theilungsstelle der Carotis. Ligatur der Carotis ext. and int. oberhalb derselben. Blutstillung durch Ligatur (Seide für Ligatur). Zwei tiefe Năhte nach Austupfen mit Sublimat. Oberfächliche Naht. Collodialstreifen.

Patient fühlt im Momente der Ligatur der Carotis interna das Verschwinden des Geräusches in Kopf. Die Ligatur der Carotis externa macht kein weiteres Gefühl.

21. Mai: Patient fühlt sich Abends vollkommen wohl. Aeuserlich an Kopf und Gesicht kein Effect der Carotisligatur zu bemerken. Patient hört liein Sausen mehr. Objectiv dasselbe noch am ganzen Schädel, besonders am Scheitelbein links nachzuweisen.

22. Mai: Ratient klagt über Störungen am linken Auge. Das Sehvermögen beschränkt sich hier auf die Empfindung von Hell und Dunkel. Projection ist noch vorhanden, Patient fühlt sich wohl.

23. Mai: Die Augenspiegeluntersuchnng ergiebt eine stärkere Füllung und Schlängelung der Venen im linken Auge. Arterien sind dagegen dünn. Die Gegend der Macula auffallend blass. Tension ist geringer wie rechts.

24. Mai: Status idem. Tension normal.

25. Mai: Ebenso.

26. Mai: Entfernen der Nähte. Alles reactionslos,

28. Mai: Es zeigt sich, dass das Gesiehtsfeld auf der temporalen Seite bedeutend besser ist als nasal. Patient zählt Finger in $10 \mathrm{~cm}$ Entfernumg, sobald sie temporal von der Fixirlinie liegen, hat dagegen auf der nasalen Seite nur leichte Lichtempfindung durchaus ohne Wahruehmung ron Gegenständen. 
Die Gefahren der Ligatur der grossen Hạlsschlagadern etc. 601

Ophthalmoskopisch (nach Dr. Heim, Assistenzarzt der Augenklinils): Venen noch stärker gefüllt als normal und leicht geschlängelt, Arterien schmal. Der ganze Hintergrund etwas blass. Auffallend weiss sieht die Maculagegend in ziemlichem Umfange aus. Die Fovea hebt sich als röthlicher Fleck scharf von der weissen Umgebung ab. Also ganz das Bild der Embolie der Centralarterie.

3. Juni: Patient geht ohne Erlaubniss aus dem Bette ins Badezimmer, um sich die Füsse zu waschen, dabei scheint er sich vornüber geneigt zu haben, plötzlich sinkt er zu Boden, kann sich nicht mehr erbeben, nicht rufen. Nach einigen Minuten wird er so gefunden und flach auf's Bett gelegt.

Status: Sensorium frei. Patient versteht alles und führt auf der lïnken Körperseite alle gewünschten Bewegungen aus. Rechts ist dagegen völlige Lähmung von Arm und Bein zu constatiren (incl. Fuss, Zehen Finger, Hand).

Der Facialis wird bei mimischen Gesichtsbewegungen nur links innervirt, mit Ausnabme des Augenastes, der beiderseitig arbeitet (rechts schwächer). Zunge wird gerade vorgestreckt, weicht wenigstens nicht auffällig ab. Sprache absolut aufgehoben bei vorhandenem Sprachverständniss. Nach circa zehn Minuten steliten sich Bewegungen in den Fingern ein und in ganz geringem Grade im Handgelenke und Ellenbogen. Patient kann aber nicht schreiben (auch nicht mit der linken Hand). Beim Beginne der Aphasieprüfung antwortet Patient plötzlich mit Nein, nachdem er sich vorher sichtlich Mühe gegeben, etwas zu sagen, aber obne Erfolg. Er sagt uur mehrmals "Nein," dann "kaun er seinen Namen sagen, und in ganz kurzer Zeit (wenigen Minaten) spricht er wieder normal. Gleichzeitig nimmt die Facialislähmung ab, der Arm wird beweglicher, und zwar von der Hand gegen die Schulter hin. Im rechten Bein sieht man jetzt einige Contractionen des Quadriceps, noch ohne viel Effect. Die übrigen Muskeln sind geläbmt. Nach circa zwei Stunden bewegt Patient das Bein schon etwas, aber die Zehen noch nicht. Nach vier Stunden werden wieder alle Muskeln gebraucht. Ein auffallender Unterschied in den Reflexen rechts und links war nicht nachweisslich, höchstens eine leichte Steigerung rechts. Mittags konnte Patient wieder schreiben, wenn auch unsicher, sowie auch lesen. Kopfschmerzen, Ohnmacht, irgendwelche sensible Symptome fehlten während der ganzen Störung völlig. Abends 
war nur noch die ungleiche mimische Facialisinnervation auffallend (links stärker).

4. Juni: Am linken Auge hente etwas stärkere pericorneale, conjunctivale und episklerale Injection. Von den Erscheinungen des Insultes restirt noch eine leichte Parese des Facialis am rechten Mundwinkel.

8. Juni: Patient klagt über Stechen im Auge. Druckverband. Am Mundwinkel nichts Abweichendes mehr zu bemerken.

9. Juni: Die Injection um die Cornea ist nuter den Druckverbänden fast vollständig zurückgegangen.

15. Juni: Patient verlässt das Bett und fühlt sich völlig wohl.

21. Juni: Man hört am Schädel noch ein leichtes Sausen, dasselbe ist am stärksten über dem linken Stiruhöcker zu hören und erstreckt sich nach unten hin bis zum Oberkiefer, wo es unterhalb des Auges beiderseits noch deutlich zu hören ist. Arteria temporalis reehts dentlich zu fühlen, links nicht. Von einer Lähmung ist nichts mehr an den Extremitäten nachzuweisen. Patient selbst hört das sausende Geräusch, dasselbe sei aber viel geringer als vor der Operation. Er hört es am Tage nicht, nur in der Nacht macht es sich noch bemerkbar. Das linke Auge zeigt noch einen geringen Exophthalmus und leichte conjunctivale und episklerale Injection.

Gesichtsfeld: Auf der temporalen Seite nur noch schwache Lichtempfindung. Nasal werden keine Lichteindrücke mehr wahrgenommen. Farbensehen erloschen.

Das ophthalmoskopische Bild ist wenig verändert. 2. Juli. Patient wird entlassen.

Erst fünf Monate nach der Ligatur hatte ich Gelegenheit, den Patienten ophthalmoskopisch zu untersuchen: Der vor der Ligatur (wie ich mich selbst wiederholt überzeugt hatte) nicht getigerte, gleichmässig rothe Hintergrund bot nun einen äusserst ungewöhnlichen Anblick (Taf. XXII, Fig. 20).

Die Papille zeigte das Bild einer einfachen Atrophie, nur waren die Gefüsse bis anf einige dünne, rothe Füdchen, welche nicht über den Rand der Papille hinaus sich verfolgen liessen, verschwundeu. Die Aderhaut liess vor allem deutlich sämmtliche Chorioidealgefässe, wenigstens die grösseren Aeste, erkennen, zum Theil in annahernd normaler Färbung, zum grossen Theil gelblichweiss verfärbt, also mit deutlichen Spuren beginnender sklerose. Bezonders fiel es auf, dass der ganze Hintergrund gleichmässig mit zahllosen, kleinsten, schwarzen 
Die Gefahren der Ligatur der grossen Halsschlagadern etc. 603

Pünktchen besät war, welche die Aderhantgefässe überlagerten. An einigen Stellen der Peripherie fanden sich einzelne grössere Pigmentansammlungen. Das Auge war schon längere Zeit völlig erblindet.

Anderthalb Jahre später, als mir der Patient wieder zu Gesicht kam, fand ich den Hintergrund des Auges abermals völlig verändert (Taf. XXIII, Fig. 21). Gut drei Viertel desselben (nasal, oben, oben aussen, unten und unten aussen) zeigten sämmtliche, auch die feinsten Chorioidealgefässe blendend weiss verfärbt, also vollständig sklerosirt. Nur in der Gegend der Macula hatten die Gefässe noch etwas röthliche Farbe. Während im letzteren, noch relativ besser erhaltenen Gebiete des Hintergrundes die feinen zahlreichen Pigmentfleckchen noch zu sehen waren, konnte im Uebrigen völlig sklerosirten Bezirke der Aderhaut nichts mehr von Pigment entdeckt werden. Dasselbe hatte sich in grossen Klumpen an der Grenze gesammelt, wo der völlig sklerosirte grosse Aderhautbezirk mit dem relativ besser erhaltenen kleineren zusammenstösst. Die feinen Gefässchen auf der atrophischen Papille hatten ibre rothe Farbe nun ebenfalls in Weiss umgewandelt.

Zur Erklärung dieser Bilder müssen wir wohl an eine Fmbolie, wie bei unserem ersten Falle, vielleicht auch an eine Thrombose der Arteria ophthalmica und der Arteria centralis retinae denken, ausgehend von Gerinnungen im Aneurysma arterio-venosum, oder von einem von der Ligaturstelle aus ascendirenden Thrombus in der Carotis interna. Später handelte es sich wohl um langsam fortschreitende Thrombose fast sämmtlicher, die Aderhaut versorgenden Ciliargefässe, wie der Arteria centralis retinae. Warum ich hier nicht mit der gleichen Sicherheit die Diagnose: "Embolie" der Centralarterie stelle, wie bei unserem ersten Falle, sondern auch an die Möglichkeit einer Thrombose denke, ist darin begründet, dass in diesem zweiten Falle die Sehkraft langsam im Verlaufe von Wochen völlig erlosch, dass ferner die Netzhautgefässe nicht vom ersten Momente der Sehstörung an einen Stillstand der Circulation mit Agglutinationserscheinungen aufwiesen wie 
beim ersten Falle, sondem dass hier erst langsam in Verlaufe von. Wochen die Circulation in den Gefässen schwand. Dies sind Verhältnisse, die eher für Thrombose der Centralarterie sprechen; zu dem fehlt mir in diesem zweiten Falle eine anatomische Untersuchung, was gewiss eine vorsichtigere Diagnosenstellung rechtfertigt.

Für die am 13. Tage nach der Ligatur plötzlich auftretende und rasch wieder verschwindende Hemiplegie und Aphasie könnte man verschiedene Ursachen verantwortlich machen.

Man könnte an eine Haemorrhagie im Gebiete der motorischen Centren denken, ferner an eine ascendirende Thrombose in der Carotis interna und in der Arteria cereb. med, weiter an eine acute Anaemie oder venöse Hyperaemie in bestimmten, wohl corticalen Bezirken und endlich an eine Embolie einer Hirnarterie.

Gegen eine Blutung irgend welcher Art, ebenso gegen eine Thrombose in der Arteria cereb. med. spricht unbedingt die kurze Zeit, die bis zur völligen Wiederherstellung der gestörten Hirnfunctionen verstrich. Eine Blutung, sowie eine Thrombose bildet sich nicht so rasch zurïck. Eine acute Anaemie oder venöse Hyperaemie könnte, wenn wir vorderhand einen Embolus ausschliessen, nur durch Störungen in der Circulation vorübergehend hervorgerufen sein, und hier müsste man das Bücken für die Ursache dieser Circulationsstörung halten. Herr Prof. Kocher neigte bei der klinischen Besprechung des Falles der Ansicht zu, es möchte das Bücken des Patienten zu einer venösen Stase wohl in der Arteria cereb. med. geführt, und so die Hirnsymptome hervorgebracht haben. Eine eingehende Besprechung der Ursache dieser erst spät eintreffenden und rasch verschwindenden Hirnsymptome unseres Falle liegt ausserhalb des Rahmens dieser Arbeit. Ich begnige mich danit, die Erscheinungen genau beschrieben zu haben, möchte aber doch beifügen, dass nach meiner Ansicht auch 
Die Gefahren der Ligatur der grossen Halsschlagadern etc. 605

an eine Embolie gedacht werden muss, welche im Momente des Bückens des Patienten zu Stande kam. Ein ähnlicher Fall wurde von Maydl ${ }^{1}$ ) mitgetheilt und im Anschluss hieran auch die übrigen bereits bekannten, erst spät auf die Carotisligatur folgenden Hemiplegieen, mit oder ohne Aphasie, besprochen. Nach inm handelt es sich wohl um eine ascendirende Thrombose der Carotis interna bis $\mathrm{zu}$ ihrer Einmündung in den Circulus Willisii. Ein Stück des in letzterem vorragenden, noch nicht organisirten Thrombus wird bei irgend welchen heftigen Bewegungen abgelöst und in eine Hirnarterie geschleudert.

Die kurze Dauer der Hirnsymptome führe ich daraut zurück, dass eben ein solcher Thrombus frisch und noch nicht organisirt ist, und so leicht dem Blutstrome oder einem Spasmus der obturirten Arterie nachgiebt und sich zerbröckeln und auflösen oder comprimiren lässt und hiermit zum grossen Theile wenigstens dem Blute den Durchgang wieder eröffnet. Eigenartig ist bei unserem Falle das völlig erhaltene Bewusstsein bei totalem Ausfall der rechten Körperhälfte.

Die feine Pigmentirung der Netzhaut, welche ähnlich hier und da bei diffuser syphilitischer Chorioiditis, speciell bei congenitaler $(\mathrm{Haab})^{2}$ ), beobachtet wird, erklärt sich durch eine hochgradige Ernährungsstörung der Aderhaut und erinnert an die Pigmentirung der Netzhaut nach Durchschneidung der Ciliararterien beim Kaninchen (Wagen$\left.\operatorname{mann}{ }^{3}\right)$ ), und an die Bilder, die von mir mit der Wahrscheinlichkeitsdiagnose "Traumatische Ruptur von Ciliararterien beim Menschen" beschrieben wurden ${ }^{4}$ ).

Die spätere Anordnung des Pigments, nämlich seine

1) Allgem. Wiener med. Zeitg. 1886. Nr. 17 u. 18.

2) Atlas der Ophthalmoskopie. 2. Aufl. Fig. 39.

s) v. Graefe s Arch. f. Ophthalm. Bd. XXXVI. Abth. 4.

4) Mittheilungen aus Ḱliniken und med. Instituten der Schweiz. Bd. III. Heft 9. II. Traumatische Puptur der Ciliararterien. 
massenhafte Ablagerung dort, wo die völlig degenerirte Aderhaut an den noch relativ besser erhaltenen centralen Bezirk derselben angrenzt, wurde in einem Falle meiner friiheren Publication bereits erwähnt, - Fall 1 -. Sie ruft uns zudem die Lagerung des Pigments bei alten chorioiditischen Heerden in Erinnerung. Auch bei diesen Heerden finden wir meist das Pigment an der Grenze der atrophischen Aderhautbezirke in grossen Klumpen angehäuft, während der atrophische Bezirk selbst mehr oder weniger frei von Pigment ist.

An diese Grenze des absterbenden Bezirkes gegen den relativ besser erhaltenen Theil der Aderhaut und Netzhaut zieht wohl ron diesem letzteren Theile ausgehend, ein Resorptionsstrom nicht nur die Degenerationsproducte der nekrotischen Aderhaut und Netzhaut, sondern auch das in die Netzhaut eingewanderte Pigmentepithel.

Die Untersuchung unseres zweiten Falles ergiebt also als Ursache für die auf die Carotisligatur folgende Erblindung des gleichseitigen Auges: eine Embolie oder Thrombose der Centralarterie, auf welche sich eine fortschreitende Thrombose der Ciliararterien anschloss, welche zu einer Sklerose der Aderhautgefässe und zu einem Einwandern des gesammten Pigmentepithels in die nekrotische Netzhaut fiuhrte.

Die Embolie oderThrombose der Centralarterie nahm wohl ihren Ansgangspunkt ron Gerinnungen im Aneurysma arterio-venosum oder ron einem von der Ligaturstelle aus ascendirenden Thrombus in der Carotis interna.

\section{Sohlussbemerkung.}

Die zwei mitgetheilten Fälle lehren, dass nach Ligatur der Carotis communis und interna das gleichseitige Auge, ohne dass es sich äusserlich verändert, erblinden kann. 
Die Gefahren der Ligatur der grossen Halsschlagadern etc. 607

Sie weisen die bei solchen Fällen bisher noch unbekannte Erblindungsursache nach und zeigen hierdurch, ähnlich wie das Material des ersten Theiles, dass Schädigungen des Auges nach Carotisligatur nicht der Ligatur als solcher zur Last gelegt werden können, sondern dass dieselben vielmehr Complicationen der Ligatur darstellen, die bedingt sind durch die pathologischen Verhältnisse, unter denen oder wegen welchen die Ligatur zur Ausführung kam. Endlich bekräftigen unsere zwei Fälle voll und ganz den Schlusssatz des ersten Theiles dieser Arbeit, welcher lautet:

"Es können also die nach Carotisligatur bisher beobachteten Störungen des Sehorganes nicht dazu benützt werden, um die Behauptung zu beweisen, dass die blosse Unterbrechung der arteriellen Circulation in der Carotis fü das gleichseitige Auge von wesentlichem Einflusse sei."

Es bleibt mir noch übrig, meinen wärmsten Dank vor Allem den Herren Prof. Kocher und Pflüger in Bern für die gütige Ueberlassung der zwei Fälle auszusprechen. Ferner bin ich Herm Prof. Axenfeld in Rostock, welcher die grosse Güte hatte, meine Befunde an Netzhaut und Hornhaut unseres ersten Patienten an der Hand meiner Präparate zu controliren, zu tiefstem Danke verpflichtet. Auch Herrn Dr. Howald, Docent für pathologische Anatomie in Bern, gebührt mein warmer Dank für manche freundliche Rathschläge.

\section{Literaturverzeichniss des II. Theiles.}

1) Haab, Ueber die sog. Embolie der Centralarterie der Netzhaut. Correspondenz-Blatt f. Schweiz. Aerzte. S. 338. 1898.

2) Reimar, Die sog. Embolie der Arteria centralis retinae nnd ihrer Aeste. Arch. f. Augenheilk. Bd. XXXVII. Heft 4. S. 291. 1899 .

3) Michel, Das Verhalten des Auges bei Störungen im Circulationsgebiete der Carotis. Beiträge zur Ophthalmologie als Festgabe Friedrich Horner gewidmet. S, 1. 1881.

v. Graefe's Arehiv für Ophthalmoilogie. L. 3. 
4) Uhthoff, Bericht über die 27. Versammlung der ophthalmulogischen Gesellschaft Heidelberg. S. 21. 1898.

5) v, Michel, Leber Thrombenbildung im Stamme der Arteria centralis retinae. Bericht über die 27. Versammlung der ophthalmolog. Gesellschaft Heidelberg. 1898. S. 243.

6) Loring-Delafield, Americ. journ. of med. sciences. Bd. LXVII. S. $313,1874$.

7) Popp, Ueber Embolie der Arteria centralis retinae. Inaug,-Diss. Erlangen 1875.

8) Hirschberg, Ueber Enbolie der Netzhantarterie. Centralbl. f. prakt. Augenheilk. 8. Jahrg. 1884, S. 1.

9) Schweigger, Vorlesungen äber den Gebranch des Angenspiegels. Berlin 1864. S. 138.

Sch w e igger - Gre eff, Vorlesungen über den Gebrauch des Augenspiegels. 1895. S. 127.

10) Sichel (fils), Note sur un cas d'oblitération subite de l'artère centrale de la rétine. Arehives de Physiologie normale et pathologique. Tome IV. $1871 / 72$. p. 83 u. 207.

11) Priestley-Smith, British med. Joumal. April IV. p. 452. Jahresbericht pro 1874, \$. 406.

12) Nettleship, Lancet II. Oct. 2, 1870

13) Watson and Nettleship, Ophthalm. Hosp. Rep. VIII. 2. p. 251.1875.

14) Rothmund-Eversbusch, Mittheilungen aus der kgl. Universitäts-Augenklinik in München. Bd, I. 1882.

15) Elschnig, Ueber den Eintuss des Verschlusses der Arteria ophthalmica und der Carotis auf das Sehorgan. v. Graefe's Arch. f. Ophthalm. Bd. XXXIX. Heft 4. S. 151.

16) Baumgarten, Die sog. Organisation des Thrombus. Leipzig 1877.

17) A. v. Graefe, Ueber Émbolie der Arteria centralis retinae als Ursache plötzlicher Erblindung. v. Graefe's Arch. f. Ophthalm. Bd. V. Abth. 1. S. 150.1809.

18) Elschnig, Ueber die Embolie der Arteria centralis retinae, Arch. f. Augenheilk. Bd. XXIV. Heft 2, 1891.

19? Wagenmann, Experimentelle Untersuchungen über den Einfluss der Circulation in den Netzhaut- und Aderhautgefässen auf die Ernährung des Auges, insbesondere der Retina und über die Folgen der Sehnervendurchschneidung. v. Graefe's Arch. f. Ophthalm, Bd. XXXVI. Abth. 4. S. 1. 1890.

20) BIessig, Ein Fall von Embolie der Arteria centralis retinae. v. Graefe's Arch. f. Ophthalm. Bd. VIII. Abth. 1. S. 216. 1861.

21) Steffan, Ueber embolische Retinalveränderungen. v. Graefe ${ }^{\circ} \mathrm{s}$ Arch. f. Ophthalm. Bd. XII. S. 34. 1866.

22) Fis cher, Ueber die Embolie der Arteria cent. ret. Leipzig 1891.

23) Tü̉, Altérations de la macula lutea. C.-Embolie de l'artère centrale de la Rétine. Altérations maculaires et autres. Archives d'ophthalmologie. T. 16. No. 3ै. p. 166. 1896.

24) Schmidt-Rim pler, Beitrag z. Kenntniss der Embolie der Arteria cent. ret. v. Graefe's Arch. f. Ophthalm. Bd. XX. Abth. 2. 1874.

25) Schnabel und Sachs, Ueher unvollständige Embolie der Netzhatutschlagader und ihrer Zweige. Arch. f. Augenheilk. Bd. XV. 8. 11. 1885 . 
Die Gefahren der Ligatur der grossen Halsschlagadern etc. 609

26) Vanz, Anatomische Untersuchung eines an Embolie der Arteria cent. ret. erblindeten Auges. Festschrift zur Feier des 70. Geburtstages von H. v. Helmholtz, 1891.

27) Kern, Zur Embolie der Arteria cent, ret. Inaug.-Diss. Zürich 1892.

28) Wagenmann, Anatomische Untersuchungen über einseitige Retinitis haemorrhagica mit Secundär-Glankom ete. v. Graefe's Arch. f. Ophthalm. Bd. XXXVIII. Abth 3. 1892.

29) Wagenmann, Beitrag zur Kenntniss der pathologischen Anatomie der Embolie der Centralarterie. v. Graefe's Archiv $f$. Ophthalm. Bd. XL. Abth. 3. 1894.

30) Wagenmann, Beitrag zur Kenntniss der Circulationsstörungen in den Netzhautgefässen. v. Graefe's Arch. t.Ophthalm. Bd. XLIV. Abth. 2. 1897.

31) Ridley, Notes on a case of thrombosis of the central retinal artery. Ophthalm. Hosp. Rep 14. p. 264. 1895.

32) v. Michel, Ueber Erkrankungen des Gefässsystems der Arteria und Vena cent. etc. Zeitschr. f. Augenheilk Bd. II. Heft 1. 1899.

33) Bärri, Experimentelle Keratitis parenchymatosa, hervorgerufen durch Einwirkung auf das Endothel der Hornhaut. Inaug.-Diss. Basel 1895.

34) Grawehr, Beitrag zur Behandlung der Keratitis parenchymatosa. Inaug.-Diss. Basel 1897.

35) E. Seyde1, Ein Beitrag zur Lehre der Keratitis neuroparalytica. v. Graefe's Areh. f. Ophthalm. Bd. XLVIII. Abth. 1. 1899.

36) E. v. Hippel, Anatomische Befunde bei eitriger Keratitis des. Menschen, II. Keratitis neuroparalytica. v. Graefe's Arch. f. Ophthalm. Bd. XLVII. Abth. 1. 1898.

\section{Theil.}

Die Gefahren der Carotisligatur für das Leben des Menschen mit besonderer Berücksichtigung des Exophthalmus pulsans.

Es sei mir gestattet, in diesem letzten Theile meiner Arbeit kurz meine Ansichten über die Gefahren der Ligatur der Carotis communis und interna für das Leben des. Patienten ganz im Allgemeinen niederzulegen.

Meine Ansichten dariber stützen sich auf ein eingehendes Studium der Literatur über Carotisligaturen, so weit dieselbe mir zugänglich, war und so weit in den zwei ersten Theilen dieser Arbeit dieselbe angegeben ist. Ferner stützen sie sich auf zahlreiche eigene an Kaninchen vorgenommenen Experimente. 
Ich beabsichtige nun einerseits später, wenn meine Ansichten durch weitere experimentelle Untersuchungen bestimmter geworden, wenn ich über zahlreiche noch dunkle Punkte bessere Aufklärung erhalten, alle diese Ergebnisse an anderer Stelle eingehender zu veröffentlichen; anderseits aber balte ich mich doch für verpflichtet, meine Spezial-Collegen schon jetzt über die bisher gewonnezen Resultate zu unterrichten, da ja die Carotisligatur fur ein Augenleiden, das in der Mehrzahl der Fälle zuerst dem Ophthalmologen zugeht, den Exophthalmus pulsans, das wichtigste therapeutische Mittel darstellt, und es daher für den Ophthalmologen nur von grossem Interesse sein kann, zu wissen, welche Prognose er einer solchen Ligatur zu stellen hat.

Ein weiterer Grund, der mich bestimmt, über die Gefahren der Carotisligatur im allgemeinen meine Ansichten zu äussern, ist der, dass ich fürchte, es möchten manche Collegen (wie dies bereits geschehen) bei der Lectüre meiner zwei für das Auge ausnahmsweise ungünstig verlaufenden Fälle die Ansicht gewinnen, ich stände der Carotisligatur überhaupt wegen deren Gefahren feindlich gegenüber, was eine durchaus irrige Vermuthung wäre. Ein letzter Grund zum Veröffentlichen meiner Ansichten liegt darin, dass aus denselben jetzt schon für die Prophylaxe der Gefahren nach Carotisligatur und für die Behandlung aller einmal eingetretenen schlimmen and gefahrdrohenden Ereignisse nach der Ligatur therapentische Maassuahmen resultiren, welche ich allen Collegen, die in den Fall kommen, die Carotis zu ligiren, dringend an's Herz legen möchte. Nach meiner Ueberzengung wird durch diese Maassnahmen sicherlich der eine oder der andere Patient vom Tode nach Carotisligatur gerettet werden können, während der gute Erfolg der von mir angegebenen therapeutischen Mittel, wenn er sich allgemein bestätigen sollte, wiederum die Richtigkeit meiner Auffassung zu beweisen im Stande sein wird,

Die Ligatur der Carotis ist die älteste Behandlungsweise gegen Exophthalmus pulsans und hat unbedingt die meisten Erfolge aufzuweisen. Meist in drei bis sechs Wochen, in seltenen Fällen erst nach ein bis mehreren Jahren ist die Heilung vollendet. Was den Erfolg der Operation angeht, so fanden sich in $63 \%$ der Fälle (nach den Angaben 
Die Gefahren der Ligatur der grossen Halsschlagadern etc. 611

von Sattler und Keller) theilweise oder völlige Heilung, gewiss eine beachtenswerthe Zahl.

Als Hauptgrund gegen die Ligatur wurde und wird auch jetzt noch häufig die Gefährlichkeit der Operation für das Leben des Patienten angeführt. Sollte dieses schwer wiegende Bedenken berechtigt sein, so würde es die Anwendung der Ligatur nur auf die äussersten Nothfälle beschränken.

Wie verhält es sich nun mit der sog. Gefährlichkeit der Carotisligatur? Wenn wir die grossen statistischen Arbeiten von Pilz, Wyeth und Friedländer einsehen, so finden wir nach der Ligatur der Carotis communis eine ganz ungeheure Mortalität verzeichnet. Bei Pilz, der 609 Ligaturen zusammenstellte, findet man eine Mortalität von $43,2 \%$, bei $\mathrm{W}$ yeth, der über 789 Ligaturen verfügte, eine solche von $40,93 \%$. Friedländer, der über 216 neue Fälle berichtete, fand bei $42,3 \%$ der Fälle einen tödtlichen Ausgang.

Ich selbst habe 172 Fälle seit 1881-1897, also aus der neuesten Zeit, zusaimmengestellt und fand eine Mortalität von $20,3 \%{ }^{1}$ ).

Nach diesen Statistiken ist ersichtlich, dass wenigstens in früheren Jabren beinahe die Hälfte aller Operirten die Operation mit ihrem Leben bezahlen musste.

Wer sich aber duroh diese statistischen Zahlen erschrecken und einschüchtern lässt und von einer Carotisligatur bei Exophthalmus pulsans lieber gar nichts wissen will, thut Unrecht daran, denn es zeigt sich auch hier wieder, dass nur dann eine Statistik einen gewissen Werth besitzt, wem sie nicht zu allgemein gehalten ist, sondern neben ihren allgemeinen Angaben auch die verschiedenartigen speziellen Verhältnisse berücksichtigt. Sucht man nämlich bei seiner Statistik die verschiedensten Leiden, wegen welchen die Ligatur zur Anwendung gelangte auseinander $z \mathrm{u}$ halten, sucht man ferner zu ergründen, wesslalb bei den verschiedenen Fällen der Tod nach

$\left.{ }^{1}\right)$ Meine eigene Statistik gedenke ich später an anderem Orte zu veröffentlichen. 
der Carotisligatur eintrat, so wird man za völlig anderen Ansichten über die Gefährlichkeit der Carotisligatur kommen.

Während die Ligatur bei Blutungen (früher wenigstens, in der neueren Zeit hat sich das geändert) die böchste Mortalität aufweist, eine geringere bei Aneurysmen, eine noch kleinere bei Tumoren oder Exstirpationen von Tumoren, ist die Mortalität geradezu gleich Null bei Nervenleiden (Neuralgieen. Epilapsie, Elephantiasis), gegen welche früher ebenfalls die Carotisligatur als Heilmittel zur Anwendung kam.

Diese statistischen Beobachtungen, die tübrigens schon längst bekannt sind, lassen sich nicht anders erklären, als dass eben die Gefäbrlichkeit der Ligatur vor Allem ron dem Grundleiden abhängt, das sie nothwendig macht. Je gesünder und ungeschwächter der Patient, je tadelloser sein Circulationssystem, desto gefahrloser die Ligatur.

Prüft man weiter bei allen bereits veröffentlichten brauchbaren Fällen von Carotisligatur diejenigen, die mit Exitus letalis endeten, und forseht man nach der näheren Todesursache, so bann man in Bezug auf dieselbe mehrere Gruppen unterscheiden:

1. Fälle, in denen der Tod auf das schwere, auch ohne Ligatur schon tödtliche Grundleiden zurückzufübren ist.

2. Fälle, in denen eine nach der Ligatur und unabhängig von derselben auftretende intercurrente Krankheit den Tod des Operirten herbeifährte.

3. Fälle: in denen Infectionen, die allerdings bei dieser Operation meist viel gefährlicher sind als bei anderen Operationen, die Todesursache abgeben.

4. Fälle: in denen der Tod in Folge ron Nachblutungen erfolgte, die meistens doch ebenfalls auf Infectionen der Wunde beruhen.

Auf diese vier Gruppen (den Gruppen I bis IV in den beigegebenen statistischen Tabelien entsprechend) fallen $193=52,0 \%$ aller 371 Todesfälle nach Carotisligatur. Bedenkt man ferner, dass bei wenigstens 26.4\% der Fälle sich durchaus ungenügende krankengeschichtliche Angaben finden, aus denen die unmittelbare Todesursache nicht geschlossen werden kann, so bleiben nur 80 Todesfälle $=21,5 \%$ sämmtlicher 'Todesfälle übrig, iiber welche genauere Angaben vorliegen und welche nicht in den oben genannten viex Gruppen untergebracht werden können. 
Die Gefahren der Ligatur der grossen Halsschlagadern etc. 613

Eingehendes Studium dieser 80 Fälle mit Exitus ergiebt folgendes interessante Resultat:

Entweder handelt es sich bei diesen Fällen um Patienten mit Herzfehlern oder mit aus-

12,5 gesprochenen Gefässerkrankungen $10 \mathrm{mal}$ 2,6 Oder se handelt sich um Patienten, bei denen die Carotisligatur noch mit anderen schweren Eingriffen verbunden wurde, z. B. mit einer Ligatur des Truneus Anonymus oder der Subclavia oder Axillaris, Patienten, welche also demnach an schweren Gefässerkrankungen, Aneurysmen der Aorta oder Anonyma etc.

13,7 litten.

$11 \mathrm{Mal}$

Oder es handelt sich um Patienten mit Cachexie in Folge vorausgegangenen schweren

18,7 Blutverlusten etc. $15 \mathrm{Mal} 4,0$ Oder man hat es zu thun mit Patienten im hoben Alter, welche das 60. Jahr überschritten

21,2 haben. 17 Mal 4,5

Oder es sind Patienten, denen bei der Operation aus Versehen der Vagus oder Sym-

5,0 pathicus unterbunden wurde $4 \mathrm{Mal}$ Oder welche sich nach der Operation hatten

1,25 Excesse zu Schulden kommen lassen 1 Mal Ein Zusammenhang zwischen Exitus und Ca-

1,25 rotisligatur war unsicher 1 Mal Beide Carotiden wurden ligirt innerbalb von

1,2515 Minuten $1 \mathrm{Mal}$ Eine ascendirende Thrombose von der Ligaturstelle aus in die Hiruarterien fand sich als

5,0 alleinige auffindbare Todesursache $4 \mathrm{Mal}$ Endlich sind es Fälle, bei denen, trotzdem dass krankengeschichtliche Angaben vorliegen, nicht direct mit Sicherheit Momente angegeben werden können, welche den schlimmen Ausgang der Operation hätten herbeiführen 20,0 können. 16 Mal 4,3

Bei einer grossen Zahl dieser letzteren 80 Fälle nun, stellten sich kurz nach der Ligatur Hemiplegieen und Hirn- 
störungen ein, so dass der Tod meist durch Circulationsstörungen im nervösen Centralorgane seine Begrindung finclet.

Woher kommen aber diese Circulationsstörungen, welche bei so vielen anderen Fällen von Carotisligatur, besonders bei allen Fällen von Nervenleiden völlig fehlen?

Die erste Theorie ${ }^{1}$, zu welcher auch Pilz sich bekennt, fülurt die nach Ocelusion der Carotis communis auftretenden Gehirnerscheinungen anf die arterielle Anaemie, verbunden mit venöser Stase und hierdurch veranlasster Gewebsschädigung des Centralnervensystems zurück.

Ansicht ron Pilz: Durch den Verschluss der Carotis communis wird eine Zufulır des für die normale Versorgung des Centralnervensystems nöthigen Blutes, wenn auch oft nur für kurze Zeit, unterbrochen. Die nächste Folge ist eine Blutleere der kleinsten Arterien, ans welcher nach dem bekannten Princip des Zustandekommens eines venösen Rückflusses des Blutes bei fehleadem arteriellen Drucke eine venöse Hyperaemie eintreten muss. Dies der Grund der direct im Anschluss an Unterbindung der Carotis auftretenden Gehirnerscheinungen, welche wieder schwinden können, wenn die anderen, nicht abgeschlossenen, zum Gehiru führenden Bahnen in Folge der grossen Drucksteigerung im arteriellen System rasch vikariirend für die obturirte Arterie eintreten und so eine ausreichende Versorgung des Gehirns zu Stande bringen. Ist dagegen die rasche Ausbildung eines genügenden Collateralkreislaufes wegen der verminderten Ausdehnungstähigkeit der betreffenden Gefässe, oder aus anderen Gründen unmöglich, so werden die Folgezustände der Anaemie noch verstärkt durch die sich an die Anaemie anschliessende renöse Stase. Dadurch tritt eine, wenn anch zuweilen nur vorübergehende, Störung der das nervöse Centralorgan zusammensetzenden Elemente in ihrer Integritat ein. Diese können nach Wiederherstellang der normalen Ernährung noch zurückkehren, für den Fall, dass die Störungen nur vorübergehende waren, d. h. wenn lieine dauernden Structurveränderungen in Folge der Forübergehenden Anänie zurlickgeblieben. Den scheinbar wichtigen Einworf, dass nach dieser

1) Ich halte mich hier an die klare Darstellung der Theorieen die Zimmermann in seiner Arbeit gegeben. 
Die Gefahren der Ligatur der grossen Halsschlagadern etc. $\mathbf{6 1 5}$

Auffassung die Lähmungen sich direkt an die Ligatur anschliessen müssten, weist Pilz mit der Behauptung zurück, dass nach Absperrung der Blutbahn die Gewebe noch mit ernährungsfähiger Flüssigkeit durchtränkt seien; mit gesteigertem Verbrauch bilden sich Paresen heraus, die, wenn nicht schon neue Ernährungsbahnen hergestellt sind, zu Paralysen werden; bleibt dagegen die Blutversorgung durch die Collateralen aus, so bilden sich tiefergreifende Veränderungen der Gehirnmasse, da das Gewebe der Nekrose verfällt und entzündliche Processe sich in der Umgebung der erweichten Heerde abspielen. Pilz lässt es dahin gestellt, inwiefern eine eventuelle Thrombosirung der kleinen Arterien die directe Ursache der Auaemie sein kann.

Zweite Theorie von Friedländer: Ihr liegt die Arbeit von Tichomirow ${ }^{1}$ ) und von $\operatorname{Roux}^{2}$ ) zu Grunde. Ersterer zeigt den Verlauf und die Vertheilung der Hirnarterien als Resultate von Injectionsversuchen, (Resultate, welche bereits $1872^{3}$ ) von $\mathrm{Heubner}$ und 1874 von Duret ${ }^{4}$ ) in vollendeter, erschöpfender Weise zur Kenntnis gegeben wurden). Letzterer giebt Gesetze für die Abzweigung von Aesten unter dem Einflusse der bydrodynamischen Kräfte.

Unter zu Zugrundelegung dieser beiden Arbeiten denkt sich Friedländer das Zustandekommen der anämischen Hirnerscheinungen folgendermassen: „Mit Schluss einer Carotis muss nicht allein eine Unkehr der Stromesrichtung in dem neuneckigen Circulus Willisii, sondern sogar eine Veränderung der hydrodynamischen Kräfte in demselben erfolgen. Durch die Umkehr der Stromesrichtung muss ein Zusammenstoss von circulierendem Blut stattinden. Dadurch liessen sich die gleich nach der Ligatur auftretenden Erscheinungen, als durch Hemmung der Circulation bedingt, erklären. In der Folge kann es nun zu einem Ausgleiche kommen und können dann die Symptome verschwinden oder es hinterbleiben Gerinuungen

1) Tichomirow, Verhandlungen der kaiserl. Russ. Gesellschaft der Naturforscher. Moskau 1880. T. 38. Heft 2.

$\left.{ }^{2}\right)$ Roux, Verzweigung der Blutgefässe. Dissertation Jena 1878.

3) Centralblatt für die med. Wissenschaften. 1872. Nr. 52 und 1874: Die luetische Erkrankung der Hirnarterien.

4) Archives de physiologie normale et pathologique. II. Serie. T. I. Jan. 1874. 
innerhalb des Circulus arteriosus Willisii als Folgen dieses Zusammenstosses, wodurch einzelne Gefässe nach Art der Thrombose von der Circulation ausgeschlossen werden. Aber selbst, wenn es zum Ausgleiche dieses Aupralles kommt, ist die Gefahr noch nicht vorüber. Denn das unter veränderten bydrodynamischen Kräften fliessende Blut wird bestrebt sein, die Richtung der Aeste zu Gunsten dieser Kräfte zu verändern; dadurch werden nun die kleinen, senkrecht vom Circulns arteriosus Willisii zum Centralbezirk abgehenden Aeste eine Knickung erleiden und so eine Anämie gewisser Centralbezirke veranlassen müssen. Für die Circulationsabsperrung des peripheren Bezirkes gilt ein anderer Modus. Hier muss das Blut, welches unter schwächerem Drucke als es im Circulus Willisii und in den diesem zunächstgelegenen, zum Centrun gehenden Aesten fliesst, dank der vielen Anastomosen sich auf eine grosse Fläche zunächst in die Pía gleischsam ausgiessen. Da nun die treibende Kraft geringer ist, so wird die Blutversorgung hier keine regelmässige sein können; einzolne Bezirke werden zu viel Blat bekommen und dadurch die Gefässe anderer Bezirke durch den Druck von Seiten der dilatirten Gefässe kromprimiren, und so den an sich schwachen Blutstrom noch mehr hindern, in sie einzutreten. Dadurch wird das Parenchym undurchgängig, und es wird sich selbst mach schnell erfolgtem Ausgleich lur ungenügend oder gar nicht die Circulation in diesen gleichsam incarcerierten Bezirken herstellen."

Dritte Theorie yon Zimmermann: Zimmermann glaubte wie Friedländer, dass die centralen Erweichungsheerde auf andere Weise entstehen als die peripheren.

Die centralen Erweichungsheerde entstehen nach Zimmermann, wenn die zu den Stammganglien ziehenden Endarterien entweder durch Embolien oder Thrombosen verlegt werden. Ist die Verlegung dieser Gefässe eine vollständige, dann ist der Erweichungsheerd weiss, d. h. es entsteht eine weisse Nekrose; ist die Verlegung aber unvollständig, dann ist die erweichte Parthie gelbroth, es entsteht eine gelbe Nekrose.

Im Weiteren kömnen aber auch centrale Erweichangsheerde auftreten, wenn der periphere Thrombus der Carotis von der Ligaturstelle ascendirt und die zu den Stammganglien ziehenden Gefässe verlegt; dies soll eintreten, wenn beim Acte der Unterbindung eine Endothelrerletzung stattfindet.

Die peripheren Erweichungsheerde kommen rach Zimmermann zu Stande, wein die Collateralen in Folge atheroma- 
töser Entartung nicht im Stande sind, vicariirend für das unterbundene Hauptgefäss in ausreichender Weise einzutreten. Es entsteht dann eine unregelmässige Blutvertheilung in den Gefässen, als deren Folgen venöse Hyperaemie und Hydrops sich einstellt. Hierdurch wird aber der intracranielle Druck gesteigert, und die schon durch den herabgesetzten Blutdruck der unterbundenen Seite weniger Blut führenden Gefässe können auf diese Weise eine vollständige Occlusion erleiden.

Die Theorie von Zimmermann wähert sich also in Vielem wieder der Theorie von Pilz, welche zur Erklärung der Hirnsymptome im Gegensatz zu Friedläuder, nicht nur die durch die Ligatur bewirkte Anaemie, sondern auch eine secundäre venöse Hyperaemie zu Hilfe ruft. Die Ansichten von Friedländer über den Ursprung der centralen Erweichungen wie über die Genese der Compression der anämischen Rindenbezirke werden von $\mathrm{Zimmermann}$ in treffender Weise (S. 16-18) zurückgewiesen. Es ist daher überflüssig, hier näher daranf einzugehen. Zum Schlusse seiner Ausführungen erwähnt Zimmermann die Ansicht Russel's, dass wahrscheinlich mehr Bedingungen für das Zustandekommen der Hirnerscheinungen eine Rolle spielen als die bisher aufgestellten Theorieen voraussetzen.

Meine persönliche Ansicht stimmt mit der von Zimmer mann überein. Auch ich glaube, dass die isolirten centralen Erweichungsheerde auf andere Weise entstehen als die peripheren, wohl meist in Folge von Embolieen oder Thrombosen. Auch eine ascendirende Thrombose, wie sie bisweilen, im Ganzen aber selten, beobachtet wird, kann die Ursache der Hirnerweichung im Centrum, wie in der Peripherie, abgeben. Solche Thrombosen, die von der Ligaturstelle peripherwärts aufstiegen und in grössere Hirnarterien sich fortsetzten, sind mir nur wenige bekannt.

Es sind folgende Fälle:

1. Verneuil 1871, referirt in der Arbeit von Friedländer Fall 33, referirt in der Arbeit von Zimmermann Fall 23, S. 23: 30jähriger Mann. Wiederholte starke Blutverluste aus gut eiternder Wunde, Pyämie.

2 und 3. Zimmermann, 1891, l. c.: 
Fall 3, S. 36-40. Carcinoma linguae drittes Recidiv. 54 jähriger Mann.

Fall 4, S. 40-45. Aneurysma der Carotis communis und ext. 38 jähriger Mann.

4. Axenfeld, 1898, persönliche Mittheilung. Fall 8 im ersten Theile dieser Arbeit. 60 Jahre alter Mann mit Arteriosklerose. Carcinom.

5. Eigene Beobachtung. Erster Fall im II. Theile dieser Arbeit. Starke Blutverluste nach Operation von Carcinoma linguae. 45jähriger Mann.

Diesen fünf klinischen Beobachtungen möchte ich noch eine eigene experimentelle höchst interessante Beobachtung bein Kaninchen beifügen.

Einem gesunden Kaninchen wurden beide Carotiden ziemlich central and die rechte Arteria vertebralis gleichzeitig mit Seide unterbunden and unter aseptischen Cautelen die Haut vernäht.

Nach $1 \frac{1}{2}$ Stunden begann das Thier wie verrückt im Zimmer herumzuspringen, nachdem es aus seinem hohen Blechkasten, in dem es zur Beobachtung verblieben, in cinem Satze entronnen war. Das Thier sprang etwa eine Minute lang in hohen Sätzen wie wahnsinnig umher und schlug den Kopf an Tischfüsse, Kästen, kurz an alles, was ihm zufällig entgegen kam. In einem Sprunge gegen mich erreichte es meine Kniee. Nach einer Minute etwa, vielleicht schon etwas früher, trat plötzlich Ruhe ein, und das Thier blieb bewegungslos, die Vorderbeine gespreizt, den Kopf gesenkt in eigenthümlicher Zwangslage liegen. Erst nach einer Stunde folgte ein neuer Anfall mit Drehbewegungen, Vor- und Rückwartssprüngen, wobei der Kopf links und rechts an alles, was im Wege stand, wuchtig angeschlagen wurde. Zu gleicher Zeit schrie das Thier laut. Nach $1 / 2-1$ Minute von neuem Ruhe. Die Anfälle wiederholten sich nun in immer kürzeren Intervallen, es tratell deutliche Drehbewegungen und Sprünge im Kreise auf, zugleich mit tiefen laut hörbaren Inspirationen. Acht Stunden nach der Ligatur war die Inspiration laut und sehr beschleunigt, $70-100$ in der Minute. Bald wurden num aus den Springkrämpfen Rollbewegungen, indem das Thier ron Zeit zn Zeit gewaltsam umgeworfen und mehrere Male um seine Längsachse gedreht wurde. Dann folgten mehr und mehr all- 
gemeine Convulsionen, und das Thier verendete unter zunehmender Respirationsfrequenz neun Stunden nach der Ligatur. Die Section zeigte in beiden Carotiden, was ich sonst niemals bei meinen experimentellen Ligaturen beobachtet habe, eine ron der Ligaturstelle ausgehende ascendirende Thrombose, welche bis an die Stelle reichte, wo die Carotiden in den Schädel eintreten.

Warum bei seltenen Fällen, wie den angeführten, von der Ligaturstelle aus der periphere Thrombus ascendirt und in die Hirnarterien sich ausbreitet, ist mir nicht bekannt. Die Ansicht von Zimmermann ${ }^{1}$, dass eine Endothelverletzung des Gefässes beim Acte der Ligatur die Ursache abgebe, scheint mir nicht unanfechtbar, da eigentlich nach den experimentellen Untersuchungen 'von Baumgarten ${ }^{2}$ ) und von Forgue et Botherat") stets bei der Ligatur eines Gefässes die inneren Gefässschichten gesprengt, also lädirt werden und gerade diese Iäsion der Gefässwandung die Vorbedingung einer normal verlaufenden Organisation eines Thrombus bildet. -

Die peripheren Erweichungsheerde bilden sich meist bei mangelhafter Function der Collateralen, wobei es dann zu venöser Hyperaemie und einem Hydrops der Gewebe kommen kann. Was ist aber Schuld an der mangelhaften Function der Collateralen? Zimmermann giebt nach dem Vorgang von $\mathrm{Pilz}$ und anderen die arteriosklerotische Erkrankung der Collateralen an, wodurch dieselben entweder in ihrer compensatorischen Erweiterung gehindert werden oder gar von vornherein in ihrem Lumen bedeutend verengt sind. Auch gewisse, theils angeborene, theils erworbene Anomalieen im Circulus arteriosus Willisii können hier eine genügende Function der Collateralen hemmen. Auf solche Anomalieen hat Ehrmann(l.c.) und

1) Loc. cit. S. 29.

2) Die sog. Organisation des Thrombus. 1877. Leipzig.

3) Archives de médicine expérimentale et d'anatomie PathoIogique. T. VI. 1894. p. 473. 
dann Pilz zum ersten Male aufmerksam gemacht. Schliesslich glaubt Zimmermann mit Russel, dass wohl noch andere Momente für das Zustandekommen der Hirnerscheinungen eine Rolle spielen, als die bisher aufgestellten Theorieen voraussetzen. Als ein solches, nach meiner Ansicht durchaus wichtiges Moment für die mangelhafte Function der Collateralen und das Auftreten von Hirnstörungen möchte ich die Schwäche des Herzens, sei dieselbe eine Folge von Herzfehlern oder von Alter oder endlich von Ernährungsstörungen, Cachexieen, Anaemieen oder Arteriosklerose etc. bezeichnen.

Die Ueberzeugung, dass der Zustand des Herzens, sowohl bei der Erklärung der Genese von Hirnerscheinungen, als auch bei dex Therapie solcher drohenden Gefahren von Seiten des Centralorganes, viel zu wenig berücksichtigt werde, hat sich bei mir tief eingewurzelt.

Wird eine Carotis commanis ligirt, so hat das Herz, will es die gleiche Blutmenge in das Centralorgan senden und daselbst gleichmässig wie früher mittelst der vier grossen Hirnarterien vertheilen, kräftiger zu arbeiten, auch wenn sich die drei passirbaren Gefässe compensatorisch erweitern. Die Anforderungen, welche an das Herz gestellt werden, wachsen, so bald die Collateralen, also die drei übrig gebliebenen Hirngefässe und deren Aeste durch endarteriitische Erkrankung rigide and so nicht genügend erweiterungsfähig oder selbst wesentlich verengt sind.

Erlahmt da das Herz allmählich, dann werden wir sofort eime ungenügende unregelmässige Ernährung in den dem ligirton Gefässe entsprechenden Gebieten des Hirnes haben, als deren Folge entweder eine Thrombose oder eine venöse $\mathrm{Hy}$ perämie, ödematöse Durchtränkung und Erweichung der Hirnmasse auftreten kann.

Eミ wäre auch möglich, dass die Carotisligatur indirect die Herzinnervation afficirt, dadurch dass das Blut der gleichseitigen Vertebralarterie in das leere Carotisgebiet, das unter niederem Drncke steht, abfliesst and so die Medulla mit den Herzentren mangelhaft ernährt wird. Die später zu erwähnenden Experimente von Jobert an Pferden lassen eine 
Die Gefahren der Ligatur der grossen Halsschlagadern etc. 621

solche Vermuthung aufkommen. Ist nun aber thatsächlich das Herz in vielen Fällen von Hirnerweichung Schuld an dem schlimmen Ausgange der Operation, so ist auch zu verstehen, warum in der Regel die Hirnstörungen nicht unmittelbar an die Ligatur sich anschliessen, sonderı erst im Laufe von ein bis mehreren Tagen auftreten. Zur Erklärung dieser eigenartigen Erscheinung braucht man dann nicht wie Pilz nach so unwahrscheinlichen Vermuthungen zu greifen, sondern es ist von selbst einleuchtend, dass das Herz, an welches plötzlich durch die Ligatur grosse Anforderungen gestellt werden, anfangs bestrebt sein wird, denselben nachzukommen, erst allmählich wird seine Kraft erlahmen früher oder später, je nach seinem Kräftezustande, und so werden die Hirnerscheinungen eben nicht sofort, sondern erst nach einiger Zeit in die Erscheinung treten.

Betrachten wir nun unter diesen Gesichtspunkten unsere 80 Todesfälle, bei welchen die Ligatur als solche directere Todesursache war, da finden wir vor Allem bei 10 Fällen, also bei $2,6 \%$, Herzfehler und auffallende Gefässveränderungen verzeichnet.

Dann finden sich 17 Fälle $=4,5 \%$, bei denen der Patient schon in bedeutend vorgerücktem Alter stand.

Weiter finden wir $1 \overline{0}=4,0 \%$ der Patienten der Ligatur erliegen, welche durch Anaemie in Folge starker Blutverluste oder durch Cachexie in Folge ihres Grundleidens (meist inoperables Carcinom) erschöpft waren.

Dass ferner ein tödtlicher Ausgang nach Carotisligatur in Fällen bei denen ein Zusammenhang zwischen Exitus und Ligatur nicht sicher ist oder bei denen neben der Carotis auch noch die Anonyma, die Subclavia oder die grossen Halsvenen ligirt wurden, nicht einfach der Carotisligatur als solcher zur Last gelegt werden kann, ist selbstverständlich. Ebenso kann eine Ligatur des.Vagus oder des Sympathicus nur von ungünstigem Einfluss auf die Innervation und Thätigkeit des Herzens sein.

Es bleiben also von den 80 Todesfällen blos 16 Fälle, 
bei denen eine Todesursache bei vorhandenen krankengeschichtlichen Angaben nicht unmittelbar zu erkennen ist.

Allerdings litten auch eine Anzahl dieser 16 Patienten an Carcinom und waren schon in vorgerïcktem, wenn auch nicht hohem Alter, so dass wohl auch hier ein gewisser Grad von Cachexie als begünstigendes Moment für den schlimmen Ausgang kann angenommen werden. Bei einigen dieser $16 \mathrm{~Pa}-$ tienten müssen wir wohl mangelhafte Anastomosen oder Anomalieen im Circulus Willisii, wie sie thatsächlich hier und da vorzukommen pflegen, oder anderweitige Einflüsse, welche die Herzkraft schwächen oder zu Embolieen führen, annebmen. Leider fehlen uns bei diesen Fällen noch die nöthigen anatomischen Beweise bei der beklagenswerthen Mangelhaftigkeit der meisten Sectionsprotokolle.

Es zeigt also auch die Betrachtung der klinischen Fälle, welche nach Carotisligatur starben, dass die grosse Mehrzahl jener Patienten, bei welchen der Exitus weder auf das schwere Grundübel, noch auf eine intercurrente Krankheit oder auf eine Infection oder auf Nachblutung zurúckzuführen war, meistens, so weit genügende krankengeschichtliche Angaben vorlagen, Anlass zur Annahme einer Herzschwäche gaben.

Auch die klinische Erfahrung giebt demnach Aufschluss über die wichtige Rolle, welche dem Herzen bei manchem guten oder schlimmen Ausgang der Carotisligatur zukommt.

Meine Ueberzeugung ron der fundamentalen Bedeutung des Herzens für die Prognose einer Carotisligatur stïtzt sich zu dem auf eine grosse Zahl ron Thierexperimenten, welche sowohl von anderen Autoren, wie ron mir selbst vorgenommen wurden. Ich möchte die Resultate dieser Experimente hier nur kurz erwähnen und eine eingehendere Besprechung derselben mir für eine spätere Specialpublication reserviren.

1. Jobert vollfuhrte im Jabre 1840 bei acht Pferden die doppelseitige Carotisligatur und legte damals seime interessanten diesbezüglichen Beobachtungen der französischen Academie vor. 
Alle ligirten Pferde starben nach einigen Stunden nicht an Hirnlaesionen, sondern an den Symptomen der Blutstauung in den Lungen. Da die Pferde, wie überhaupt, die Solitungula sehr enge Vertebralarterien haben, ist bei ihnen die doppelseitige Ligatur ein sehr ernster Eingriff; um so auffalleader ist es, dass nicht die Hirnsymptome; sondern die Symptome einer gestörten und verminderten Herzkraft, welche sich in den Blutstauungen der Lungen äusserten, so praevalirten.

2. Ich selbst unterband bei 50 Kaninchen, bei der einen Hälfte in Chloroform-Narkose, bei der anderen ohne Narkose beide Carotides communes, oder beide Carotides cummunes sammt einer Vertrebalis oder beide Vertebralarterien, und eine Carotis. Von allen diesen Thieren, welche diese Ligaturen in der Regel ganz leicht überstanden, starben nur solche Thiere (sechs Stück), welche chloroformirt waren.

Unter den sechs an den Folgen der Ligatur verendeten Thieren fanden sich drei, bei denen die Todesursache anatomisch nachgewiesenes Lungenoedem war. Die meisten chloroformirten Thiere machten iuberhaupt nach der Ligatur eine mehr oder weniger lange. Periode einer merklichen Dyspnoe durch and wiesen öfter im Urin Eiweiss und Zucker nebst Cylindern auf Bei den nicht chloroformirten Thieren waren diese Erscheinungen weniger ausgesprochen.

Zwei Thiere gingen wach der Ligatur in Narkose, nach etwa drei Wochen an einer nephritisartigen Erkrankung zu Grunde. Diese zwei Thiere magerten unter stetiger Ausscheidung von massenhaftem Eiweiss und Cylindern im Urin enorm und ungemein rasch ab, zeigten einen auffallenden, fast unstillbaren Durst und die anatomische Untersuchung der Nieren wies in einer breiten Zone an der Grenze von Mark und Rinde zahlreiche, grössere, cystische Hohlräume, die mit flachem Epithel (wie Endotbel) bekleidet waren, nach. Ein drittes Thier, welches die gleichen Anfangssymptome zeigte, wurde schon am sechsten Tage getödtet. Man fand in den Nieren eine stark ausgesprochene Hyperaemie, speciell zwischen Mark und Rinde.

Eine weitere auffallende Erscheinung war, dass zablreiche (nicht alle) Kaninchen, deuen ich mehrere Hirngefässe unterbunden hatte, und die mit dem Leben davongekommen waren, nach sechs bis acht Wochen (nach dieser Zeit wurden sie getödtet), bedeutende Herzhypertrophie aufwiesen, welche auf das Deutlicliste dafür sprach, dass an das Herz seit der Liv. Graefe's Archiv für Ophthalmologie. L. 3. 
gatur der Halsgefässe vermehrte Anforderungen gestellt worden waren ${ }^{1}$ ).

Also anch das Experiment bestätigt, ebenso wie die klinische Erfahrung, die Richtigkeit der Anschauung, dass bei der Carotisligatur der Zustand des Herzens einen wesentlichen Einfluss auf den Endausgang auszuiben rermöge. Was haben wir nun nach alle dem rein theoretisch von der Prognose der Carotisligatur bei Exophthalmus pulsans zu denken?

Wir haben es bei Exophthalmus pulsans meist nicht mit geschwächten, wirklich kranken cachektischen oder anämischen Patienten zu thun. Die Affection stellt an das Herz keine besonderen Ansprüche. Wir laben daher im Allgemeinen unbedingt eine gute Prognose zu stellen. Gefahren drohen dem Patienten auch hier wohl nur, wenn der Patient alt und gebrechlich oder an einem Herzfehler leidet. Endlich werden die Fälle mit idiopathischem Exophthalmus pulsaus eine schlechtere Prognose aufzuweisen haben, als die traumatischen, weil bei ersterem meist Gefässerkrankungen

1) Die Vertebralarterie kann auf folgende Weise äusserst leicht und ohne jegliche ernstere $\nabla$ erletzung, ebenso wie ohne jeglichen Blutverlust ligirt werden: Medianschnitt rom Manubrium sterni etwa $6-8 \mathrm{~cm}$ gegen das Zungenbein zu. Durchtrennung der Halsfascie, Einführung von zwei grossen Haken. Auf den einen wird der M. Sterno-Cleidomastoideus mit den tiefen grossen Halsgefässen und Halsnerven genommen und nach aussen abgezogen, auf den zweiten die medialen Halsmuskeln, der Oesophagus und die Trachea und medianwärts abgezogen. So erhält man ohme Blutverlust die Vorderfläche der Wirbelsäule mit dem Longus colli in Sicht. Indem man die Hacken genügend gegen das Sternum zu hinunter schiebt, wird jener spitze Winkel deutlich frei gelegt, welchen die Scaleni bilden, indem sie an die Wirbelsäule treten. Gerade in der Spitze dieses Winkels findet sich die Vertebralarterie unbedeckt und kann mit Leichtigkeit nach etwas Uebung unterbunden werden. Es werden anf diese Weise die schweren Verletzungen, wie Resection des Manubrium sterni etc. vermieden, welche Kussmaul und Tenner, um. ähnliche Ziele zu erreichen, ansfühen mussten. 
Die Gefahren der Ligatur der grossen Halsschlagadern etc. 625

dem Leiden zu Grunde liegen, Beobachtungen welche bereits von Sattler und allen späteren Autoren, welche sich mit der Ligatur bei Exophthalmus pulsans beschäftigten, voll und ganz gewürdigt wurden.

Wie bestätigt die Praxis diese theoretischen Ausichten von der relativen Ungefährlichkeit der Carotisligatur bei Exophthalmus pulsans?

Nach den Arbeiten von Sattler und Keller wurden bis auf den heutigen Tag 113 Ligaturen der Carotis communis bei Exophthalmus pulsans ausgeführt, nämlich: 76 bei traumatischem Exophthalmus pulsans, 10 bei Exophthalmus pulsans in Folge von Tumoren, 27 bei idiopathisehem Exophthalmus pulsans.

Von den 76 Ligaturen bei traumatischem Exophthalmus pulsans starben $4=5,26 \%$. Alle vier gehören der Zeit vor 1880 an. Die 32 traumatischen Fälle, welche seit 1880 ligirt wurden, kamen alle mit dem Leben davon. Drei dieser vier Todesfälle ans frïherer Zeit beruhen anf schweren Infectionen. Der vierte Fall auf Nachblutungen', die wohl auch auf Infectionen zurückzuführen sind. Diese Todesfälle sind also nicht der Ligatur als solcher anzurechnen.

Von den zehn Fällen von Exophthalmus pulsans in Folge von malignen Tumoren starb kein Fall unmittelbar oder nachweislich in Folge der Operation. Von den 27 idiopathischen Fällen starben nach der Ligatur sechs Patienten, 22,2\%. Einer dieser Fälle starb in Folge von Nachblutung bei Infection. Drei dieserr Fälle hatten das 60. Jahr (zwei das 65. Jahr) übersehritten. Ein Fall betraf ein anaemisches Mädehen, und nur bei einem einzigen Falle konnte keine unmittelbare Todesursache gefunden werden. Die Patienten war 45 Jahre alt und von zarten Aussehen.

Schliessen wir die Infectionen aus der Statistik aus, so kommen wir zu folgendem statistischen Ergebnisse:

1. Unter den traumatischen Fällen von Exophthalmus pulsans starb kein einziger an der Ligatur der Carotis communis.

2. Unter den Fällen von Exopthalmus pulsans in Folge von Tumoren ebenfalls keiner.

3. Nur die idiopathische Form von Exopthalmus pulsans hat einige Todesfälle nach der Carotisligatur aufzuweisen, nämlich auf 26 Fälle 5 Mal Exitus let. $=19,2 \%$. Schliesst man 
die Fälle aus, bei denen die Operirten älter als 60 Jahre waren, so hat man $2 \mathrm{Mal}$ Exitus let. auf 23 Fälle $=8,7 \%$. Von diesen zwei Fällen war die eine Patientin noch anaemisch.

$\mathrm{Zu}$ bemerken ist noch, dass bei sieben Fällen fon traumatischem Exophthalmus pulsans beide Carotiden in bestimmten Intervallen ligirt wurden, und dass von diesen sieben $\mathrm{Pa}$ tienten kein einziger starb.

Resumiren wir nochmals: Bei 113 Fällen von Carotisligatur bei Exophthalmus pulsans fanden sich 10 Exitus let. $=8,84 \%$, oder wenn die fünf Infectionen und Nachblutungen, die auch auf Infectionen beruhen, ausgeschlossen werden: bei 108 Fällen $=5$ Exitus let. $=4,6 \%$; endlich bei Ausschluss der drei Patienten, welche das 60. Jahr überschritten hatten, bei 105 Fällen $=2$ Exitus let. $=1,9 \%$.

Eine weitere Frage, die hier doch auch besprochen werden soll, ist die, nach dem Einfluss des Alters auf die Gefährlichkeit der Carotisligatur. Bei den Chirurgen gilt im Allgemeinen eine Ligatur der Carotis communis bei allen Patienten, welche das 40. Jahr überschritten haben, für gefährlich und zwar wegen den meist schon rorhandenen Gefässveränderungen und der in Folge hiervon bereits verminderten Elasticität der Gefässe, welche eine ausreichende Collateralversorgung erschwert.

Wollen wir uns ein objectives Urtheil über die Richtigkeit dieser Anschauung der Chirurgen. verschaffen, und wollen wir wirklich die Rolle kenuen lernen, welche das AJter für die mehr oder weniger grosse Gefährlichkeit der Carotisligatur bei bejahrteren Patienten spielt, so dürfen wir durchaus nicht die Gesammtheit der bisher beschriebenen Carotisligaturen in's Auge fassen, sondern wir müssen uns anbedingt an die einzelnen Gruppen der Ligaturen halten, welche je nach dem Grundleiden, wegen dem die Ligatur ausgeführt wurde, aufgestellt sind. Nur auf diese Weise kann es uns gelingen, festzustellen, worauf bei einer allenfalls gefundenen grösseren Mortalität bei höherem Alter diese Steigerung der Mortalität zurückzuführen ist, denn es ist in dem einzelnen Falle durchaus nicht von vornherein klar, ob ausschliesslich das vor- 
gerückte Alter des Patienten und die bei höherem Alter angeblich vorhandenen Gefässveränderungen die Gefährlichkeit der Ligatur der Carotis steigerte, oder ob bei dem hohen. Alter des Patienten das Grundleiden, z. B. eine heftige Blutung, trotz der Ligatur den Tod herbeigeführt, oder endlich, ob eben in einem vorgeschrittenen Alter die Ligatur zusammen mit bestimmten Grundleiden den schlimmen Ausgang verschuldet hat.

Soll uns ausschliesslich der Einfluss des Alters auf die Gefährlichkeit der Carotisligatur klar vor Angen treten, so müssen wir zu unserer Betrachtung jene Fälle von Carotisligatur wählen, bei denen das Grundleiden, wegen dessen ligirt wurde, eben bei der Feststellung der Ursachen eines etwa erfolgten Todes vernachlässigt werden kann, mit anderen Worten, in denen das Grundleiden in keiner Weise ernstlich die Gesundheit und die Widerstandskraft des menschlichen Organismus schädigt, oder doch noch nicht im Momente der Ligatur der Carotis geschädigt hatte. Als der beste Repräsentant muss die Gruppe der Carotisligaturen gegen Nervenleiden und Elephantiasis faciei gelten. Annäbrend gleich gut zu gebrauchen sind zu diesem Zwecke die Carotisligaturen bei Exophthalmus pulsans traumaticus, dann bei Exophthalmus pulsans in Folge von Orbitaltumoren, vorausgesetzt, dass die Tumoren noch nicht $\mathrm{zu}$ weit vorgeschritten sind und $\mathrm{zu}$ allgemeinem Kräfteverfall gefübrt haben. Weniger gut, aber immer noch besser, als die Ligaturen bei den übrigen Leiden, sind zu gebrauchen, die Ligaturen bei Exophthalmus pulsans idiopathicus, weil wir hier eben doch schon Gefässveränderungen treffen, die oft nicht bloss in der Carotis interna der erkrankten Seite localisirt sind, sondern viel allgemeinere Ausdehnung erreicht haben. Endlich könnte man allenfalls noch, wenn auch nur mit gewissen Beschränkungen, jene Gruppe von Carotisligaturen gebrauchen, bei der die Ligatur angewandt wurde, um das Wachsthum gewisser Tumoren zu beschränken. Hier hat allerdings, leider nur zu oft, schon das Allgemeinbefinden der $\mathrm{Pa}$ tienten schwer gelitten, und wir können dann nicht mehr den alleinigen Einfluss des Alters auf den Ausgang der Ligatur studiren.

Betrachten wir uns vor Allem die Gruppe der Ligaturen gegen Nervenleiden näher. Die folgende Tabelle zeigt sie nach dem Lebensalter der ligirten Patienten geordnet. 
Tabelle I.

Ligaturen bei Nervenleiden und Elephantiasis faciei.

\begin{tabular}{c|c|c|c}
\hline Altersjahr & $\begin{array}{c}\text { Zahi } \\
\text { der Ligaturen }\end{array}$ & Heilung & Exitus \\
\hline $0-10$ & 0 & & - \\
$10-20$ & 6 & $6=100 \%$ & - \\
$20-30$ & 8 & $8=100$ & - \\
$30-40$ & 3 & $3=100$ & - \\
$40-50$ & 6 & $6=100$ & - \\
$50-60$ & 4 & $4=100$ & - \\
$60-70$ & 2 & $2=100$ & - \\
Alter unbekannt & 12 & $11=91,6$ & 1 \\
\hline Summe & 41 & 40 & 1
\end{tabular}

Aus dieser Tabelle scheint sich zu ergeben, dass das Alter des Patienten überbaupt keinen Einfluss auf den Ausgang der Carotisligatur ausübt. Die Zahl der verfügbaren Ligaturen ist allerdings klein. Nur zwölf Patienten zwischen 40 und 70 Jahren wurden ligirt and kamen alle mit dem Leben davon. Es ist daher erwünscht, bei der Gruppe des Exophthalmus pulsans traumaticus etc. ein grösseres Material zur Verfügung zil haben.

\section{Tabelle II.}

Ligaturen bei Exophthalmus pulsans traumaticus.

\begin{tabular}{|c|c|c|c|c|}
\hline Altersjahr & Zabl & Heilung & Exitus let. & $\begin{array}{l}\text { Nummer des Falles } \\
\text { mit Exitus let. }\end{array}$ \\
\hline $\begin{array}{c}0-10 \\
10-20 \\
20-30 \\
30-40 \\
40-50 \\
50-60 \\
60-70 \\
\text { Alter } \\
\text { unbekannt }\end{array}$ & $\begin{array}{r}1 \\
13 \\
17 \\
17 \\
14 \\
5 \\
0\end{array}$ & $\begin{aligned} 1 & =100 \% \\
12 & =92,3 \\
16 & =94,1 \\
16 & =94,1 \\
13 & =92,8 \\
5 & =100 \\
& - \\
9 & =100\end{aligned}$ & $\begin{array}{c}1=\overline{7}, 7 \% \\
1=5,9 \\
1=5,9 \\
1=7,2 \\
-\end{array}$ & $\begin{array}{l}\text { Sattler 57, Infection } \\
\text { Sattler 93, Nachblutung } \\
\text { Sattler 101, Infection } \\
\text { Sattler 40, Infection }\end{array}$ \\
\hline Summe & 76 & 72 & 4 & \\
\hline
\end{tabular}


Die Gefahren der Ligatur der grossen Halsschlagadern etc. 629

Tabelle III.

Ligaturen bei Exophthalmus pulsans in Folge Tumoren.

\begin{tabular}{c|c|c|c|c}
\hline \hline Altersjahr & $\begin{array}{c}\text { Zahl } \\
\text { d. Ligaturen }\end{array}$ & Heilung & Exitus let. & $\begin{array}{c}\text { Nummer des Falles mit } \\
\text { Exitus let. }\end{array}$ \\
\hline \hline $0-10$ & 2 & $2=100 \%$ & - & \\
$10-20$ & 1 & $1=100$ & - & \\
$20-30$ & 3 & $3=100$ & - & \\
$30-40$ & 2 & $2=100$ & - & \\
$40-50$ & 2 & $2=100$ & - & \\
$50-60$ & - & - & - & \\
$60-70$ & - & - & - & \\
Alter & & - & - & \\
unbekannt & - & - & - & \\
\hline Summe & 10 & 10 &
\end{tabular}

Tabelle IV.

Ligaturen bei Exophthalmus pulsans idiopathicus.

\begin{tabular}{|c|c|c|c|c|}
\hline $0-10$ & - & - & - & - \\
\hline $10-20$ & 2 & $2=100 \%$ & - & \\
\hline $20-30$ & 8 & $6=75$ & $2=25 \%$ & $\begin{array}{l}\text { Sattler 88. Anaemie } \\
\text { Keller } 81 . \text { Nachblutung }\end{array}$ \\
\hline $30-40$ & 5 & $5=100$ & - & \\
\hline $40-50$ & 7 & $6=85,7$ & $1=14,3$ & $\begin{array}{l}\text { Sattler 102. Patient ron } \\
\text { zartem Aussehen }\end{array}$ \\
\hline $50-60$ & - & - & - & \\
\hline $60-70$ & 4 & $1=2 \overline{0}$ & $3=75$ & $\begin{array}{l}\text { Sattler 67. Nachblutung } \\
\text { Sattler 41. Gefässverän- } \\
\text { derung } \\
\text { Keller 79. 67jähr. Mann }\end{array}$ \\
\hline $\begin{array}{c}\text { Alter } \\
\text { unbekannt }\end{array}$ & 1 & $1=100$ & - & \\
\hline Summe & 27 & 21 & 6 & \\
\hline
\end{tabular}

Ligaturen bei sämmtlichen Arten von Exophthalmus pulsans.

\begin{tabular}{r|r|r|r|r}
$0-10$ & 3 & $3=100 \%$ & - & \\
$10-20$ & 16 & $15=93,7$ & $1=6,3 \%$ \\
$20-30$ & 28 & $25=89,2$ & $3=10,8$ & \\
$30-40$ & 24 & $23=95,8$ & $1=4,2$ & \\
$40-50$ & 23 & $21=91,3$ & $2=8,7$ & \\
$50-60$ & 5 & $5=100$ & $-\overline{75}$ & \\
$60-70$ & 4 & $1=25,0$ & $3=7,0$ & \\
$\begin{array}{c}\text { Alter } \\
\text { unbekannt }\end{array}$ & 10 & $10=100$ & - & \\
\hline Summe & 113 & 103 & 10 &
\end{tabular}




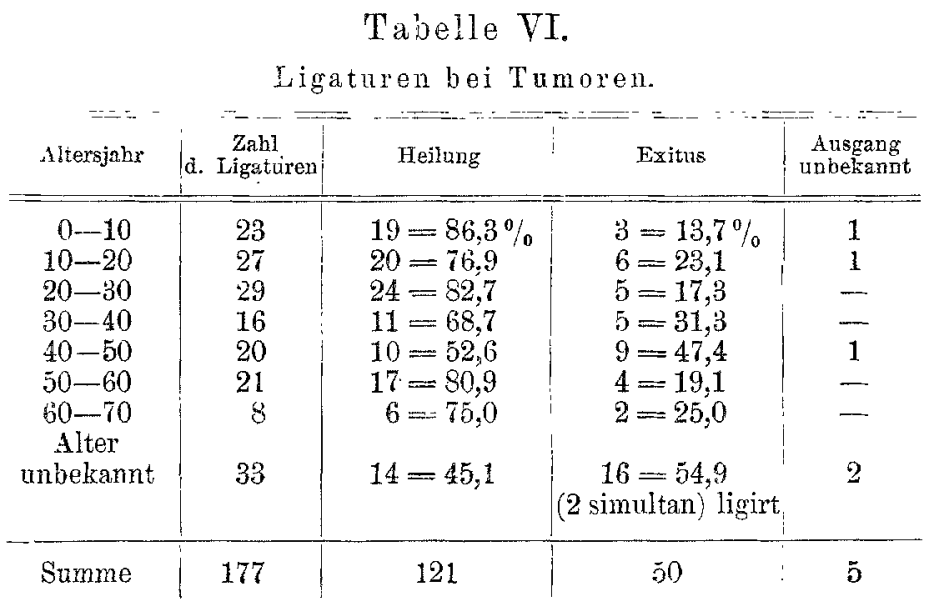

Tabelle II $-\dot{\mathrm{V}}$ zeigt die Ligaturen bei Exophthalmus pulsans (soweit sie in den Arbeiten von Sattlex und Keller zusammengestellt sind) ebenfalls nach dem Alter der ligirten Patienten geordnet.

Beim Exophthalmus pulsans traumaticus finden wir, ähnlich wie bei den Nervenleiden, keinen sichtbaren Einfluss des Alters anf die Gefährlichkeit der Carotisligatur, ebenso bei dem Exophthalmus pulsans in Folge von Orbitaltumoren. Bei beiden zusammen wurden 21 Patienten zwischen dem 40. und 60. Lebenjahre ligirt und nar einer von ibnen starb, und dieser erlag, wie aus den Tabellen über die Todesursachen nach Carotisligatur zu ersehen ist, durchaus nicht der Carotisligatur als solcher, sondern einer bei der Ligatur erfolgten Wundinfection.

Beim Exophthalmus pulsans idiopathicus finden wir insofern etwas ungünstigere Verhäitnisse, da hier von den sieben, zwischen dem 40.-50. Jahre ligirten Patienten der eine starb; derselbe war von zartem Aussehen, wie in der betreffenden Krankengeschichte zu lesen ist. Feruer starben von den vier, zwischen dem 60.-70. Lebensjahre ligirten Patienten drei, also $75 \%$, Doch entstand bei dem einen dieser Fälle eine starke venöse Blutung bei der Ligatur, und zahlreiche Nachblutungen haben wohl endlich den schlimmen Ausgang herbeigeführt. (Fall 41, Sattler). Bei dem zweiten Falle ist ausdrücklich angegeben dass der Patient corpulent war (Fettherz?), und dass die Aorta und wohl auch die anderen Körperarterien 
atheromatös entartet waren (Fall 67, Sattler). Der dritte Fall (Keller, Fall 79) war 67jälirig, und es lässt sich aus den gemachten Angaben nicht auf besondere, den Tod begünstigende Verhältnisse schliessen, aber schon der Umstand, dass der Exophthalmus pulsans idiopathisch ist, setzt eigentlich Gefässveränderungen voraus. Wir können also bei Exophthalmus pulsans idiopathicus böchstens einen schädigenden Einfluss des bohen Alters über 60 Jahre auf den Ausgang der Ligatur constatiren. Zwischen 40-50 Jahren haben wir ja hier sogar eine geringere Mortalitäten als zwischen 20-30 Jahren.

Also auch die Tabellen II-V über die Ligaturen der Carotis bei Exophthalmus pulsans zeigen in keiner Weise einen wesentlichen Einfluss des hohen Alters des Ligirten auf den Ausgang der Carotisligatur, höchstens scheinen Patienten, welche das 60. Jahr überschritten haben, etwas mehr gefährdet $\mathrm{zu}$ sein.

Tabelle VI zeigt die Ligaturen bei Tumoren, um dieselben durch Entziebung der Nahrung zum Schwinden zu bringen. Obgleich wir es hier oft mit Patienten zu thun baben, die in Folge von inoperablen Carcinomen schwer in ihrem Allgemeinbefinden geschädigt waren, können wir doch auch bier keinen Einfluss des Alters, selbst nicht des höchsten, auf den Ausgang der Carotisligatur ersehen. Ja wir finden, dass im Alter von 60-70 Jahren relativ weniger Patienten der Ligatur erlagen, als im Alter von 30-40 Jahren, dass ferner im Alter von 50-60 Jahren relativ mehr Patienten mit den Leben davon kamen $(80,9 \%)$, als im Alter von $40-50$ Jahren $(52,6 \%)$, oder im Alter von $30-40$ Jahren $(68,7 \%)$, oder endlich selbst im Alter von 10-20 Jahren $(76,9 \%)$.

Aus der Betrachtung dieser Tabellen muss mit Nothwendigkeit der Schluss gezogen werden, auch wenn derselbe etwas ungewohnt lanten sollte, dass bei allen Leiden, welche das Allgemeinbefinden des Patienten nicht wesentlich alteriren oder wenigstens noch nicht $z \mathfrak{u}$ sehr im schlimmen Sinne alterirt haben, also bei Nervenleiden, Elephantiasis faciei, Exophthalmus pulsans, oder Tumoren, ferner bei allen Leideu, bei denen keine besonders ausgesprochenen Gefässerkrankungen sich finden, wie sie bei Alkoholismus oder Lues vorkommen, und die die Grundlage von Aneurysmen abgeben können, das höhere Alter des Patienten keinen wesentlichen Einfluss auf den Ausgang der Ligatur auszuüben vermag. Etwas anders liegen die Verhältnisse bei den Aneurysmen, bei den Exstirpationen, und bei 
632

A. Siegrist.

den Blutungen, bei welchen die Carotisligatur ausgeführt w'urde. Tabelle VII - X zeigt die einzelnen Fälle wiederum dem Alter nach geordnet.

\section{Tabelle VII.}

Ligaturen bei Aneurysmen, einschliesslich Exophthalmus pulsans traumaticus und idiopathicus.

\begin{tabular}{c|c|c|c|c}
\hline Altersjahr & $\begin{array}{c}\text { Zahl } \\
\text { d. Ligaturen }\end{array}$ & Heilung & Exitus & $\begin{array}{c}\text { Augang } \\
\text { unbekannt }\end{array}$ \\
\hline $0-10$ & 6 & $5=83,3 \%$ & $1=16,7 \%$ & - \\
$10-20$ & 16 & $14=87,5$ & $2=12,5$ & - \\
$20-30$ & 51 & $40=78,4$ & $11=21,6$ & - \\
$30-40$ & 69 & $50=72,4$ & $19=27,6$ & - \\
$40-50$ & 70 & $50=72,4$ & $19=27,5$ & 1 \\
$50-60$ & 33 & $21=65,6$ & $11=34,4$ & 1 \\
$60-70$ & 25 & $8=32,0$ & $17=68,0$ & - \\
Alter unbekannt & 72 & $44=62$ & $27=38$ & 1 \\
\hline Summe & 342 & 232 & 107 & 3
\end{tabular}

\section{Tabelle VIII.}

Ligaturen bei Aneurysmen ausschliesslich Exophthalmus pulsans.

\begin{tabular}{c|r|r|r:c}
$0-10$ & 5 & $4=80,0 \%$ & $1=20,0 \%$ & - \\
$10-20$ & 6 & $5=83,3$ & $1=16,7$ & - \\
$20-30$ & 32 & $23=71,8$ & $9=28,2$ & - \\
$30-40$ & 58 & $39=67,2$ & $19=32,8$ & - \\
$40-50$ & 58 & $38=66,6$ & $19=33,4$ & 1 \\
$50-60$ & 29 & $17=58,6$ & $11=41,4$ & 1 \\
$60-70$ & 23 & $8=34,7$ & $15=65,3$ & $\overline{1}$ \\
Alter unbekannt & 65 & $37=57,0$ & $27=43,0$ & 1 \\
\hline Summe & 276 & 171 & 102 & 3
\end{tabular}

Tabelle IX.

Ligaturen bei Exstirpationen.

\begin{tabular}{c|c|c|c|c}
$0-10$ & 6 & $4=66,6 \%$ & $2=33,4 \%$ & - \\
$10-20$ & 10 & $8=80,0$ & $2=20,0$ & - \\
$20-30$ & 12 & $6=50,0$ & $6=50,0$ & - \\
$30-40$ & 13 & $6=46,1$ & $7=53,9$ & - \\
$40-50$ & 17 & $6=40,0$ & $9=60,0$ & 2 \\
$50-60$ & 19 & $7=36.8$ & $12=63,2$ & $\frac{2}{2}$ \\
$60-70$ & 14 & $8=66,6$ & $4=33,4$ & 2 \\
Alter unbekannt & 24 & $13=65,0$ & $7=35,0$ & 4 \\
\hline Summe & 115 & 58 & 49 & 8
\end{tabular}


Tabelle X.

Ligaturen bei Blutungen.

\begin{tabular}{c|c|c|c|c}
\hline \hline Altersjahr & $\begin{array}{c}\text { Zahl } \\
\text { d. Ligaturen }\end{array}$ & Heilung & Exitus & $\begin{array}{c}\text { Ansgang } \\
\text { unbekannt }\end{array}$ \\
\hline $0-10$ & 7 & $6=85,7 \%$ & $1=14,3 \%$ & - \\
$10-20$ & 16 & $9=64,3$ & $5=35,7$ & 2 \\
$20-30$ & 61 & $37=61,6$ & $23=38,4$ & 1 \\
$30-40$ & 33 & $20=62,5$ & $13=37,5$ & - \\
$40-50$ & 21 & $10=47,6$ & $11=52,4$ & - \\
$50-60$ & 9 & $2=25,0$ & $6=75,0$ & 1 \\
$60-70$ & 13 & $1=7,7$ & $12=92,3$ & - \\
Alter & 162 & $60=37,0$ & $92=63,0$ & 10 \\
unbekannt & 162 & 163 & 14 \\
\hline Summe & 322 & 145 & 163 &
\end{tabular}

Bei diesen Ligaturen sehen wir deutlich, dass-mit dem höheren Alter stetig die Mortalität zunimmt. Relativ wenig nimmt sie zu, bei den Aneurysmen inclusive Exophthalmus pulsans traumaticus und idiopathicus (Tab. VII), etwas mehr schon bei den Aneurysmen exclusive Exophthalmus pulsans (Tab. VIII). Noch mehr steigt die Mortalität mit dem höheren Alter bei den Extirpationen, nur ist hier auffallend, dass die Mortalität der ligirten Patienten zwischen 60 und 70 Jahren plötzlich wieder bedeutend sinkt. Dass dies ein Zufall ist, der bei der kleinen, der Statistik verfügbaren Zahl sehr leicht möglich sein kann, ist wahrscheinlich. Am auffallendsten zeigt ein gewaltiges Aufsteigen der Mortalität der Carotisligatur mit dem zunehmenden Alter der Patienten, die Tab. $\mathrm{X}$ mit den Blutungen. Es scheint demnach eine Carotisligatur bei gleichzeitigen Blutverlusten im höheren Alter (nach dem 40. Jahr, besonders aber nach dem 50. und 60.) nur selten mehr vertragen zu werden, was schon aus unseren theoretischen Betrachtungen über die Bedeutung des Herzens für die Prognose der Carotisligatur sich ergab. Aus diesen letzten Tabellen (VII-X) geht nun deutlich hervor, dass mit dem höheren Alter die Carotisligatur immer gefährlicher wird bei allen Affectionen, welche die Kraft und die Gesundheit des Patienten alterirt haben, ferner bei allen jenen Patienten, bei denen offenkundig ausgesprochene Gefässveränderungen vorliegen, die nicht mit den gewöhnlich bei allen alten Leuten gefundenen Gefässalterationen zusammenfallen.

Doch auch bei allen diesen Affectionen ist der Grad des 
directen Einflusses des mittleren und böheren Alters durchaus nicht immer so klar zu Tage liegend. Patienten, die das 60. Jabr überschritten haben, scheinen sicherlich durch eine Carotisligator unter den genannten Umständen, also bei den genannten Affectionen (Blutung, Exstirpationen und Anenrysmen) schwer gefährdet zu sein. Die wenigen alten Patienten, zwischen 40-60 Jahren, dagegen scheinen nicht im gleichem Grade gefährdet. Wenn wir auch bei ihnen mit dem höheren Alter eine stetige Zunahme der Mortalität finden, so ist dieselbe doch, wie aus den früheren Tabellen über die Todesursache nach Carotisligatur hervorgeht, nur in einer beschränkten Zahl von Fällen ausschliesslich durch das höhere Alter zn erklären, sehr oft aber durch ganz andere Momente, wie Infection, Nachblutungen, schweres Grundleiden, intercurrente Affectionen etc., welche allerdings zum Theil wenigstens, durch ein böheres Alter in ihrem Entstehen begünstigt werden können.

Wie aus den früheren Tabellen hervorgeht, war nur bei 16 Fällen $(4,3 \%)$ von 371 Fällen von Carotisligaturen, die tödtlich endeten, ausser der. Carotisligatur keine andere Todesursache nachweisbar. Dass wir auch bei diesen 16 Fällen keine andere Todesursache sicher anzugeben vermögen, mag, wie bereits früher erwähnt, an den mangelhaften Krankengeschichten, mehr noch vielleicht an den oft so dürftigen Sectionsberichten liegen, die meist weder Aufschluss über deu Zustand der Hirngefässe, über die Vollständigkeit und das normale Verhaiten des Circulus arteriosus Willisii, noch über den Zustand des Herzens u. s. w. geben. Unter diesen 16 Fälleu, dass muss eingeräumt werden, fanden sich allerdings elf, welche das 40. Jahr überschritten batten. Fünf von diesen elf Fällen litten an mächtigen Carcinomen; die übrigen secbs an Aneurysmen der Anonyma oder Carotis.

Als Resultat dieser Betrachtungen über den Einfluss des Alters auf die Gefährlichkeit der Carotisligatur ergiebt sich nun:

1. Das blosse hohe Alter des Patienten bis zum 60. Jahre, ja selbst bis zum 70., hat keinen wesentlichen Einfluss anf die Prognose einer Carotisligatur, so lange der Patient nicht durch sein 
Die Gefahren der Ligatur der grossen Halsschlagadern etc. 635

Grundleiden oder sonstige Momente in seiner Ernährung schwer gelitten hat.

Also bei Nervenleiden, besonders bei uncomplicirtem Exophthalmus pulsans ist das höhere Alter des Patienten keine Contraindication gegen die Carotisligatur.

2. Ueberall da, wo der Gesundheitszustand des Patienten schwer gelitten hat, wo die Kräfte desselben geschwunden sind, sei es in Folge von bösartigen Tumoren oder ganz besonders von schweren Blutverlusten, dann auch bei ausgesprochenen Gefässerkrankungen, wie sie Aneurysmen zu Grunde liegen, überall da verschlechtert sich mit zunehmendem Alter des Patienten die Prognose der Carotisligatur.

3. Endlich sind, wie bei den jüngeren Patienten, gewisse Momente im höheren Alter besonders prognostisch gefährlich, so: ausgesprochene Herzfehler, oder gleichzeitige Ligatur von Vagus oder Sympathicus.

Was folgt nun aus den gewonnenen Anschauungen und Erfahrungen für die Therapie, für die chirurgische Behandlung des Exophthalmus pulsans?

1. Der Ligatur sollte, wenn immer möglich, eine systematische, einige Zeit regelmässig ausgeführte Compressionsbehandlung vorausgehen, um das Herz an die Mehrarbeit zu gewöhnen und die Collateralen auszubilden, eine Tendenz, welche bereits allgemeine Anerkennung gefunden.

2. Fs muss vor Allem mehr als bei anderen Operationen strengste Antisepsis bei der Ligatur der Carotis communis herrschen, da eine Wundinfection leicht zu septischem Zerfall der Thromben führt, als dessen Folge wir nicht nur die septische metastatische Hirnerweichung, den 
Hirnabscess, die Panophthalmie und die Meningitis etc., betrachten müssen, sondern auch die lebensgefährlichen Nachblutungen aus der Ligaturstelle.

3. Es soll womöglich nur unter Cocainanaesthesie die Ligatur ausgeführt werden, um das Herz, welchem eine so grosse Bedeutung auf den Ausgang der Ligatur zukommt, nicht durch Chloroform zu schwächen. Verschiedene Operateure haben speciell in der Neuzeit (z. B. Kocher), das Chloroform bei der Carotisligatur thunlichst vermieden und ausschliesslich Cocain zur Narkose angewandt.

4. Patienten mit Herzfehler und Gefässdegenerationen, ferner Patienten, die aus irgend welchen Ursachen anaemisch oder cachectisch sind, sollten, besonders wenn sie das 40. Jahr überschritten haben, nur im dringendsten Nothfalle ligirt werden. Zuvor sollte man, wenn möglich, versuchen, die Anaemie, die Erschöpfung etc., durch geeignete allgemeine Therapie zu beben.

Patienten mit Herzfehlern, Gefässalterationen überhaupt mit aus irgend einem Grunde reducirten Kräften, wo eben auch das Herz grösseren Anforderungen nicht gewachsen ist, sollte allenfalls vor der Operation Digitalis etc. gegeben werden, jedenfalls sofort nach derselben.

5. Wenn nach der Ligatur Gefahr droht, sollte ebenfalls ein Herzmittel (Digitalis) versucht werden, besonders auch die leider allzusehr in Verruf gerathene Venaesection, welche das Herz entlastet und welche so oft von den Alten mit glänzendem Erfolge bei Gefahren nach Carotisligatur angewandt wurde.

Die Zeit wird lehren, ob wir nicht durch Befolgung dieser Regeln eine geringere Mortalität der Carotisligatur bei Exophthalmus pulsans im Speciellen, sowie bei Carotisligatur bei den verschiedensten Leiden im Allgemeinen, erzwingen werden. 
Die Gefahren der Ligatur der grossen Halsschlagadern etc. 637

Anhang.

Todesursachen bei 371 Ligaturen mit Exitus von 969 Carotisligaturen mit bekanntem Ausgange.

Infection

Nachblutung

Schweres Grundleiden

Intercurrente Erkrankung

Total

Ungenügende Angaben

Varia

$$
\begin{aligned}
& \mathbf{\imath}_{4}=19,9 \% \text { sämmtlicher Exitus. } \\
& 62=16,7 \% \quad \text { " } \\
& 42=11,3 \% \quad " \quad \\
& 15=4,0 \% \quad \text { " } \\
& 193=52,0 \% \quad \text {, } \\
& 98=26,4 \% \quad \text { " } \\
& 80=21,5 \% \quad \%
\end{aligned}
$$

Gefäss oder Herzleiden $10=12,5 \%$ der Varia und $2,6 \%$ sämmtlicher 371 Exitus.

Mehrere grosse Gefässe ligirt $11=13,7 \%$ der Varia und 2,9\% sämmtlicher 371 Exitus.

Cachexie oder Anaemie $15=18,7 \%$ der Varia und 4,0\% sämmtlicher 371 Exitus.

Hohes Alter $17=21,2 \%$ der Varia und $4,5 \%$ sämmtlicher 371 Exitus.

$\cdot \stackrel{\overparen{Z}}{\mathrm{Z}}$ Vagus oder Sympathicus ligirt $4=5,0 \%$ der Varia und 1,0\% sämmtlicher 371 Exitus.

Excess im Trinken $\mathbf{1}=\mathbf{1 , 2 5 \%}$ der Varia und $0,26 \%$ sämmtlicher 371 Exitus.

Zusammenhang von Exitus und Ligatur unsicher $1=1,25 \%$ der Varia 1,,26\% sämmtlicher 371 Exitus.

\begin{tabular}{|c|c|c|c|c|c|c|c|c|c|}
\hline & \multicolumn{8}{|c|}{ Ursache des Todes nach der Ligatur } & \multirow[b]{2}{*}{$\mid \begin{array}{c}\text { Ausgang } \\
\text { unbe- } \\
\text { kannt }\end{array}$} \\
\hline Autor & d. Ligat & Exitus & \begin{tabular}{|l} 
Tödtl, \\
Grund- \\
leidend
\end{tabular} & $\begin{array}{c}\text { Inter- } \\
\text { currente } \\
\text { Erkran- } \\
\text { kung }\end{array}$ & $\begin{array}{l}\text { In } \\
\text { fection } \\
\end{array}$ & $\begin{array}{c}\text { Nach- } \\
\text { blutung }\end{array}$ & $\begin{array}{c}\text { Kranken- } \\
\text { geschichte } \\
\text { ungenü- } \\
\text { gend. }\end{array}$ & Varia & \\
\hline Pilz & $\begin{array}{c}34 \\
7 \text { doppelt } \\
\text { u. geheilt }\end{array}$ & $\begin{array}{c}=1 \\
2,9 \%\end{array}$ & - & - & - & - & $\begin{array}{c}1 . \\
\text { Nr. } 541 .\end{array}$ & - & - \\
\hline $\begin{array}{l}\text { Fried- } \\
\text { länder }\end{array}$ & $\begin{array}{c}\quad 6 \\
1 \text { doppelt } \\
\text { n. geheilt }\end{array}$ & $0=$ & - & - & - & - & & - & - \\
\hline Siegrist & 1 & $\begin{array}{l}0= \\
0 \%\end{array}$ & - & - & - & - & & - & - \\
\hline Total & 41 & $\begin{array}{r}1= \\
2,4 \%\end{array}$ & - & - & - & - & 1. & - & - \\
\hline
\end{tabular}

Beide Carotiden simultan ligirt $1=1,25 \%$ der Varia und $0,26 \%$ sämmtlicher 371 Exitus.

Ascendirende Thrombose von der Ligaturstelle $4=5,0 \%$ der Varia und 1,0\% sämmtlicher 371 Exitus.

(Rest $16=20,0$ der Varia und $4,3 \%$ sämmtlicher 371 Exitus.

Nervenleiden und Elephantiasis. 
A. Siegrist.

\begin{tabular}{|c|c|c|c|c|c|c|}
\hline & 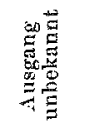 & 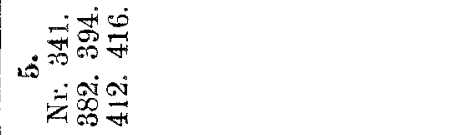 & $\dot{\theta}$ & $\dot{\theta} 1$ & $10^{\circ}$ & 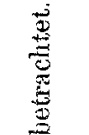 \\
\hline & 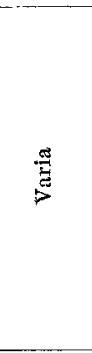 & 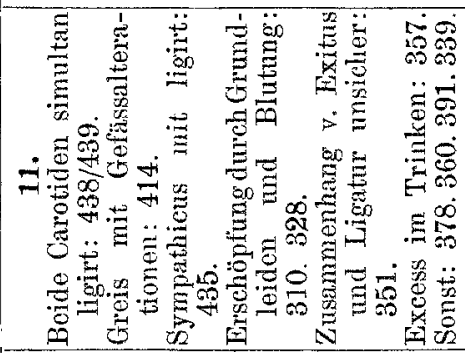 & 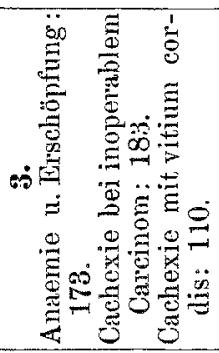 & 1 & $\dot{\square}$ & 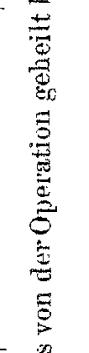 \\
\hline & 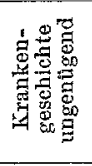 & 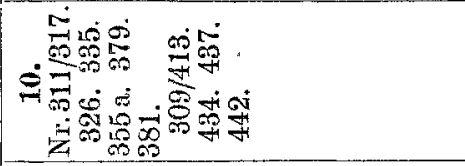 & oi & 1 & $\stackrel{g}{\mathcal{i}}$ & 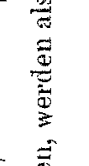 \\
\hline & 龸 & 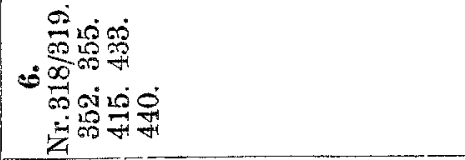 & $\dot{-\dot{H}}$ & $!$ & $\dot{\mathbf{n}}$ & 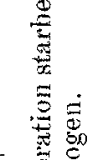 \\
\hline & 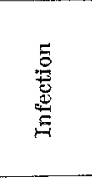 & 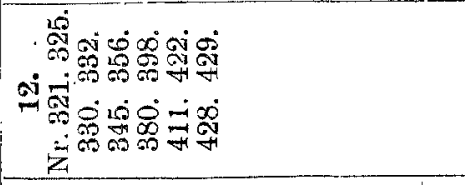 & : & $!$ & $\stackrel{\text { a }}{\rightleftharpoons}$ & 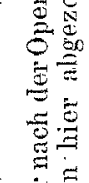 \\
\hline & 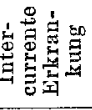 & 1 & 1 & 1 & $\dot{0}$ & 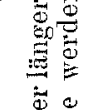 \\
\hline & 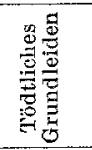 & 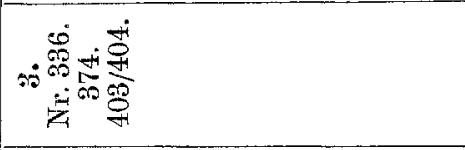 & $\begin{array}{r}\dot{\infty} \\
\text { a } \\
\dot{a} \\
\dot{a} \\
\end{array}$ & ! & نما & 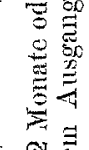 \\
\hline & 兽 & 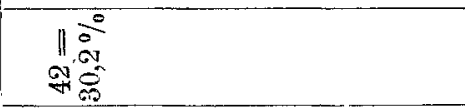 & 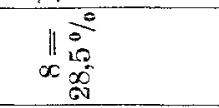 & 1120 & 110 & 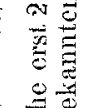 \\
\hline & 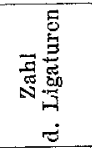 & 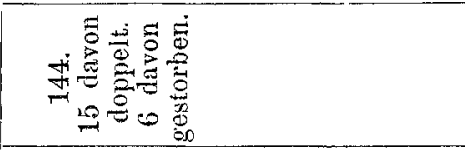 & $\stackrel{\infty}{\infty}$ & 10 & 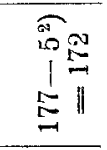 & 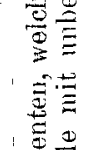 \\
\hline & 苍 & $\stackrel{N}{=}$ & 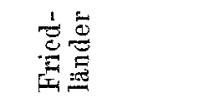 & 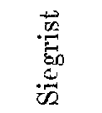 & 要 & 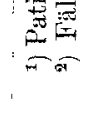 \\
\hline
\end{tabular}


Die Gefahren der Ligatur der grossen Halsschlagadern etc. 639

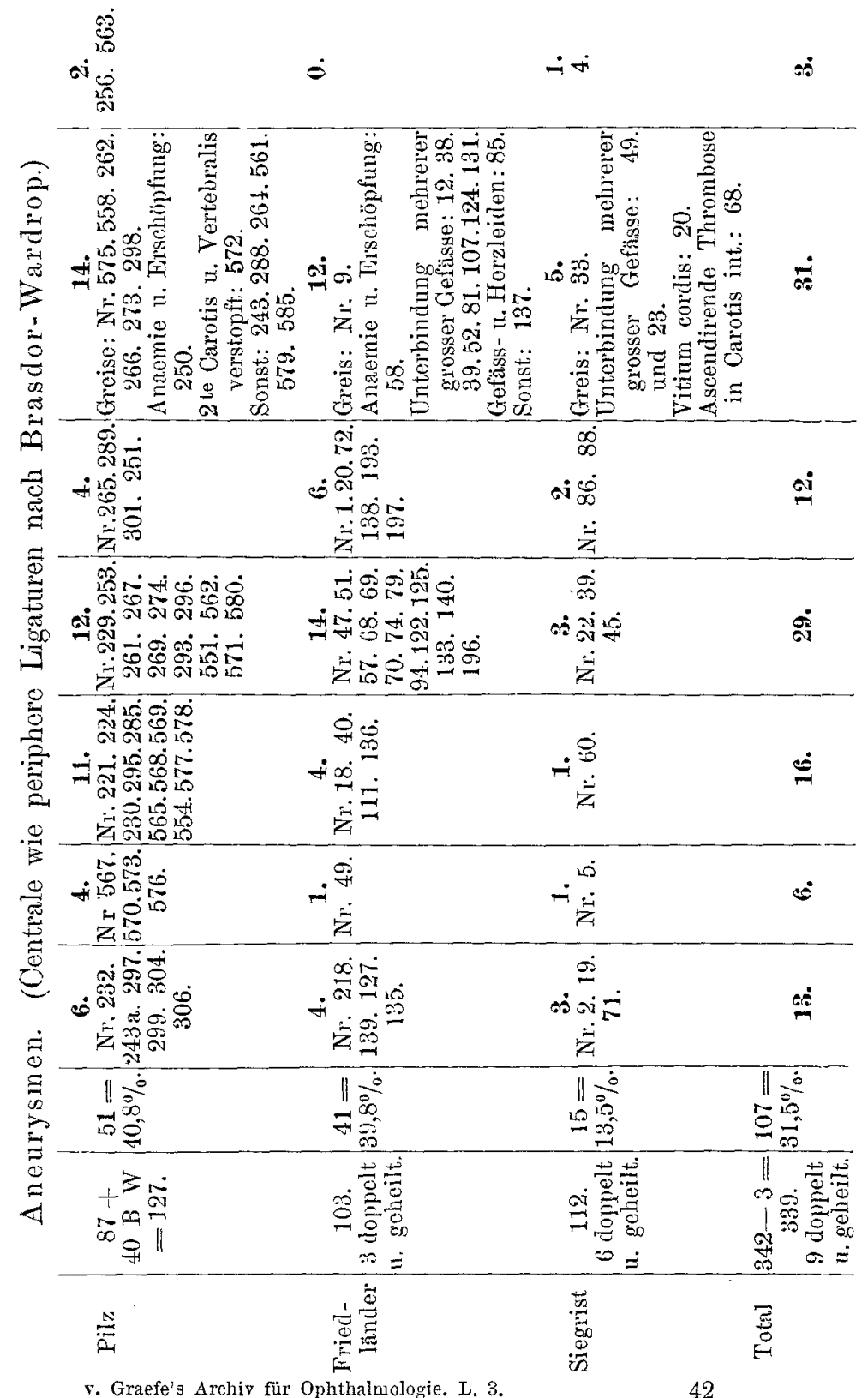

v. Graefe's Archiv für Ophthalnologie. L. 3. 
A. Siegrist.

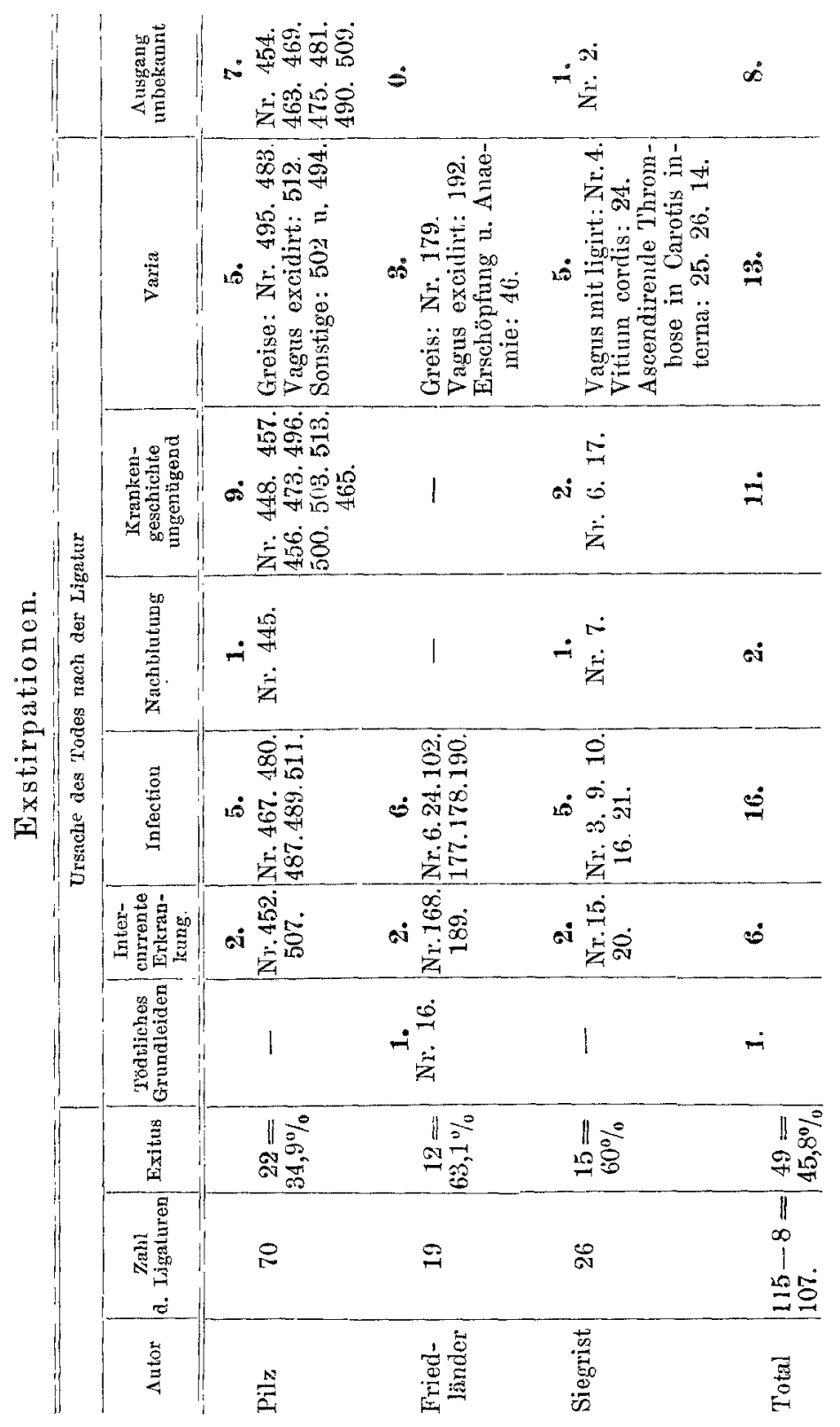


Die Gefahren der Ligatur der grossen Halsschlagadern ete. 641

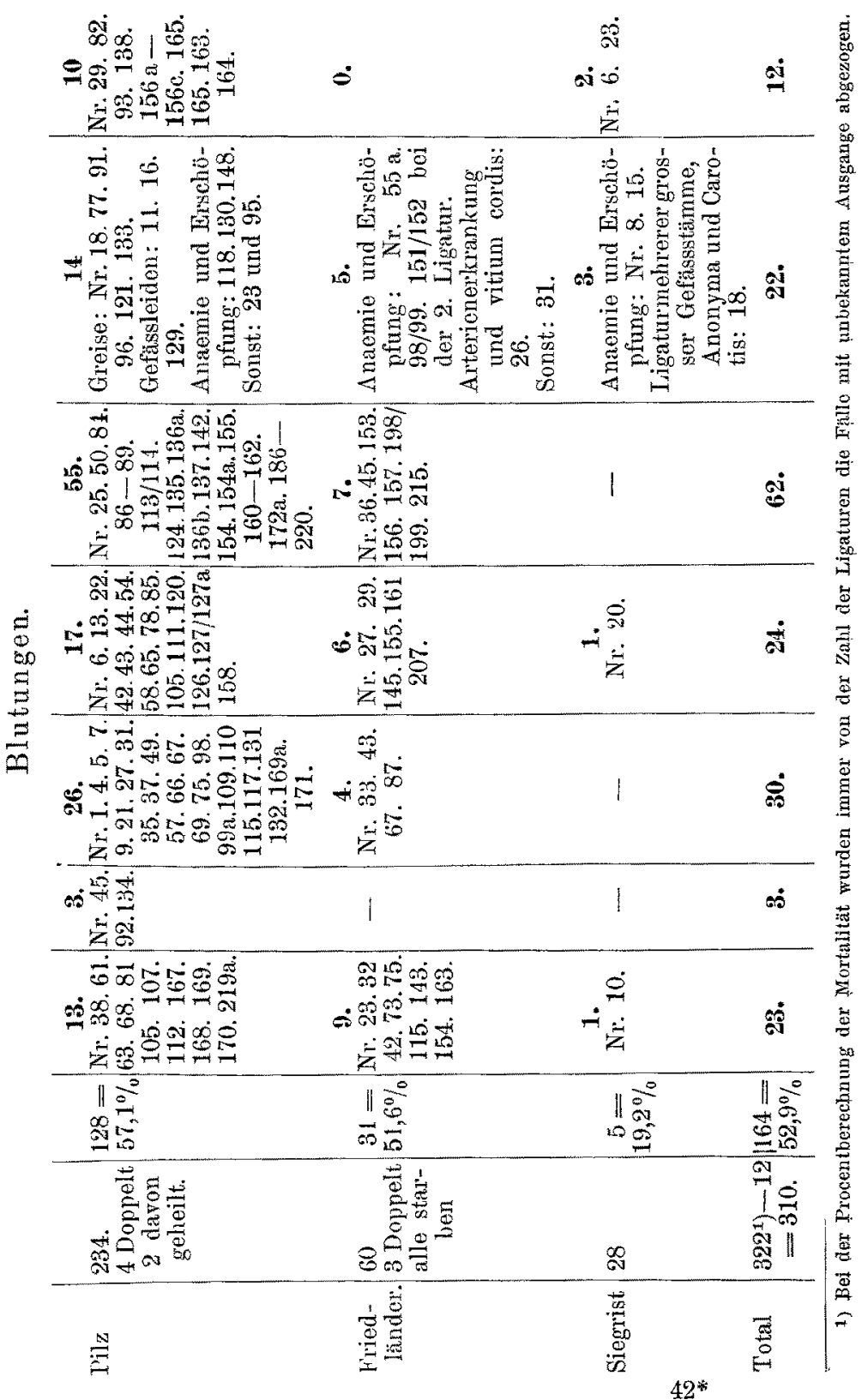


A. Siegrist.

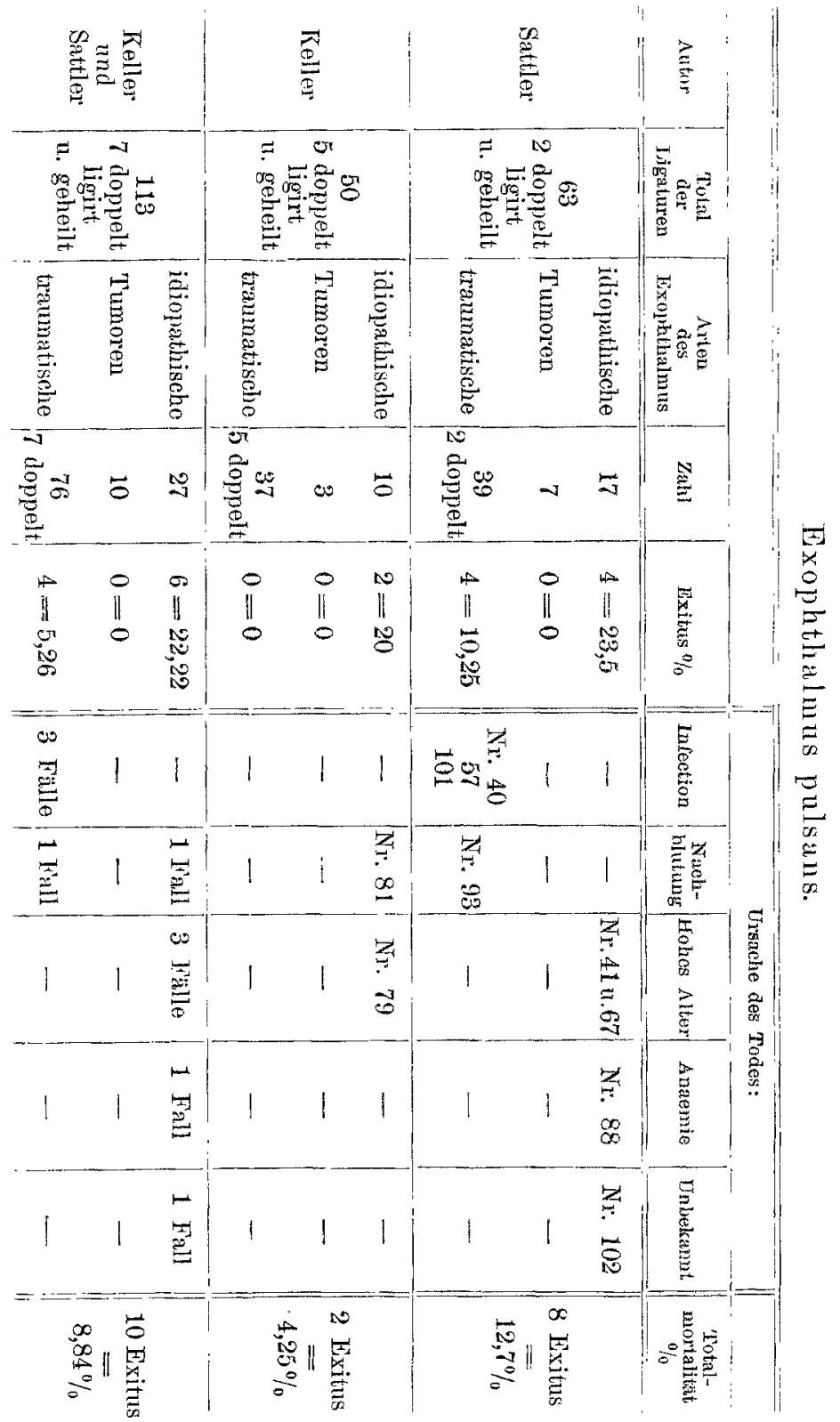


Die Gefahren der Ligatur der grossen Halsschlagadern etc. 643

\section{Erklärung der Abbildungen auf Taf. XVII--XXIII,} Fig. 1-21.

Fig. 1. Embolie der Centralarterie: Oedem der Netzhaut, speciell in der Gegend der Papille und Macula. Foreola centralis als kleiner kirschrother Punkt sichtbar. Gefässe der Netzhaut sehr dünn und die Blutsänle unterbrochen, bestehend aus farblosen und abwechselnd rothen Cylinderchen.

Die Blutsäulchen bewegen sich in den Arterien centrifugal, stehen kurze Zeit still und wandern dann wieder centripetal, um nach wenigen Secunden wieder centrifugal zul marschiren ete. In den Venen ist keine Bewegung der Blutcylinder wahrzunehmen.

Fig. 2. Sagittalschnitt durch die Carotis interna und den centralen Theil des Nervus opticus.

$o=$ Längsschnitt durch den Sehnerven. Carotis interna ist von einem völlig obturirenden rothen Thrombus erfüllt, der sich etwa $6 \mathrm{~mm}$ weit in die Arteria ophthalmica hinein fortsetzt, wo er kegelförmig zugespitzt endet. Mehr peripheriewärts ist die Arteria ophthalmica abermals getroffen und ihr Lumen völlig frei.

Fig. 3-6 u. Fig. 9. Querschnitte durch den Sehnerven und dessen Umgebung im Bereiche der Augenhöhle und zwar peripher von jenem Stücke des Sehnerven, welches auf Tafel XVIII dargestellt ist.

$$
\begin{aligned}
o & =\text { Nervus opticus. } \\
\text { Art. oph. } & =\text { Arteria ophthalmica. } \\
C . N . & =\text { Ciliarnerven. } \\
O . M . & =\text { Oculomotorius. }
\end{aligned}
$$

Art. cent. ret. $=$ Arteria centralis retinae.

Ggl. cil. $=$ Ganglion ciliare.

Fig. 3. Zeigt in der Arteria ophthalmica vor ihrer Theilung in ihre Hauptäste das zugespitzte Ende eines obturirenden Pfropfes.

Fig. 4. Zeigt die Arteria ophthalmica etwas mehr peripherwärts, wo der obturirende Pfropf das Lumen der Arterie beinahe ganz erfüllt, nirgends aber der Gefässwand völlig anliegt.

Fig. 5. Zeigt den Moment der Theilung der Arteria ophthalmica. in drei Aeste. Der ohturirende Pfropf befindet sich ausschliesslich in dem kleinen Aestchen, welches die ursprüngliche Richtung der Arteria ophthalmica innehält und die Arteria centralis retinae ist. Der Hauptstamm der Arteria ophthalmica ist gerade im Begriff, rechtwinklig nach einwärts abzubiegen und in zwei Hauptäste (Oph. I und Oph. II) zu zerfallen.

Fig. 6. Die Theilung des Hauptstammes der Arteria ophthalmica in die zwei Hauptäste (Oph. I und Oph. II) ist bereits vollzogen und diese zwei Aeste, welche wieder parallel dem Sehnerven laufen, sind quer getroffen, ebenso die kleine Arteria centralis retinae, welche die ursprüngliche Richtung 
der Arteria ophthalmica innegehalten hat. Im Lumen der Centralarterie sitzt der obturirende Propf (Embolus), nur einen schmalen halbmondförmigen Raum freilassend. Gegen. diesen freien etwas Blut führenden Theil des Gefässlumens zu ist der Embolus durch ein eigenes Endothelhäutchen abgegrenzt. Dort, wo er die intacte Gefässwand berührt, sendet das Gefässendothel Sprossen in ihn hinein (beginnende Organisation)

Fig. 7 und 8 sind partielle starke Vergrösserungen von Fig. 6.

Fig. 7, zeigt wie der Embolus (Em) gegen das schmale halbmondförmige noch freie Lumen $B$ der Centralarterie hin, das mit normalem Blute erfitllt ist, durch ein eigenes Endothelhäutchen ( $E$ d $)$ abgegrenzt wird.

II. $=$ Muscularis der Centralarterie.

El. = Elastica der Centralarterie.

Fig. 8, zeigt die dem halbmondförmigen freien Lumen der Centralarterie gegenüberliegende Seite, wo das Endothel in den der Gefässwand dicht anliegenden Embolus Sprossen ( $S p$.) hineinsendet. Es sind dies jene, die begimnende Organisation einleitenden Endothelsprossen, welche schon bei Fig. 6 erwähnt wurden.

Fig. 9. Die Centralarterie, welche etwas vom Sehnerven abgerïckt ist, beginnt nun in grossem Bogen sich wieder dem Sehnerven zu nähern und in denselben einzutreten. Kurz vor dem Eintritt der Arterie in den. Sehnerven findet der obturirende Pfropf seinen Absehluss.

Fig. 10, giebt ein Uebersichtsbild, welches aus den Längsschnitten durch das centrale Ende des Sehmerven - Fig. 2 - wie aus den Serienschnitten des ganzen Orbitalinhaltes bis zur Papille (Fig. 3-9) zum besseren Verständnisse der beschriebenen Verhältnisse construirt wurde.

Fig. 11-13: Schnitte durch die Netzhaut bei frischer Embolie der Centralarterie, Fig. 11 bei schwächerer, Fig. 12 and 13 bei starker Vergrösserung.

$$
\begin{aligned}
N f & =\text { Nervenfasserschicht. } \\
R g f . & =\text { Retinalgefäss. } \\
G . & =\text { Ganglienzellenschichte. } \\
i K . & =\text { innere Körnerschichte, } \\
\ddot{a} K & =\text { äussere }
\end{aligned}
$$

St. Zpf. = Stähchen-Zapfenschicht.

Alle drei Figuren zeigen die Abhebungen der Limitans int. durch glasige Schollen und Kugein; Auflockerung und serüse Durchtränkwng der Nervenfaserschicht.

Da wo die Nervenfaserbündel quer getroffen sind (Fig. 12 und 13), in der Gegend der Papille, sind die einzelnen Bündel durch blasige homogene Massen von einander getrennt. Statt der normalen Faserquerschnitte sieht man unregelmässige Tropfchen und myelinartige Figuren.

Fig. 11 zeigt besonders dentlich die cystischen Hohlränme zwischen den Stützfasern rings ưm ein längsgetroffenes Retinalgefäss (R. gf.) in der Nervenfaserschicht. 
Fig. 14, Schnitt durch die Maculagegend.

$$
\begin{aligned}
F v l . & =\text { Foveola, } \\
C l . & =\text { Clivus foveae, }
\end{aligned}
$$

Zfsch. = Zapfenfaserschichte.

Das Bild zeigt deutlich die mächtige Auflockerung der Zapfenfaserschicht im Bereiche der Fovea centralis, aber auch noch in deren Umgebung in ein System von zahlreichen kleinblasigen Hohlränmen (Oedem). Die Foveola (Fvl) selbst, das Centrum der Fovea centralis, welche den kirsehrothen centralen Fleck im oplthalmoskopischen Bilde bei Embolie der Centralartarie entspricht, ist frei von Oedem, da die ödematös durchtränkten Schichten hier fehlen.

Fig. 15. Sagittalschnitt durch den vorderen Augenabschnitt.

Hypraemie der conjunctivalen und episkleralen Gefässe mit Rundzelleninfiltration der Ungebung. Diese Zelleninfiltration gewinnt gegen den Limbus corneae an Mächtigkeit und breitet sich dann in den oberflächlichen Hornhautschichten gegen die Hornhautmitte zu aus, wo sie in den oberffächlichen und mittleren Schichten ein ganz besonders intensives rundliches Infiltrat von etwa $2 \mathrm{~mm}$ Durchmesser darstellt. Das Ligament. pectinatum zeigt ebenfalls eine deutliche Infiltration seines Maschenwerkes mit Rundzellen. Auch auf dem Endothel der Descemeti findet sich eine mässige Auflagerung ron Rundzellen.

Fig. 16 zeigt bei stärkerer Vergrösserung das centrale Hornhautinfiltrat, die Rundzellen sitzen zu Ketten angeordnet in den erweiterten Spalträumen zwischen den Hornhautlamellen. Direct über dem Centrum $(U)$ des Infiltrates fellit in kleinster Ausdehnung nicht nur das Hornhautepithel, sondern auch die Bowman'sche Membran und ist durch einige fibrinöse structurlose Auflagerungen ersetzt. Deutlicher sind die Rundzellen zu erkennen, welche zum Theil das Endothel der Descemeti (D) bedecken.

Fig. 17 und 18 zeigen das Hornhautepithel sowohl in der nächsten Nähe des centralen Ulcus (Fig. 18), wie in einiger aber mässiger Entfernung von demselben (Fig. 17) nebst einem Theil des unmittelbar darunter liegenden Hornhautparenchyms.

Fig. 18 zeigt das Epithel einschichtig aus geschrumpften niederen Zellen bestehend. Das Parenchym der Hornhaut lässt die zahlreichen oft sehr grosskernigen Zellen erkennen, welche kettenförmig in den erweiterten Spalträumen der Hornhaut sich finden und zum grössten Theile aus Rundzellen, zum kleineren aus vergrösserten geschwellten fixen Hornhautzellen bestehen.

Fig. 17 zeigt die eigenthümilichen Epithelveränderungen in einer Zone von etwa $1,5 \mathrm{~mm}$ Breite um das centrale Hornhautinfiltrat. Die cylinderförmigen Basiszellen sind sowohl in ihrer Längsrichtung als auch in der Breite gut um das Dreifache vergrössert und stellen grosse blasenförmige Zellen mit vergrössertem Kerne dar. $(\boldsymbol{B z}$.)

Zwischen ihnen finden sich stellenweise einzelne, gleichfalls sehr zusammengepresste Zellen, welche oben arkaden- 
646 A. Siegrist, Die Gefahren d. Ligatur d. grossen Halsschlagadern etc.

förmig sich ausbreiten (Az). Die weiteren, mehr änsseren Schichten des Epithels zeigen gleichfalls bedeutende Vergrösserung.

Die Leiber aller dieser gequollenen und vergrösserten Zellen sind kaum gefärbt, ihre vergrösserten Kerne sehr schlecht.

$$
\begin{aligned}
E & =\text { Epithel. } \\
M B & =\text { Bow man'sche Nembran. } \\
P . & =\text { Parenchym. }
\end{aligned}
$$

Fig. 19. Starke Vergrösserung der Epithelveränderungen in der Umgebung des centralen Ulcus $(U$, in dessen Bereich Epithel und Bowman'sche Membran, welche sich conisch gegen. das centrale Ulcus hin zuspitzt, fehlen. II ist die Fortsetzung von $I$, a die Fläche an der sie zusammenstossen. Veber dem centralen Uleus bei $U$. einige structurlose fibrinöse Schollen.

$$
\begin{aligned}
E & =\text { Epithel, } \\
M B & =\text { Bowman 'sche Membran. }
\end{aligned}
$$

Fig. 20. Augenhintergrund fünf Monate nach Ligatur der gleichseitigen Carotis ext. und int. bei Exophthalmus pulsans (2. Fall).

Die Papille zeigt das Bild der einfachen Atrophie. Die Gefässe sind jedoch bis auf einige dünne rothe Fädchen, welche den Rand der Papille nicht überschreiten, verschwunden. Die Aderhaut lässt alle grösseren Gefässe dentlich, zum Theil in annähernd normaler Färbung, zum grösseren Theile aber gelblich-weiss verfürbt (Sklerose), erkennen. Der ganze Hintergrund ist gleichmässig mit zahllosen kleinsten, schwarzen Pigmentpünktchen besät, welche die Aderhautgefässe überlagern.

Fig. 21. Hintergrund desselben Auges nach anderthalb Jahren.

Oben, nasal und unten zeigen sich álle, auch die feinsten Aderhautgefässe blendend weiss verfärbt (völlig sklerosirt). Nur in der Gegend der Macula haben die Gefässe noch etwas röthlichen Farbenton. Während in diesem letzteren noch etwas besser erhaltenen Gebiete des Hintergrundes die feinen zahlreichen Pigmentfleckchen noch $\mathrm{zu}$ sehen sind, karn im Uebrigen völlig sklerosirten Bezirke der Aderhaut nichts mehr von Pigment entdeckt verden. Dasselbe hat sich in grossen Klumpen an der Grenze gesammelt wo der völlig sklerosirte grosse Aderhautbezirk mit dem relativ besser erhaltenen kleineren zusammenstösst.

Die Gefässchen anf der Papille sind weiss geworden. 
Fig. 1.

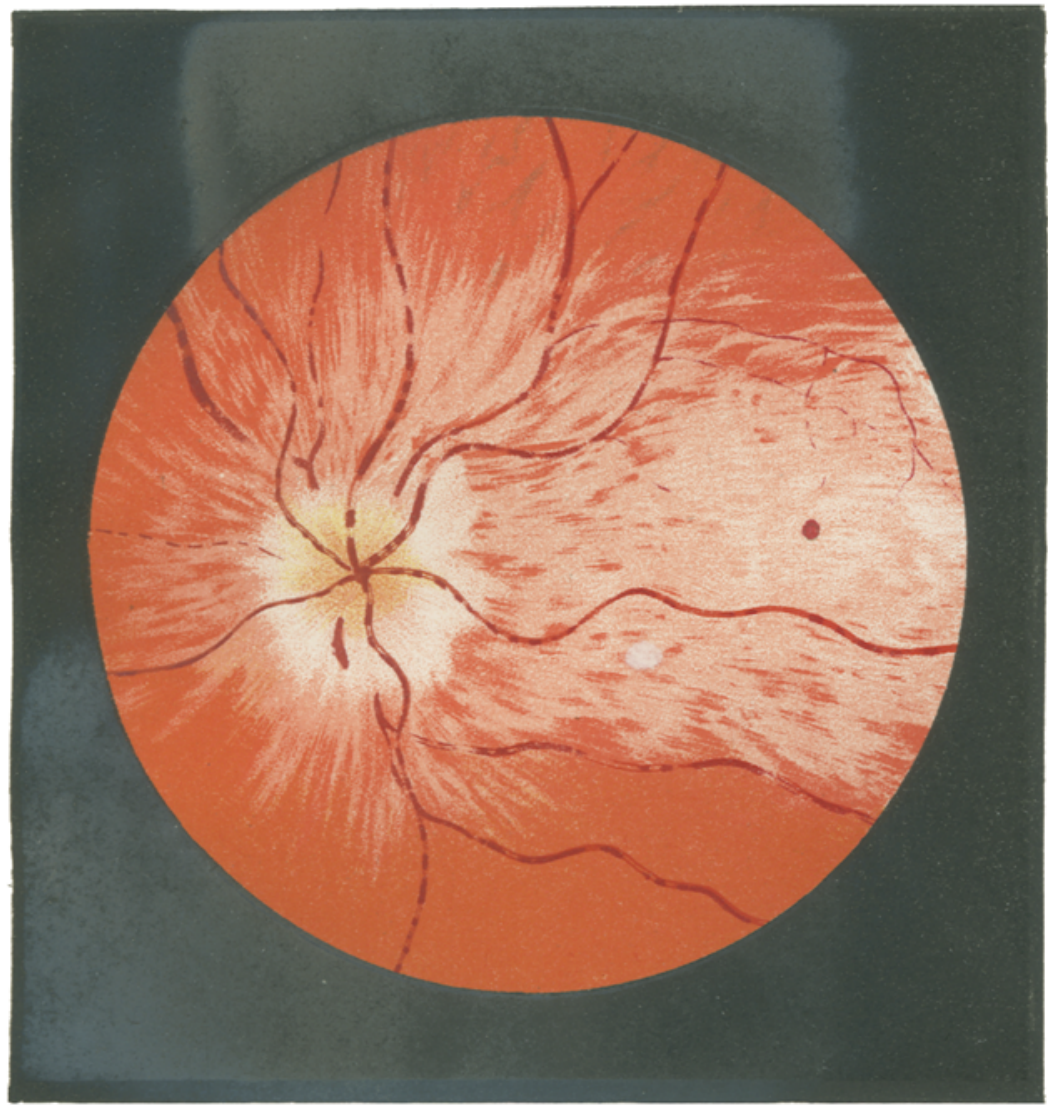


Fig. ?.

Arl.oph.

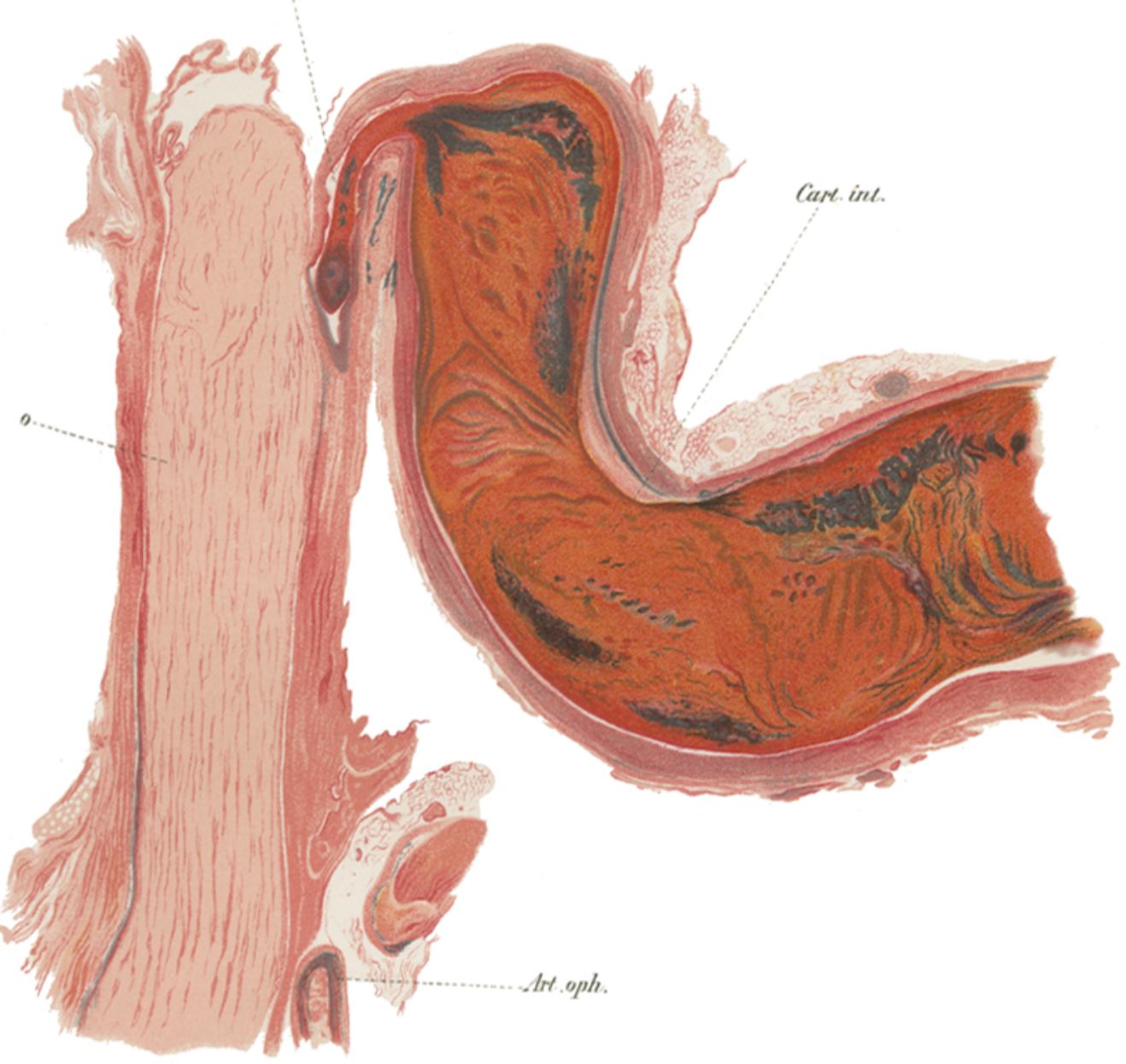


.
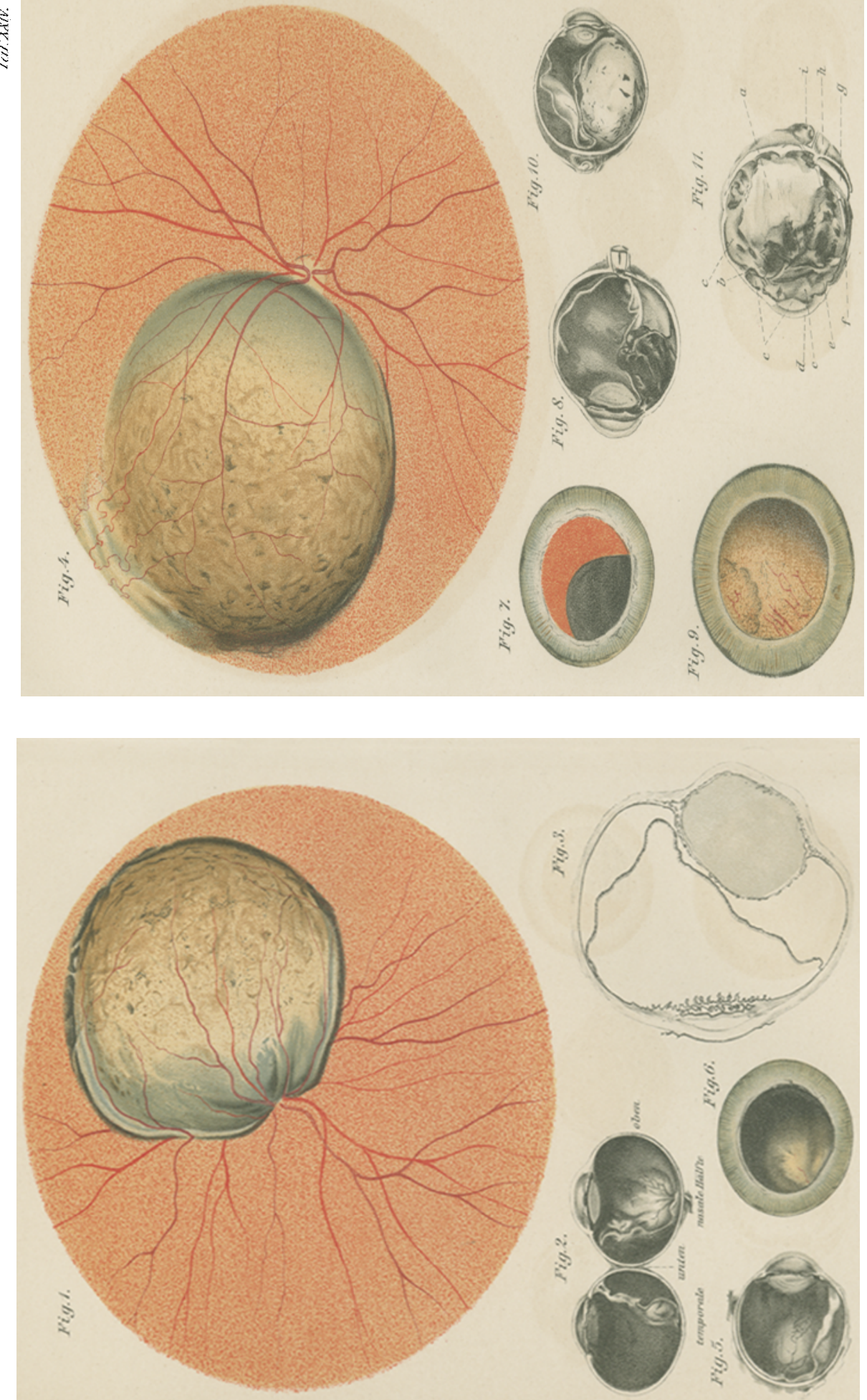